\title{
NBSIR 81-2202
}

\section{Fire Tests of Stairwell-Sprinkler Systems}

Leonard Y. Cooper and John G. O'Neill

Center for Fire Research National Engineering Laboratory U.S. Department of Commerce National Bureau of Standards

Washington, DC 20234

February 1981

Final Report

Issued April 1981

Prepared for:

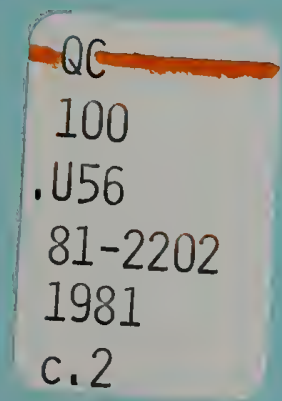

The Occupational Safety and Health Administration (OSHA) Department of Labor Washington, DC 20210 

NBSIR $81-2202$

III

FIRE TESTS OF STAIRWELL-SPRINKLER SYSTEMS

\section{SYSTEMS}

Leonard Y. Cooper and John G. O'Neill

Center for Fire Research

National Engineering Laboratory

U.S. Department of Commerce

National Bureau of Standards

Washington, DC 20234

February 1981

Final Report

Issued April 1981

Prepared for:

The Occupational Safety and Health Administration (OSHA)

Department of Labor

Washington, DC 20210

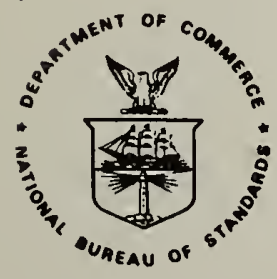

U.S. DEPARTMENT OF COMMERCE, Malcoim Baldrige, Secretary NATIONAL BUREAU OF STANDARDS, Ernest Ambler, Director 

This report on fire tests of stairwell-sprinkler systems is one product of an ongoing joint research program of the Occupational Safety and Health Administration (OSHA) of the Department of Labor and the National Bureau of Standards (NBS), Center for Fire Research. The program is entitled: Key Elements of Emergency Escape Requirements for Employees in Workspaces Under OSHA Jurisdiction. Other areas of research presently included in this program are: estimating available safe egress times for workspaces subsequent to the ignition of hazardous fires; the relation of building design and human factors to emergency evacuation of workspaces; and studies of the smoke leakage of door assemblies. 
TABLE OF CONTENTS

Page

PREFACE . . . . . . . . . . . . . . . . . . . . 1 . . .

LIST OF TABLES. . . . . . . . . . . . . . . . . . vi vi

LIST OF FIGURES . . . . . . . . . . . . . . . . . . vi vi

NOMENCLATURE. . . . . . . . . . . . . . . . . . viii

Abstract. . . . . . . . . . . . . . . . . . . 1

1. INTRODUCTION. . . . . . . . . . . . . . 2

2. PROJECT OBJECTIVES AND SCOPE . . . . . . . . . . . 4

3. REVIEW OF PREVIOUS WORK . . . . . . . . . . . . . 5

4. EXPERIMENTAL DETAILS. . . . . . . . . . . . . . 6

4.1 Test Facility. . . . . . . . . . . . . . 6

4.2 Fire Protection Systems. . . . . . . . . . . . 7

4.3 Instrumentation. . . . . . . . . . . . 9

4.4 Test Program . . . . . . . . . . . . . . 10

4.5 Test Procedure ................ . 10

5. TEST RESULTS. . . . . . . . . . . . . . . 12

5.1 Water Curtain System Tests . . . . . . . . . . 12

5.2 Spray Nozzle System Tests. . . . . . . . . 13

6. ANALYSIS OF THE DATA AND CONCLUSIONS . . . . . . . . . 14

6.1 The Concept of a Stairwell-Sprinkler Component . . . . 14

6.2 The Physical Bounds of the Stairwell-Sprinkler

Component. . . . . . . . . . . . . . . . . 16

6.3 Parameters to Describe the Component Performance

Characteristics. . . . . . . . . . . . . . 17

6.4 The Flow Phenomenology in the Experimental Facility. . 12

6.5 A Useful Operating Characteristic of the Stairtower

Facility Burn Room . . . . . . . . . . . . 22

6.6 Some Performance Characteristics of Stairwe11-

Sprinkler Components: The Experimental Results

and Their Correlation. . . . . . . . . . . 25

6.6.1 Plots of the Experimentally Obtained

Component Efficiencies. . . . . . . . . 25

6.6.2 Correlation of the Reduced Data Results . . . . 27

6.6.2.1 Cooling Efficiency as a Function

of Water Flow Rate........ . 27 


\section{TABLE OF CONTENTS (Continued)}

Page

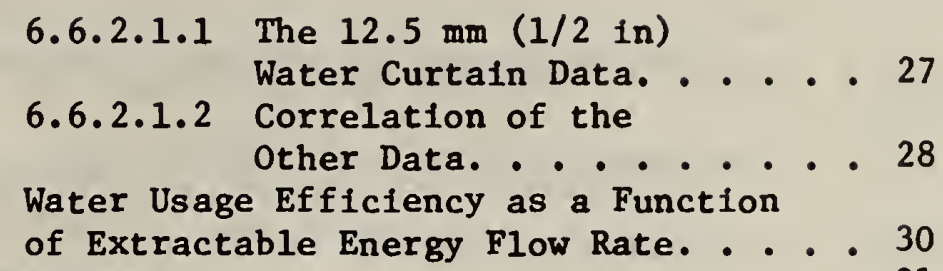

6.7 Discussion of Results. . . . . . . . . . . 31

6.7.1 Cooling Efficiency and It's Application .... . 31

6.7.2 Water Usage Efficiency and It's Potential

Improvement ............ 33

6.7.3 Extension of the Results to Other Geometries

and Configurations............. 34

7. SUMMARY OF CONCLUSIONS. ............... 38

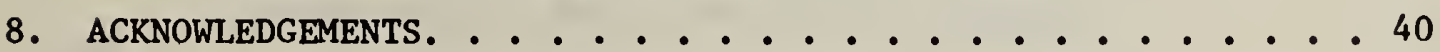

9. REFERENCES. . . . . . . . . . . . . 41

APPENDIX A. PROPERTY VALUES AND DETAILS OF DATA MANIPULATION . . 42 
Table 1. Water curtain and spray nozzle systems ...... 45

Table 2. Deployment of the instrumentation . . . . . . . 46

Table 3. A listing of the test runs............. 48

Table 4. Data from unsprinklered operation of the stairtower used to estimate $\overline{\mathrm{hA}}$ from Eq. (6). . . . . . . . 49

LIST OF FIGURES

Page

Figure 1. Plan view of lowest level of stairtower
including the burn room................ 50

Figure 2. A section of the stairtower elevation ....... 51

Figure 3. Plan views of the first and second floors of the stairtower................. 52

Figure 4. Water curtain system . . . . . . . . . . 53

Figure 5. Spray nozzle system .............. 54

Figure 6. Burn room temperature profiles with two different lower vent areas.............. 55

Figure 7. Temperature at first floor vs nominal average flow rate for water curtain and for a fire energy of $1.5 \mathrm{MW}\left[5.5\left(10^{6}\right) \mathrm{BTU} / \mathrm{hr}\right] . . . . . . .256$

Figure 8. Nominal average water flow rate vs combustion gas exhaust rate for the water curtain system and a fire energy of $1.5 \mathrm{MW}\left[5.5\left(10^{6}\right) \mathrm{BTU} / \mathrm{hr}\right] . . . . . . .57$

Figure 9. Temperature at first floor vs nominal average water flow rate for the water curtain system and a fire energy of $4 \mathrm{MW}\left[13.6\left(10^{6}\right) \mathrm{BTU} / \mathrm{hr}\right] . . . . . . .55$

Figure 10. Water flow rate vs combustion gas exhaust rate for the water curtain system and a fire energy of $4 \mathrm{MW}\left[13.6\left(10^{6}\right) \mathrm{BTU} / \mathrm{hr}\right]$. 
Page

Figure 11. Nominal average water flow rate vs combustion gas exhaust rate for the spray nozzle system and a fire energy of $4 \mathrm{MW}\left[13.6\left(10^{6}\right) \mathrm{BTU} / \mathrm{hr}\right]$. . . . . 60

Figure 12. Model of phenomena in the overall stairwel1sprinkler system. . . . . . . . . . . . 61

Figure 13. The stairtower: an instrument used to measure the performance characteristics of a stairwe11sprinkler system component. . . . . . . . . . 62

Figure 14. P1ot of cooling efficiency as a function of water usage - WC, $12.5 \mathrm{~mm}(1 / 2 \mathrm{in})$ nozzle ..... 63

Figure 15. P1ot of cooling efficiency as a function of water usage - WC, $10 \mathrm{~mm}(3 / 8 \mathrm{in})$ nozzle . . . . . 64

Figure 16. P1ot of cooling efficiency as a function of water usage $-\mathrm{SN}, 12.5 \mathrm{~mm}(1 / 2 \mathrm{in})$ nozzle ..... 65

Figure 17. P1ot of cooling efficiency as a function of water usage - SN, $10 \mathrm{~mm}(3 / 8 \mathrm{in})$ nozzle ...... 66

Figure 18. Plot of water usage efficiency as a function of extractable energy flow - WC, $12.5 \mathrm{~mm}$ (1/2 in) nozzle................

Figure 19. Plot of water usage efficiency as a function of extractable energy flow - WC, $10 \mathrm{~mm}$ (3/8 in) nozzle................

Figure 20. P1ot of water usage efficiency as a function of extractable energy flow - SN, $12.5 \mathrm{~mm}$ (1/2 in) nozzle.............. . 69

Figure 21. P1ot of water usage efficiency as a function of extractable energy flow - SN, $10 \mathrm{~mm}$ (3/8 in) nozzle................ 70

Figure 22. Estimate of cooling efficiency as a function of water usage for the four tested designs a plot of Eq. (11). . . . . . . . . . . 71

Figure 23. Relation between dry and saturated air temperatures at one atmosphere. . . . . . . . 72

Figure 24. Heat of vaporization of water as a function of saturation temperature . . . . . . . . 73 


\section{NOMENCLATURE}

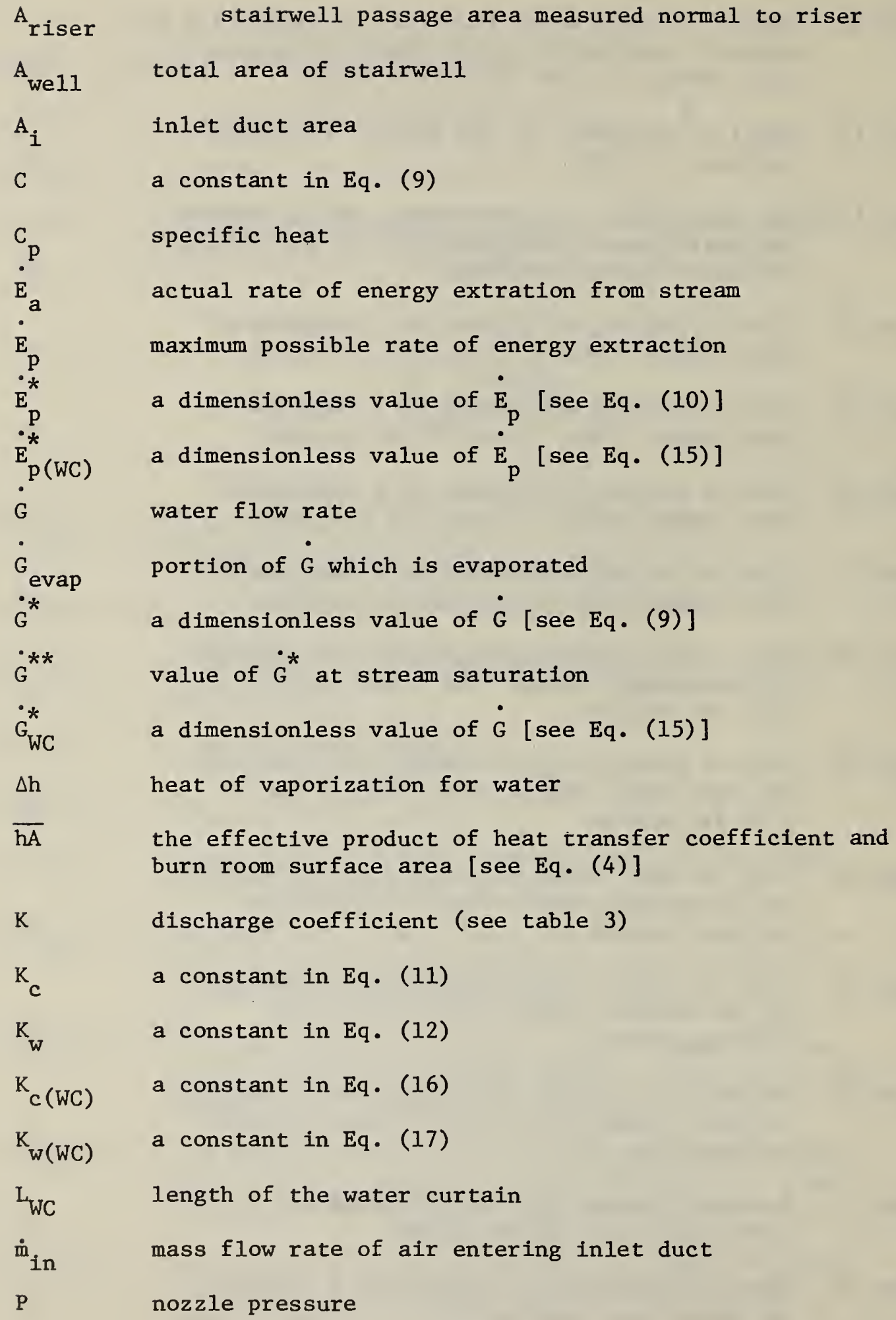




\begin{tabular}{|c|c|}
\hline $\begin{array}{l}P_{\text {amb }} \\
P_{\text {tower }}\end{array}$ & $\begin{array}{l}\text { pressure of the ambient air outside the stairtower } \\
\text { pressure within the stairtower }\end{array}$ \\
\hline$\Delta \mathbf{P}$ & pressure differential across velocity probe \\
\hline$\dot{Q}$ & energy release rate of burner \\
\hline$\dot{Q}_{1 \text { oss }}$ & portion of $\dot{Q}$ transferred to surfaces of burn room \\
\hline $\mathbf{T}$ & effective temperature of burn room gases [see Eq. (4)] \\
\hline $\mathrm{T}_{\mathrm{amb}}$ & temperature of ambient air \\
\hline$T_{\text {in }}$ & temperature of gases entering stairwell \\
\hline $\mathbf{T}_{\text {out }}$ & temperature of gases leaving stairwell \\
\hline $\mathrm{T}_{\text {wa11 }}$ & effective temperature of burn room surfaces \\
\hline$T_{\text {sat }}$ & saturation temperature of air \\
\hline $\mathrm{T}_{\mathrm{dry}}$ & temperature of dry air \\
\hline $\mathbf{v}$ & velocity measured by probe \\
\hline$v_{1}$ & air velocity at stairtower inlet duct \\
\hline W & width of stairwell \\
\hline$z_{n}$ & elevation where $P_{a m b}=P_{\text {tower }}$ \\
\hline$\delta$ & $\begin{array}{l}\text { distance between edge of stalrwell opening and water } \\
\text { curtain nozzles }\end{array}$ \\
\hline$n_{c}$ & cooling efficiency [see Eq. (2)] \\
\hline$\eta_{w}$ & water usage efficiency [see Eq. (2)] \\
\hline$\rho_{\text {amb }}$ & density of ambient air \\
\hline iq) & density of liquid water \\
\hline
\end{tabular}





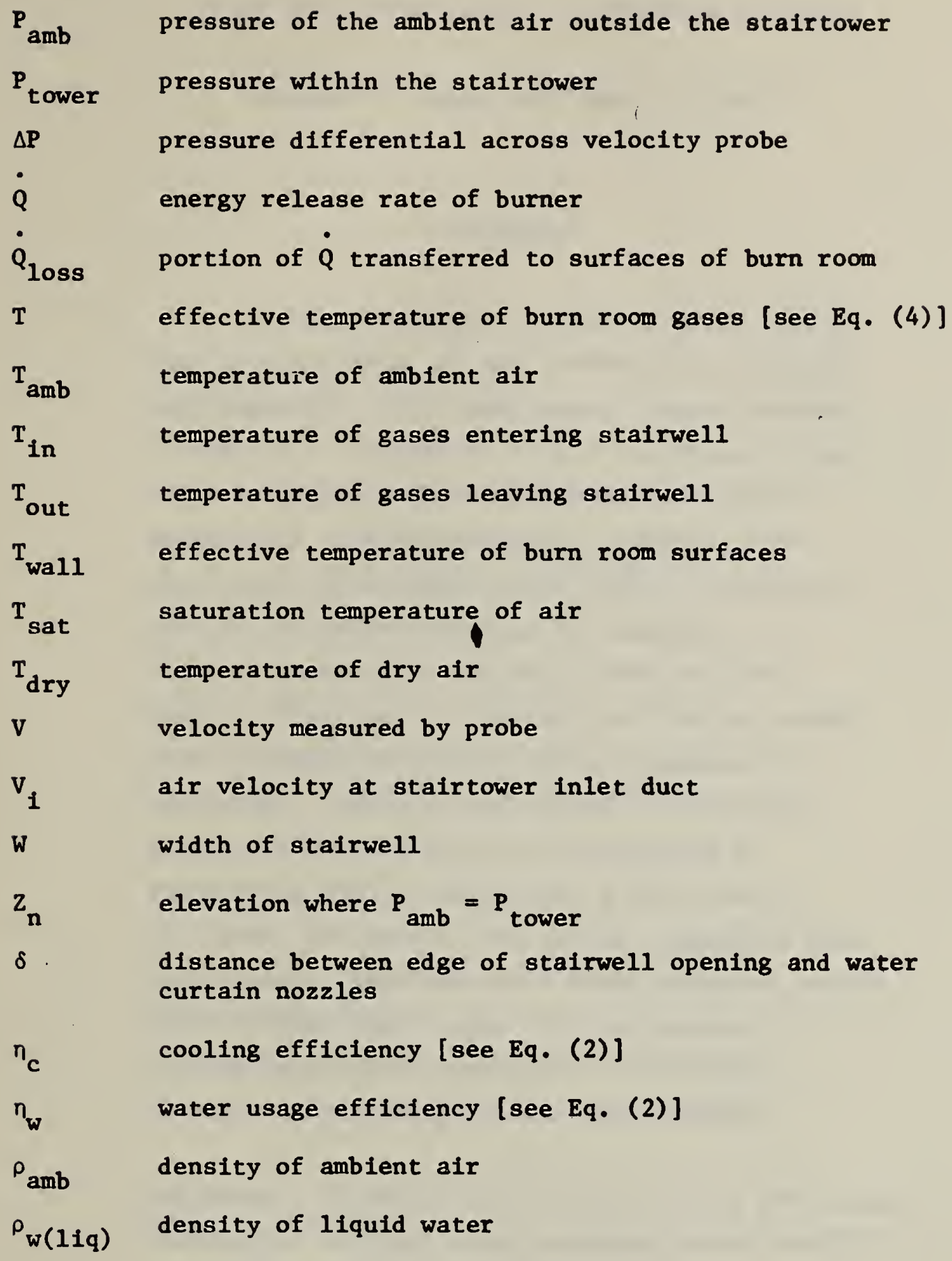



FIRE TESTS OF STAIRWELL - SPRINKLER SYSTEMS

Leonard Y. Cooper and John G. O'Ne111

Abstract

The effect of water curtain or spray nozzle fire protection of an open stairwell was studied experimentally. The experimental setup includes a three story stairtower with a contiguous first story burn room. The instrumentation used to measure the flow phenomenology resulting from fire sizes up to $4 \mathrm{MW} /\left[13.6\left(10^{6}\right) \mathrm{BTU} / \mathrm{hr}\right]$ with and without sprinkler operation is described. A model of evaporation cooling of the hot fire gases as they pass up through the first to second floor stairwell-sprinkler system component is introduced. Based on this model the data are analyzed and correlated for the purpose of identifying both a cooling and a water usage efficiency for each of the system components that were tested. Application of these measured performance characteristics and their extension to stairwell-sprinkler components of different geometries and configurations are discussed.

Key words: Automatic sprinklers, cooling efficiency, evaporation cooling, smoke movement, spray nozzle, stairway protection, ventilated stair. 


\section{INTRODUCTION}

A traditional method of providing fire protection in commercial and industrial buildings is to subdivide the building into areas and floors by means of fire rated construction. This compartmentation is intended to confine a fire to a given floor and area and thereby limit property damage and reduce the exposure of the occupants of buildings to heat, smoke and toxic gases. By confining the fire to a given area, the fire rated construction acts to retard smoke and toxic gases from entering exit ways and other areas of the building where occupants either are proceeding toward exits or where they must take refuge until the fire is brought under control.

Building codes typically require fire rated closures (e.g., door assemblies, duct dampers, etc.) for openings through the fire rated walls and floor-ceilings to insure the integrity of compartmentation. Openings through floor-ceilings for exit stairs must be protected not only to limit the fire to the floor of fire origin but also to keep the stairway safe for a given time to permit the occupants to exit from the building. These types of stairways are usually enclosed in shafts constructed of fire rated walls and door assemblies.

Not all stairways, however, are intended to serve as fire exits. In mercantile buildings, for instance, escalators may be used extensively to move occupants from one floor to another. These escalators are usually not intended to serve as fire exits; other enclosed stairways are provided to serve this purpose and are marked as such. The fire protection for such an opening which is not intended as an exit way must primarily prevent smoke and heat from extending to other floors.

Some building codes permit these stairs and escalators, not designated as fire exits for the building, to be unenclosed if alternative methods of stopping smoke and heat are provided, e.g., sprinkler or spray nozzle systems. A survey of codes and standards by $0^{\prime} \mathrm{Neill}$ 
indicated that alternative methods incorporating the stairway-sprinkler systems are generally permitted in certain occupancies only if automatic sprinklers are installed throughout the building $[1]^{1}$.

In many older buildings built prior to the development of modern building codes the stairways are often open; that is, they are not enclosed in fire rated construction. In many new buildings, architects have sought to utilize open stairways and open atriums to enhance the interior arrangement of the buildings. Many older commercial buildings are being restored with the purpose of making these buildings useful in terms of current living standards as well as retaining the atmosphere created by the original classic architecture. Designers of these restoration projects often desire to retain, for instance, open ornamental stairways which were often the focal point in the layout of the building. In many older buildings not undergoing extensive restoration projects more practical reasons arise for retaining open stairways; that is, the cost of enclosing such stairways is often prohibitive and the enclosure of stairways may seriously interrupt the functional use of the building. In such cases, a serious life safety hazard remains as well.

As mentioned previously, present criteria in building codes would usually require the installation of a complete automatic sprinkler system in all cases where open stairways are desired. Thus, the alternative to a costly construction of a fire rated enclosure for an open stairway may then be a more costly installation of a complete automatic sprinkler system.

The examination of technology for using sprinkler or spray nozzle systems for protecting open stairways in buildings without a complete automatic suppression system may provide an alternate, less costly means of protecting these types of openings. Prompted by the need for examining this technology the Occupational Health and Safety Administration, U.S. Department of Labor requested the Center for Fire Research (CFR), at the Numbers in brackets indicate the literature references at the end of
this paper. 
National Bureau of Standards (NBS) to investigate the use of sprinkler and spray nozzle systems to protect open stairways subjected to a freely burning fire. This report provides the results of the research program.

\section{PROJECT OBJECTIVES AND SCOPE}

The objective of this project was to determine the performance of selected water curtain sprinkler systems and spray nozzle systems in their capacities to reduce the flow of heated gases into a stairwell. The project examined various design parameters of these systems, including flow rates and nozzle pressures and their impact on the overall performance of the different stairwe11-sprinkler system designs. Specifically, the performance of the systems was studied in terms of cooling efficiency, efficiency of water usage, and ability to reduce the flow of combustion gases up through the stairway.

The project encompassed two major activities. The first activity involved a full scale experimental program. This test program was formulated with a major objective of studying the overall effects of deploying sprinkler or spray nozzle systems around or within open stairwells during different fire scenarios. The tests used a particular three story stair tower structure with the stairwell open to a freely communicating room of fire origin on the bottom level. Two different water delivery systems were used in the tests. The first system consisted of a water curtain arrangement made up of standard open-orifice sprinklers placed between the burn room and the stairwell. The second system consisted of spray nozzles located in the stairwell at the second level and directed downward into the stairwell. To a lesser extent, the impact of draft curtains placed around the stairway was also investigated. The experimental procedure was such as to model freely burning fire threats, i.e., there was no simulation of fire extinguishment. This first activity of the project is described below in sections 4 and 5 . 
The second major activity of the project involved an analysis and generalization of the test data. The analysis was carried out with specific reference to the effectiveness of sprinklers/spray nozzles in cooling of flow-through fire gases. This activity was included in the project once it became clear that the major effect of stairwell-sprinkler systems on the migration of combustion projects is in the reduction of fire gas buoyancy. This second activity of the project is discussed in section 6 .

This project did not investigate the performance of stairwellsprinkler systems in conjunction with fully sprinklered installations. Most building codes which presently allow sprinkler protection of open stairwells do so only in fully sprinklered buildings.

\section{REVIEW OF PREVIOUS WORK}

A review of previous experimental work is contained in the previously mentioned report by 0 'Neil1 [1]. Experimental work reported by Thompson at Factory Mutual Laboratories (FM) was specifically considered in the development of the test plan reported here [2]. In that work spray nozzle systems were evaluated with regard to their capability to protect conveyor openings through fire rated walls and ceiling assemblies. The results of these tests indicated improved cooling of gases passing the opening as nozzle pressures were increased for given flow rates. The report also indicated that the position of the nozzles and the shape of the spray cone were important design considerations to insure optimum coverage of the opening with the water spray. A flow density of 81.5 to $163 \mathrm{l} / \mathrm{min} / \mathrm{m}^{2}$ (2 to $4 \mathrm{gal} / \mathrm{min} / \mathrm{ft}^{2}$ ) was recommended for protection of openings through walls and ceilings. 


\section{EXPERIMENTAL DETAILS}

\subsection{Test Facility}

The experimental procedure was carried out in a $3-1 / 2$ story structure shown in figures 1 through 3. The structure was constructed in and above a structure previously used as a NIKE Missile Pit located on Federal property adjacent to NBS. Figure 1 shows the layout of the structure located in the pit itself which served as the bottom floor of the test structure. This basement level, which is equivalent to $1-1 / 2$ stories in height, consisted of a burn room adjacent to the base of a stairway which extended an additional two stories above grade level. A ventilation port was provided to bring combustion air into the burn room from the remaining unused area in the pit outside of the burn room structure. During the test period this remaining pit area was opened to the exterior by means of an open doorway, which provided an unlimited air supply to the pit area. A $1.9 \mathrm{~m}^{2}\left(20 \mathrm{ft}^{2}\right)$ nominally sized vent was located in the roof of the tower. In the basement level the test structure consisted of concrete block walls with a cementitious fireproofing material applied to the inside to provide increased fire resistance. The ceiling in the burn room consisted of the reinforced concrete construction existing in the pit with a coating of the cementitious fireproofing material applied to the area inside the burn room.

As previously mentioned, a stairway of steel construction extended 3-1/2 stories from the lowest level, adjacent to the burn room, up to the top of the tower. Cementitious fireproofing was applied to the columns and stringers and underside of the stair risers and landings in the lowest level to protect the steel from the initial heat exposure prior to the actuation of water curtain or spray nozzle systems. Fire rated doors provided access into the test facility at the lowest level and at the grade level and fire rated wired glass windows were installed in the two levels above grade. The floors which were built surrounding the stairway at grade level and at the top level, as well as the roof structure consisted of hollow core precast concrete panels supported by exterior bearing walls and steel I beams. 
The heat source consisted of a large propane burner as shown in figure 4 , located in the burn room at the lowest level. The burner consisted of 39 orifices divided into seven zones to permit operation of the burner at varying rates of heat release. The maximum heat release rate $(\dot{Q})$ of the burner was approximately $4 \mathrm{MW}\left[13.6\left(10^{6}\right)\right.$ $\mathrm{BTU} / \mathrm{hr}$ ]. Propane was piped to the burner from a battery of propane storage cylinders located above and outside the test area at grade level. The burner was remotely controlled from an instrumentation trailer located at grade level. During testing the burner was continuously monitored with the video equipment.

\subsection{Fire Protection Systems}

The first system used in the experimental program was a water curtain consisting of a row of open pendant sprinklers spaced $1.8 \mathrm{~m}$ ( 6 $f t$ ) on centers, located at the opening between the burn room and the base of the stairway. This spacing is recommended for the location of closed ordinary sprinklers around openings for escalators in the National Fire Protection Association (NFPA) Standard No. 13, Standard for Installation of Sprinkler Systems [3]. Sprinkler heads selected for the tests were of the same manufacturer and model. Two different orifice sizes were examined; $12.5 \mathrm{~mm}(1 / 2 \mathrm{in})$ and $10 \mathrm{~mm}(3 / 8 \mathrm{in})$. The water curtain piping was supplied by a fire hose from a fire department pumper located at grade level. Water flow was controlled and measured by a mechanical water meter and an on/off control valve. The water meter was equipped with a voltage output and the flow rate was continuously recorded with the test data aquisition system. Figure 4 details the installation of the water curtain sprinklers.

The second system consisted of five conical shaped spray nozzles located on the second level and directed downward into the stairway. The two different orifice sizes used in the first system were also used here. The conical shaped spray nozzles were used since this type of 
nozzle directs a conical shape spray pattern which completely fills the area of protection with spray droplets. The design of the spray nozzle system was based on engineering design information provided by the manufacturer concerning the area of coverage versus the distance from the spray nozzle. (This type of data is typically provided from the manufacturers for these type of special spray nozzles.) The flow from these nozzles was supplied and controlled in the same way as the water curtain system. Figure 5 provides the design details for the locations of the nozzles. It should be noted that current guidelines primarily address straight run stairs (such as escalators) through openings in floor/ceiling assemblies and not stairs which change directions at landings such as the stairway in the test facility. The opening perpendicular to the landing, therefore, was included in the area of coverage and in total water flow demand calculations.

For several tests, aluminum sheet panels were installed around the stairway at the first floor. The purpose of the panels were to enhance the air entrainment properties of the spray nozzles.

The baseline flow parameters from the systems were determined in accordance with criteria contained in nationally used standards. The NFPA No. 13 [3] recommends that sprinklers placed around escalators be designed for a minimum flow rate of $37.2 \mathrm{l} / \mathrm{min} / \mathrm{m}(3 \mathrm{gal} / \mathrm{min} / \mathrm{ft})$ along the perimeter with sprinklers spaced $1.8 \mathrm{~m}(6 \mathrm{ft})$ on centers. With 12.5 $\mathrm{mm}(1 / 2 \mathrm{in})$ orifice size sprinklers these design criteria equate to each sprinkler operating at a minimum $56.8 \mathrm{l} / \mathrm{min}$ (15 $\mathrm{gal} / \mathrm{min})$ with a nozzle pressure of $51.7 \mathrm{kPa}(7.5 \mathrm{psi})$. The baseline flow parameter for the spray nozzle system was based on a requirement of $81.5 \mathrm{l} / \mathrm{min} / \mathrm{m}^{2}$ (2 gal/

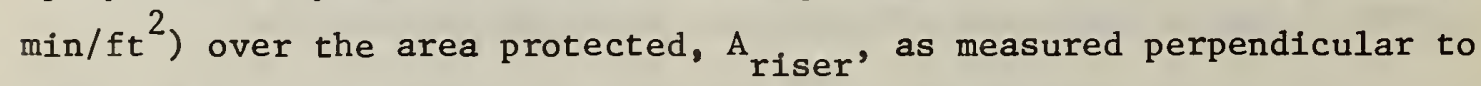
the risers of the stairs. This criterion is contained in the Life Safety Code 101 [4].

A summary of the sprinkler systems that were evaluated is presented in table 1. 


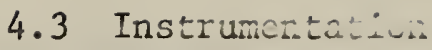

The instrumentation used in the test is listed in table 2 and the specific locations for the two series are shown in figures $1-3$. Signals from the instrumentation channels were recorded at 10 second intervals on a magnetic tape data acquisition system.

Chromel-alumel type unsheathed thermocouples, $0.25 \mathrm{~mm}$ (30 gauge); measured gas and surface temperatures throughout the test area.

Calibrated, water-cooled heat flux meters measured total heat flux in the burn room and across the lower level on the opposite side of the stairway from the burner. The velocity of air and gases entering the burn room and exhausting through the roof of the stairwell were measured with directional low velocity probes placed in the openings. This type of probe was developed by Heskestad [5] and the description and construction details of these devices are provided in the reference. The differential pressure was measured with a calibrated diaphragm-type pressure-transducer. Calibration techniques are provided by McCaffrey and Heskestad [6].

Oxygen was measured at three locations as shown in figures $1-3$. Gases were pumped through cold traps to remove condensable vapors before being sampled by electrolytic oxygen cells for $\mathrm{O}_{2}$ concentrations.

Pressure differential measurements were made between the following areas in the facility:
a. Burn room and exterior at the basement level.
b. Burn room and stairwell at the basement level.
c. Basement and 1st floor in the stairwell.
d. 1st and 2nd floor in the stairwell.

Water flow rate measurements were made using a vane type meter with a frequency analog converter which permitted flow rates to be recorded by the data acquisition system. 


\subsection{Test Program}

The test program concentrated on the investigation of two selected fire protection system technologies to reduce the flow of products of combustion into an open stairway. Before measuring the relative performance of the systems, an investigation was needed to characterize the flow of combustion gases in the stairtower which served as the test facility. It was essential that the test fires and resulting flow of products of combustion were repeatable from test to test in order to compare the performances of various fire protection systems interms of selected parameters. Also, an analysis of the relative efficiencies of the different fire protection systems being examined required an initial quantification of the test fires in this facility in the "non-sprinkler" mode.

The test program addressed these tasks:

a. Quantify the flow of products of combustion in the test facility at the selected burning rates.

b. Measure the impact that sprinkler and spray nozzle systems have on cooling and reducing flow of the product of combustion gas stream.

c. Determine the impact of draft panels installed around the stairway on the performance of the spray nozzle systems.

\subsection{Test Procedure}

Prior to the water curtain tests "dry" burns were conducted to characterize the profile of the stream of hot gases passing under the arch between the burn room and the base of the stairway. Since the burner emitted a fairly narrow column of flame and the deep beams 
created channels in the burn room perpendicular to the opening, cuere was a concern that the flow of heated gases would be concentrated in the center of the opening. A series of test fires were conducted using a thermocouple tree as described in table 2 to measure the temperature profile. The tests were conducted at $\dot{Q}=1.5 \mathrm{MW}\left[5.5\left(10^{6}\right) \mathrm{BTU} / \mathrm{hr}\right]$ and under two different ventilation conditions. The first test series incorporated a combustion air inlet of $0.39 \mathrm{~m}^{2}\left(4.25 \mathrm{ft}^{2}\right)$ and for the second series the inlet was increased to $1.6 \mathrm{~m}^{2}\left(18 \mathrm{ft}^{2}\right)$. The roof (exhaust) vent remained the same, $1.75 \mathrm{~m}^{2}\left(18.8 \mathrm{ft}^{2}\right)$ for both tests. The temperature profile was made at each of the two ventilation conditions by moving the thermocouple tree from one location to another between tests. The temperatures were recorded after quasi-steady state conditions were reached in the test area. The results as shown in figure 6 gave assurance that the construction across the opening between the burn room and the base of the stairway created a generally uniform distribution of the flow of gases under the arch.

The initial tests of the water curtain systems were conducted at a burner setting of $\dot{Q}=1.5 \mathrm{MW}\left[5.5\left(10^{6}\right) \mathrm{BTU} / \mathrm{hr}\right]$. For each test, the burner was fired and after three minutes, when quasi-steady conditions were reached, the water curtain was activated at a specified total water flow rate $(\dot{G})$. The water flow at the established rate was then maintained for 5 minutes by which time a quasi-steady condition was again achieved. In several water curtain tests, the water flow rates were increased at 5 minute increments. Intermediate test flows were repeated and the results were found to be consistent. For example, a single test of a water curtain system included nominal average flow rates per unit length of water curtain $\left(\dot{G}_{/} \mathrm{L}_{W C}\right)$ of $37.2,49.6,62.0$, and $74.5 \mathrm{l} / \mathrm{min} / \mathrm{m}$ $(3,4,5$, and $6 \mathrm{gal} / \mathrm{min} / \mathrm{ft})$, where $L_{W C}$ is the length of the water curtain. $\mathrm{L}_{W C}$ in these tests was fixed at $7.9 \mathrm{~m}(26 \mathrm{ft})$ (see figure 1). A repeated test at both 62.0 and $74.5 \mathrm{l} / \mathrm{min} / \mathrm{m}(5,6 \mathrm{gal} / \mathrm{min} / \mathrm{ft})$ provided equivalent results. Table 3 lists the tests conducted in the series. 


\section{TEST RESULTS}

\subsection{Water Curtain System Tests}

The initial tests of the water curtain fire protection scheme were conducted with the burner delivering $\dot{Q}=1.5 \mathrm{MW}\left[5.5\left(10^{6}\right) \mathrm{BTU} / \mathrm{hr}\right]$. Figure 7 provides the temperature reduction results of the tests at nominal average flow rates varying from 37.2 to $74.5 \mathrm{l} / \mathrm{min} / \mathrm{m}$ (3 to 6 $\mathrm{gal} / \mathrm{min} / \mathrm{ft})$ for both the $12.5 \mathrm{~mm}(1 / 2 \mathrm{in})$ and $10 \mathrm{~mm}(3 / 8 \mathrm{in})$ sprinklers. At a $\dot{Q}=1.5 \mathrm{MW}\left[5.5\left(10^{6}\right) \mathrm{BTU} / \mathrm{hr}\right]$, the quasi-steady gas stream temperature recorded in the stairway at the 1 st floor was $120^{\circ} \mathrm{C}\left(248^{\circ} \mathrm{F}\right)$ in the absence of a water spray protection system. When water flow was initiated and was increased in intensity, the gas stream temperatures decreased eventually to a low of $39^{\circ} \mathrm{C}\left(102^{\circ} \mathrm{F}\right)$. For both the $12.5 \mathrm{~mm}(1 / 2 \mathrm{in})$ and $10 \mathrm{~mm}(3 / 8 \mathrm{in})$ sprinklers this low temperature was reached at $\mathrm{G} / \mathrm{L}_{\mathrm{WC}}=$ $62 \mathrm{l} / \mathrm{min} / \mathrm{m}$ ( $5 \mathrm{gal} / \mathrm{min} / \mathrm{ft}$ ). The first floor temperatures did not decrease when $\mathrm{flows}$ were increased beyond this to $74.5 \mathrm{l} / \mathrm{min} / \mathrm{m}$ ( $6 \mathrm{gal} / \mathrm{min} / \mathrm{ft})$. At a flow rate of $37.2 \mathrm{l} / \mathrm{min} / \mathrm{m}$ ( $3 \mathrm{gal} / \mathrm{min} / \mathrm{ft}$ ), which is the minimum flow rate recommended in NFPA 13 [3] for sprinklers around escalator openings, greater cooling was achieved with the $10 \mathrm{~mm}(3 / 8 \mathrm{in})$ orifice sprinkler.

The volumetric flow rates of the gas stream through the roof vent at the varying water flow rates is shown in figure 8 . As expected, the range of performance was consistent with the gas cooling data shown in figure 7 . The flow through the stairway and the flow of combustion air were eventually reduced to the point where the burner became starved.

The next series of tests was conducted with $\dot{Q}=4 \mathrm{MW}\left[13.6\left(10^{6}\right)\right.$ $\mathrm{BTU} / \mathrm{hr}$ ]. Steady state gas temperatures in the stairwell at the 1 st floor reached $234^{\circ} \mathrm{C}\left(485^{\circ} \mathrm{F}\right)$ prior to operation of the water curtain. The reduction of gas temperatures measured at this location as a function of varying water flow rates for both the $12.5 \mathrm{~mm}(1 / 2 \mathrm{in})$ and $10 \mathrm{~mm}$ ( $3 / 8$ in) orifice sprinklers is shown in figure 9. The improvement in the cooling of the gas stream by the $10 \mathrm{~mm}$ (3/8 in) sprinklers was significant. 


$$
\text { At } \dot{G} / L_{W C}=74.5 \mathrm{l} / \mathrm{min} / \mathrm{m}(6 \mathrm{gal} / \mathrm{min} / \mathrm{ft}) \text { for the } 10 \mathrm{~mm}(3 / 8 \mathrm{in})
$$

sprinkler and at $\mathrm{G} / \mathrm{L}_{\mathrm{WC}}=86.9 \mathrm{l} / \mathrm{min} / \mathrm{m}(7 \mathrm{gal} / \mathrm{min} / \mathrm{ft})$ for the $12.5 \mathrm{~mm}$ (1/2 in) sprinkler the cooling phenomenon appeared to be approaching a maximum level where the heated gas stream became saturated by the spray droplets. At this cooling level, temperature measured at the 1st floor was approximately $60^{\circ} \mathrm{C}$.

As shown in figure 10, the water curtain systems at the higher water flow rates were able to substantially reduce the flow of the gas stream. However, once the gas stream approached a saturated condition, the flow of gases continued upward through stairwell at a constant rate of around $102 \mathrm{~m}^{3} / \mathrm{min}\left(3600 \mathrm{ft}^{3} / \mathrm{min}\right.$ ) as measured at the roof exhaust. This situation represented the point where increased water flow rates for the systems would not result in significant further cooling of the gas stream. Therefore, the rate of the flow the products of combustion at these water flow rates asymptotically reached a minimum, essentially constant rate. In short, the flow of products of combustion could not be further reduced in these tests with $\dot{Q}=4 \mathrm{MW}\left[13.6\left(10^{6}\right) \mathrm{BTU} / \mathrm{hr}\right]$.

\subsection{Spray Nozzle System Tests}

The spray nozzle system tests were all conducted with $\dot{Q}=4 \mathrm{MW}$ [13.6 $\left(10^{6}\right) \mathrm{BTU} / \mathrm{hr}$ ]. The initial fire test was conducted at water flow rates per unit equivalent passage sectional area, $\dot{G}_{\mathrm{A}} \mathrm{eq}$, of $81.5 \mathrm{l} / \mathrm{min} / \mathrm{m}^{2}$ (2 $\mathrm{gal} / \mathrm{min} / \mathrm{ft}^{2}$ ) which is the design criterion contained in NFPA 101 [4] for spray nozzle system protecting escalator openings. Here A eq, is the equivalent passage sectional area of the stairway as defined in [4]. At this water flow rate, the $10 \mathrm{~mm}$ (3/8 in) spray nozzle system substantially reduced the flow of gases up through the stairwell as indicated in figure 11. In this test the flow of incoming combustion air was reduced to the point where the burner became starved before the test was terminated. Prior to the termination the gas stream up through the stairwell became saturated and flow gases continued upward at a relatively constant but reduced rate. Figure 11 provides the results of 
tests at varying water flow rates and their impact on the flow of the gas stream. The $10 \mathrm{~mm}$ (3/8 in) nozzles operating at higher nozzle pressures provided significantly better results than the $12.5 \mathrm{~mm}(1 / 2$ in) nozzles.

In a series of non-fire tests, it was determined that the spray nozzle systems, projecting high velocity sprays downward, created a downdraft in the stairway. The installation of draft panels surrounding three sides of the stairwell at the first floor level was found to slightly increase this downdraft effect.

As discussed later in the analysis of the data, a major function of the spray nozzle system (as well as the water curtain system) in reducing the flow of the gas stream in the stairway is to $\operatorname{cool}$ and reduce the buoyancy of the heated gas stream. With regard to this function the installation of the draft panels around the stairway did not improve the performance of the spray nozzle systems for the few fire tests where they were employed. It is envisaged, however, that in other stairwe11sprinkler configurations draft panels or suspended draft curtains may be effective in channeling the gas stream in a manner as to enhance gaswater mixing and improve cooling efficiency.

\section{ANALYSIS OF THE DATA AND CONCLUSIONS}

\subsection{The Concept of a Stairwe11-Sprinkler Component}

As mentioned in section 2, the overall purpose of this experimental investigation is to study the effect of water sprinkler operation on the spread of products of combustion through open stairways. There are basically three mechanisms by which hot products of combustion migrate through a room of fire origin and eventually throughout an entire building structure. These mechanisms are buoyancy, expansion, and forced ventilation. The experimental part of the program indicated that the sprinkler systems investigated had a primary effect on the buoyancy mechanism. Such systems positioned around or within open stairway floor 
penetrations would produce a fundamental variation in intrabuilding migration of the products of combustion by virtue of their effect in reducing the buoyancy of (i.e., in cooling) those gases which pass through their region of influence.

Reducing the buoyancy of the products of combustion as they pass from a room of fire origin to an adjacent space may be beneficial or detrimental to the overall hazard development within a building. Indeed, the overall effect of sprinkler operation would depend on, and must be studied in the context of the overall building design (including active ventilation systems) and on the particular fire scenario which generates the threat. It is outside the scope of the present investigation to consider such an overall systems problem. As such, it turns out to be premature and, in a sense, inappropriate to address the general question: Sprinkler protection of open stairways - good or bad? Rather, open stairway sprinkler protection should more appropriately be studied as a potential fire protection system component. To ultimately investigate its utility in a given application it must first be understood in terms of its separate component performance characteristics. In view of this, the reduction and analysis of the acquired full scale experimental data was carried out with the goal of identifying and, to the maximum possible extent, deducing meaningful performance characteristics of these sprinkler components.

In the remaining discussion of this section we first proceed to define the physical bounds of the open stairwell-sprinkler system component. Following this, certain parameters which will prove useful in describing the component performance characteristics will be defined. A qualitative review of the principles which govern the flow phenomenology within the experimental stairtower facility will then be discussed. In the present context this facility should be thought of as an instrument where the stairwell-sprinkler component under study is inserted, and with which the desired component characteristics are measured. Certain experimentally obtained and useful operating characteristics of 
this facility instrument, in the absence of sprinkler operation, will be presented. Data acquired during operation of the various stairwaysprinkler types and appropriately reduced in the context of defined component performance characteristics will be presented. Finally plots of these reduced data and their implications will be discussed.

6.2 The Physical Bounds of the Stairwell-Sprinkler Component

In order to identify performance characteristics for the system component under investigation it is important to develop definitions both for the physical bounds of the component and for its input and output.

Here we are talking about an array of sprinkler heads which either surround the perihery of, or are placed within an open stairwell. At a minimum the overall component description would require the type of sprinkler heads, the spacing or general positioning of the heads, the area of the stairwell, and any other special devices or characteristics of the overall configuration.

The bounds of the overall component can be usefully described by the surfaces indicated by the dashed lines of figure 12 . The input to the stairway-sprinkler component is the hot gas which enters the imaginary vertical surface of these bounds. The output of the component is the relatively cool gas which passes up through the imaginary horizontal surface. This input and output is also indicated by arrows in figure 12 .

As discussed previously the present experimental program has investigated two basic component design types and a few variations of each of these. The component design types are summarized in table 1. 
The designs involve a fixed floor to ceiling distance of approximately $3.7 \mathrm{~m}\left(12 \mathrm{ft}\right.$ ) and a square stairwell area of $9.3 \mathrm{~m}^{2}$ (100 $\mathrm{ft}^{2}$ ). As will be seen, even with the limited available data a reasonable basis for generalization of the present experimental results to other geometries and configurations can be formulated.

\subsection{Parameters to Describe the Component Performance Characteristics}

As noted in the introductory paragraph to this section the major effect of the stairwell-sprinkler component is to reduce the temperature or buoyancy of hot gases that pass through it. The mechanism by which the incoming gases are cooled is primarily evaporation. Most of the inlet gas which enters the stairwell-sprinkler component is the ambient air which has been heated to high temperatures by mixing with the products of combustion within the fire plume. As a result of this heating one can anticipate that the relative humidity of this inlet gas will be very low. That is, the absolute water content of the air in its original ambient state together with the amount of water added from the products of combustion represents a relatively small percentage of the total water (vapor) carrying capacity of the air in its newly heated inlet state. Thus, as the relatively dry hot air enters the confines of the stairwell-sprinkler component envelope, a great deal of cooling of this stream can be potentially achieved if the sprinklers bring it anywhere near its fully saturated state.

of the several possible component designs that one might consider in providing this evaporative cooling, the one which achieves a fully saturated output gas stream with the least total water usage would appear to have advantages over the others. In any event, one would like to have the capability of estimating the degree of cooling which will be achieved by a given design for given inlet stream conditions and as a function of water usage. Such a capability would represent the component design performance characteristics being sought. 
The above discussion suggests that the following parameters would be useful in providing a description of inlet and outlet gas stream properties and in relating these to component performance:

$\dot{E}_{p}$ - Maximum possible rate at which energy can be extracted from the inlet air stream by virtue of adiabatically bringing the stream from an assumed zero saturation inlet state to a fully saturated outletustate. Additional energy extraction (temperature drop) that may be achieved by further cooling from the fully saturated state (by sensible cooling) is assumed to be negligible compared to the energy extraction associated with the above evaporation cooling.

$\dot{\mathrm{E}}_{\mathrm{a}}$ - Actual rate at which a specific stairway-sprinkler component design, assumed to be adiabatic, extracts energy from the inlet stream.

$\dot{G}_{a}$ - Actual volume rate of water flow delivered by all of the sprinklers in a given design.

$\dot{G}_{\text {evap }}$ - Amount of $\dot{G}$ which is actually evaporated during the course of extracting energy from the stream. To estimate this from the data the assumption of a zero humidity inlet state is made. It is further assumed that the total energy which the inlet gas stream provides to the entire sprinkler water stream as this water goes from its original temperature to its final temperature is negligible compared to the heat of vaporization associated with $\dot{G}_{\text {evap }}$.

The above definitions can be expressed as follows:

$$
\begin{aligned}
& \dot{E}_{p}=\dot{m}_{\text {in }} C_{p}\left(T_{\text {sat }}-T_{\text {in }}\right) \\
& \dot{E}_{a}=\dot{m}_{\text {in }} C_{p}\left(T_{\text {out }}-T_{\text {in }}\right) \\
& \dot{G}=\text { volume rate of water delivered by all sprinklers }
\end{aligned}
$$




$$
\dot{G}_{\text {evap }}=\dot{\mathrm{E}}_{\mathrm{a}} /\left[\rho_{\mathrm{w}(1 \mathrm{iq})} \Delta \mathrm{h}\right]
$$

where $T_{\text {out }}$ is the average temperature of the flow in the outlet stream, $\mathrm{T}_{\text {in }}$ is the average temperature of the (assumed dry) inlet stream, $\mathrm{T}_{\text {sat }}$ is the adiabatic saturation temperature of this inlet stream, $\dot{m}_{i n}$ is the mass rate of inlet gas flow, $\rho_{w(1 i q)}$ is the density of liquid water, $\Delta h$ is the enthalpy of vaporization of water, and $C_{p}$ is the (assumed constant) specific heat of the inlet gas. The properties of the inlet stream will be taken to be those of air. Also the mass rate of air flowing through the stairtower's lower vent and into the burn room will be assumed to be identical to $\dot{\mathrm{m}}_{i n}$. This latter assumption is essentially equivalent to neglecting the mass rate addition into the burn room of fuel (propane) compared to air. Condensation on relatively cool burn room surfaces is also neglected.

From the above assumptions and analysis it is possible to define the following two types of efficiencies which will be useful in establishing the performance of a given stairwell-sprinkler design:

$$
\begin{aligned}
& \eta_{c}=\dot{E}_{a} / \dot{E}_{p}=\text { cooling efficiency } \\
& \eta_{w}=\dot{G}_{\text {evap }} / \dot{G}=\text { water usage efficiency }
\end{aligned}
$$

\subsection{The Flow Phenomenology in the Experimental Facility}

A simplified sketch of the experimental stairtower facility is presented in figure 13. As mentioned earlier, this facility should be thought of as an instrument wherein the stairwell-sprinkler component is inserted for its performance evaluation. Referring to figure 13, the component under study is "placed" on the right side of the lower level. The fire source is placed on the left side of this lower space. Together with air which is brought in through the lower level vent, this source ultimately generates the high energy gas inlet stream with its associated $\dot{\mathrm{E}}_{\mathrm{p}}$ to the insitu stairwell-sprinkler component under investigation. 
The inlet stream passes through the stairwell-sprinkler component and, if the sprinklers are engaged, it enters the next level of the tower in a cooled and humid state. From there the stream passes up through the stairwell to the third level and finally exits from the facility through the ceiling vent. While passing through the second and third level, complicated mixing of the stream leads to significant heat transfer to the upper structural components of the facility. With further cooling of the flowthrough stream, condensation of water vapor from the warm humid gases to the cool walls could play a significant role in this heat transfer process.

In the context of the remarks at the beginning of this section the stairtower test facility includes a fire scenario and a very specific building design system, one component of which is represented by the stairwell-sprinkler system. Thus, activation of the sprinklers will influence, but not completely determine, the overall rate of migration of the products of combustion. In order to understand the effect of sprinkler operation in this particular building design it is useful to briefly describe the interfacility flow phenomenology and outline the major physical considerations that bring it about. This can best be accomplished by discussing the vertical pressure distributions both inside and outside the stairtower structure.

Between the levels of the lower and upper vents of the structure the uniform vertical outside temperature (density) distribution leads to a linear variation of ambient pressure. This is sketched in figure 12 . Now assume an airflow into the lower vent, past the fire, up through the stairway and out of the upper vent. Having been heated by the fire, the temperature of the gas flowing through the facility will generally have a high temperature compared to the ambient. This gas temperature will be highest at the lower level. Due to heat transfer to the walls, floors, etc. the temperature of the gases will generally decrease while flowing upward through the tower. Depending on the specific vertical 
temperature (density) profile (which can be significantly altered by operation of the sprinkler system) the variation of inside pressure between the elevations of the upper and lower facility vents would look something like the sketch in figure 12.

Compatible with the above assumption on the basic flow direction, and as indicated in the sketch of figure 12, it is evident that there must be a (neutral plane) level, $z_{n}$, between the two vent elevations. At this elevation, $P_{a m b}\left(z_{n}\right)=P_{\text {tower }}\left(z_{n}\right)$. Thus, pressure drops exist from outside to inside the facility at the lower vent and from inside to outside the facility at the upper vent. The pressure drops at these two vents are required to actually drive the flow of air and air plus products of combustion plus water (added by the sprinklers - if they are operating) through the lower and upper vents respectively. The actual rate of flow through the two vents must of course be compatible with the overall principles of mass and momentum conservation (for example, smaller vent openings would require a larger pressure drop to maintain the same mass rate of flow). The coupled principles of energy, momentum, and mass conservation dictate the temperature distribution that will result from various additions and deletions of energy to the stream as it passes through the inside of the facility. All these considerations taken together determine the rate of which air will enter the facility, provide oxygen for the fire and ultimately supply a particular inlet flow condition to a stairwell sprinkler component whose performance is under investigation.

It is clear from the above that the actual operation of the stairwell-sprinkler component will, in and of itself, alter the state of the flow throughout the entire facility. By varying the water flow through the sprinklers, the inlet flow to the stairwell-sprinkler component itself will be varied. This latter inlet flow variation will depend on performance characteristics of the overall facility design. In particular, the state of the flow before and after sprinkler operation 
will not be a measure solely of stairwell-sprinkler component performance characteristics. In order to extract such characteristics it would appear that simultaneous measurement of both inlet and outlet stream parameters during actual operation of the component is required.

As it turns out, it is neither practical nor necessary to directly measure bulk inlet stream parameters, say bulk temperature $\mathrm{T}_{\text {in, during }}$ actual sprinkler operation. However, it is possible to experimentally deduce such parameters as function of easily measureable fire size and mass rate of air flow through the lower vent and into the burn room.

A functional dependence of $\mathrm{T}_{\text {in }}$ on $\dot{\mathrm{m}}_{\text {in }}$ and fire size has been obtained from measurements taken during nonsprinkler operation of the facility. This will be discussed in the next section.

\subsection{A Useful Operating Characteristic of the Stairtower Facility Burn Room}

This section focuses attention on the phenomenology within the burn room. Referring again to figure 12, ambient air is drawn in through the lower vent and is entrained within the plume above the propane burner. For the experiments under discussion the entrained air actually supplies (more than enough of) the oxygen required to support the combustion of the fuel. The hot products of combustion rise in the plume to the ceiling. Once a quasisteady state has been achieved, the flow in this plume maintains an upper hot layer of products of combustion throughout the burn room and, at the same time, supplies a continuous flow of hot gases from this layer to the stairwell opening.

As has been discussed earlier, the amount of air which is brought into the burn room, $\dot{\mathrm{m}}_{\mathrm{in}}$, is a function of the rate of fuel supply and of the overall stairtower design parameters. Nonetheless, by applying conservation principles solely to the burn room envelope an estimate of the properties of the flow exiting the burn room (or entering the domain of influence of the stairwell-sprinkler component) can be obtained as a function of $\dot{\mathrm{m}}_{\text {in }}$, whatever its value. It is the objective of this paragraph to develop such a functional relationship. 
For the experiments under discussion the rate of mass flow of propane introduced by the burner is small compared to the rate of inlet air mass flow, $\dot{\mathrm{m}}_{\text {in }}$. Also, any mass transfer to or from the burn room wall ceiling and floor surfaces can be assumed to be small compared to

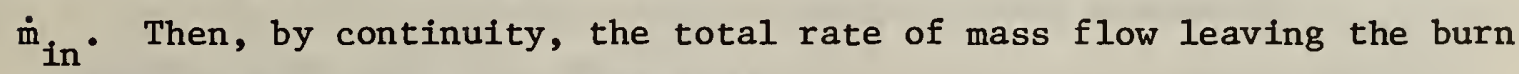
room is substantially the same as $\dot{\mathrm{m}}_{\text {in }}$.

Applying conservation of energy to an envelope surrounding the gases in the burn room and in the absence of any sprinkler operation the following results:

$$
\dot{\mathrm{m}}_{\text {in }} \mathrm{C}_{\mathrm{p}}\left(\mathrm{T}_{\text {out }}-\mathrm{T}_{\mathrm{amb}}\right)=\dot{\mathrm{Q}}-\dot{\mathrm{Q}}_{\text {loss }}
$$

where $C_{p}$ is the specific heat of the gases (assumed to be identical to that of air) entering and leaving the burn room, $Q$ is the heat addition due to fuel combustion, and $\dot{Q}_{1 \text { loss }}$ are the energy losses due to heat transfer to internal surfaces of the burn room.

Since the rate of propane supply to the burner is controlled and measured, and since complete combustion within the burn room is likely, the value of $\dot{Q}$ in the above equation can be accurately estimated. Also, $\dot{\mathrm{m}}_{\text {in }}$ is easily computed from a velocity probe measurement in the lower stairtower vent. $\mathrm{T}_{\mathrm{amb}}$ is also measured at this lower vent location.

Finally, $T_{\text {out }}$ can be estimated from measurements of two thermocouples which are submerged in the hot outlet stream somewhat above the stairwell opening at the lower part of the first floor level.

It is convenient to express the $\dot{Q}_{10 s s}$ term of $\mathrm{Eq}$. (3) in the following conventional terms:

$$
\dot{\mathrm{Q}}_{\text {loss }}=\overline{\mathrm{hA}}\left(\mathrm{T}-\mathrm{T}_{\text {wall }}\right)
$$

Here, $\overline{h A}$ represents an effective product of heat transfer coefficient and exposed burn room surface area, $\mathrm{T}_{\text {wall }}$ represents an effective temperature of this surface area, and $T$ represents an effective temperature of the burn room gases from which the net energy $\dot{Q}_{10 s s}$ is being transferred. 
$\mathrm{T}_{\text {out }}$ of Eq. (3) is clearly representative of a characteristic value for $T$. Also, during the limited interval of a given test, which is initiated with the burn room in an initial ambient temperature state, the effective temperature of the burn room surfaces, $\mathrm{T}_{\text {wall }}$, can be taken as $\mathrm{T}_{\mathrm{amb}}$. In view of all this, and since, heretofore, none of the individual terms on the right hand side of Eq. (4) have been defined precisely, it is reasonable to make the replacements $\mathrm{T}_{\text {out }}$ and $\mathrm{T}_{\text {amb }}$ for $\mathrm{T}$ and $\mathrm{T}_{\text {wall }}$, respectively. By doing this, all of the complex burn room phenomenology is thrown into the coefficient $\overline{\mathrm{hA}}$. Thus

$\dot{\mathrm{Q}}_{\text {loss }}=\overline{\mathrm{hA}}\left(\mathrm{T}_{\text {out }}-\mathrm{T}_{\mathrm{amb}}\right)$

Using this in Eq. (3) leads to the following equation for $\overline{\mathrm{hA}}$ :

$$
\overline{\mathrm{hA}}=\dot{\mathrm{Q}} /\left(\mathrm{T}_{\text {out }}-\mathrm{T}_{\text {amb }}\right)-\dot{\mathrm{m}}_{\text {in }} \mathrm{C}_{\mathrm{p}}
$$

The stairtower was exercised, without sprinkler operation, for a variety of different combinations of $\dot{Q}$ and upper vent area. The measurable variables mentioned above were averaged during that time interval of a given test run when quasisteady behavior was exhibited. The averaged data for these variables are presented in table 3 along with computed values [according to Eq. (6)] for $\overline{\mathrm{hA}}$.

As can be seen in table 4, the measured values of $\overline{\mathrm{hA}}$ are remarkably uniform. For all five of the tests in the present series which were appropriate for the present $\overline{\mathrm{hA}}$ evaluation and which are enumerated in the table, the average value

$$
\overline{\mathrm{hA}}=466 \mathrm{BTU} /\left(\min { }^{\circ} \mathrm{F}\right)=14.7 \mathrm{~kW} /{ }^{\circ} \mathrm{C}
$$

is accurate to within ten percent. This exceedingly useful result must be considered as strictly empirical, and by no means general beyond the range of experimental parameters from which it was deduced. Thus, the complex heat and mass transfer phenomena which dictate the value of $\overline{\mathrm{hA}}$ do not provide any clear basis on which to extrapolate this constant $\overline{\mathrm{hA}}$ result. Indeed, that $\overline{\mathrm{hA}}$ should exhibit constant behavior at all must be viewed as fortultous. 
With a known value of $\overline{\mathrm{hA}}$ in hand, Eq. (6) can be rewritten so as to provide an estimate for $T_{\text {out }}$ as a function of the measured experimental values $\dot{Q}, \dot{\mathrm{m}}_{\mathrm{in}}$, and $\mathrm{T}_{\mathrm{amb}}$.

$$
\mathrm{T}_{\text {out }}=\mathrm{T}_{\mathrm{amb}}+\dot{\mathrm{Q}} /\left(\dot{\mathrm{m}}_{\text {in }} \mathrm{C}_{\mathrm{p}}+\overline{\mathrm{hA}}\right)
$$

As defined earlier, $T_{\text {out }}$ is the temperature of the mixed gas stream as it exits from the stairwell to the second level of the stairtower. Also, this section does not consider any sprinkler operation. It is now reasonable to assume that the contribution to the heat loss term of Eq. (5) which takes place at boundaries of the stairwell-sprinkler system (i.e., at the surfaces on the right hand side of the burn room - c.f. figure 12) is negligible compared to the heat transfered to the burn room surfaces themselves (i.e., on the left side of the burn room). Accordingly, $T_{\text {out }}$ in the above equation can then be replaced by $T_{\text {in }}$, the average temperature of the stairwell-sprinkler component inlet gas stream. Doing so yields the following final working result of this section

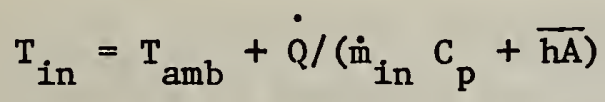

Together with the definitions of section 6.3 and the data acquired according to the description of earlier sections, the result of $\mathrm{Eq}$. (8) will be utilized in the next section to obtain operating characteristics of stairwell-sprinkler components.

\subsection{Some Performance Characteristics of Stairwe11-Sprinkler Components -- The Experimental Results and Their Correlation}

\subsubsection{Plots of the Experimentally Obtained Component Efficiencies}

As described in earlier sections, the stairwell-sprinkler components identified above in section 6.2 were operated in the stairtower structure under various water flow rates and fire sizes. With Eqs. (1), (2), and 
(8) the data from each of these test runs were used to compute the corresponding values of cooling efficiency, $\eta_{c}$, and water usage efficiency, $\eta_{w}$. The appendix describes the property values and the details of the data manipulation which were used in performing these computations.

For each of the component types, water curtain (WC) and spray nozzle $(\mathrm{SN})$, and for each of their two variations $[12.5 \mathrm{~mm}(1 / 2 \mathrm{inch})$ nozzles and $10 \mathrm{~mm}$ (3/8 inch) nozzles] a plot of $\eta_{c}$ as a function of the water usage parameter

$$
\dot{\mathrm{G}}^{*}=\dot{\mathrm{G}} /\left(\mathrm{gpm} \cdot \mathrm{A}_{\mathrm{we} 11} / \mathrm{ft}^{2}\right)=.0245 \dot{\mathrm{G}} /\left[(\ell / \mathrm{min})\left(\mathrm{A}_{\text {we } 11} / \mathrm{m}^{2}\right)\right]
$$

is provided in figures 14-17, where $A_{\text {well }}$ is the planview area of the total stairwell opening which was taken to be $9.3 \mathrm{~m}^{2}\left(100 \mathrm{ft}^{2}\right)$. The computed value of the extractable energy flow rate parameter

$$
\dot{\mathrm{E}}_{\mathrm{p}}^{*}=\dot{\mathrm{E}}_{\mathrm{p}} /\left[\left(10^{4} \mathrm{BTU} / \mathrm{hr}\right)\left(\mathrm{A}_{\mathrm{we} 11} / \mathrm{ft}^{2}\right)\right]=.0317 \dot{\mathrm{E}}_{\mathrm{p}} /\left[\mathrm{kW} \cdot\left(\mathrm{A}_{\mathrm{we} 11} / \mathrm{m}^{2}\right)\right]
$$

is also included in these plots alongside each data point. In a similar manner, plots of $\eta_{w}$ as a function of $\dot{E}_{p}^{*}$ are presented in figures 18-21. $\dot{G}^{*}$ is also included alongside each of the data points in these latter plots.

As indicated above, the parameters $\dot{\mathrm{G}}^{*}$ and $\dot{\mathrm{E}}_{\mathrm{p}}^{*}$ are measures of $\dot{\mathrm{G}}$ and $\dot{\mathrm{E}}_{\mathrm{p}}$ per unit stairwell area.

According to the model adopted here, every data point with corresponding computed $\eta_{c} \geq 1$ is assumed to represent a fully saturated outlet flow. The letter $S$ is therefore attached to every data point of this category in a11 Figures 14-21. 


\subsubsection{Correlation of the Reduced Data Results}

\subsubsection{Cooling Efficiency as a Function of Water Flow Rate 6.6.2.1.1 The $12.5 \mathrm{~mm}(1 / 2$ Inch) Water Curtain Data}

Attention is focused on the $\eta_{c}$ vs $\dot{G}^{*}$ plots of figures 14-17. Within this group the figure 14 data for the $12.5 \mathrm{~mm}(1 / 2 \mathrm{in})$ nozzle water curtain will first be discussed, and an empirical correlation of these will be developed. The same discussion and method of correlation will then be extended to the data of figures 15-17.

According to the assumed model of the phenomena, $\eta_{c}$ can exceed 1 only by providing more than enough sprinkler water flow to saturate the outlet stream. Further, the model assumes that (for practical systems) increased cooling beyond the fully saturated state will not be significantly greater than the cooling that would have been achieved if the outlet stream was exactly in a saturated state. This assumption, which is equivalent to the expectation that $\eta_{c}$ should never be significantly greater than 1 , is clearly consistent with the data of figure 14.

Following the line of reasoning of the model further, as $\dot{G}^{*}$ is increased, say for a fixed, arbitrary $\dot{\mathrm{E}}_{\mathrm{p}}^{*}$, the outlet stream would be expected to eventually reach the saturated condition and $\eta_{c}$ would reach a value of 1 . Larger $\dot{G}^{*}$ 's would lead to saturated outlet conditions with $\eta_{c}$ 's only slightly greater than 1 . At the other extreme of the $\dot{G}^{*}$ spectrum it is evident that (again, independent of $\dot{\mathrm{E}}_{\mathrm{p}}^{*}$ ) as $\dot{G}^{*}$ goes to zero, $\eta_{c}$ must go to zero. For $\dot{E}_{p}^{*}$ in some fixed range and for outlet streams which are unsaturated (e.g., for all data points of figure 14 without the attached $S$ ) it is therefore anticipated that reduced data plotted in $n_{c}, \dot{G}^{*}$ coordinates should fall in a band. This band would originate at the $\eta_{c}=\dot{G}^{*}=0$ point on the left and eventually terminate at some (apriori unknown) point $\eta_{c}=1, \dot{G}^{*}=\dot{G}^{* *}$ on the right. Beyond this latter point (i.e., for $\dot{G}^{*}>G^{* *}$ ) all data points should represent saturated outlet states and they should essentially lie on the line $n_{c}=1$. 
It is evident from the data in figure 14 that, in the entire available range $.39 \leq \dot{E}_{p}^{*} \leq 2.04$, good correlation with the (five unsaturated) data points is achieved by assuming the above described band to be a single straight 1ine. A least squares curve fit of this figure 14 data leads to a line of slope 0.84 and an $\eta_{c}=1$ intercept at $\dot{G}^{* *}=$ $1 . / 0.84=1.19$. This line along with the continuing $\eta_{c}=1$ line is included in the figure 14 plot. Together, these lines represent the empirical correlation of the data and its logical extension.

It is anticipated that there would be a breakdown of the above, narrow band (single line) correlation for $\dot{\mathrm{E}}_{\mathrm{p}}^{*}$ 's that were significantly larger than 2.04. However, some extension of the correlation's validity beyond the strict values $.39 \leq \dot{E}_{p}^{*} \leq 2.04$, say to the general range $\dot{E}_{p}^{*}$ of the order of one, e.g., from 0.2 to 5, would appear to be both valid and of great practical use.

A11 of the above analysis and discussion leads to the following conclusion:

For $\dot{E}_{p}^{*}$ of the order of one, the cooling efficiency performance characteristic of the $12.5 \mathrm{~mm}$ (1/2 in) nozzle water curtain component design which was tested in the stairtower can be estimated by

$$
\eta_{c}= \begin{cases}0.84 \dot{G}^{*} ; \dot{G}^{*} \leq 1.19 \\ 1 & ; \dot{G}^{*}>1.19\end{cases}
$$

\subsection{Correlation of the Other Data}

The entire analysis and discussion of the last paragraph has been applied to the $10 \mathrm{~mm}$ ( $3 / 8 \mathrm{in}$ ) nozzle WC component design (figure 15) and to the $S N$ component design with both $12.5 \mathrm{~mm}(1 / 2 \mathrm{in})$ (figure 16) and 10 $\mathrm{mm}(3 / 8 \mathrm{in})$ (figure 17 ) nozzles. The general conclusion from all of this is as follows: 
For $\dot{E}_{p}^{*}$ of the order of one, the cooling efficiency performance characteristics of the stairwell-sprinkler components which were tested in the stairtower can generally be estimated from:

$$
m_{c}= \begin{cases}\mathrm{K}_{\mathrm{c}} \dot{\mathrm{G}}^{*} ; \dot{\mathrm{G}}^{*} \leq 1 / \mathrm{K}_{\mathrm{c}} \\ 1 & ; \dot{\mathrm{G}}^{*}>1 / \mathrm{K}_{\mathrm{c}}\end{cases}
$$

where $K_{c}$ is some constant associated with the type of stairwell-sprinkler component used, 1.e.,

$$
\mathrm{K}_{c}=\mathrm{K}_{\mathrm{c}} \text { (stairwell-sprinkler component type) }
$$

and where, specifically,

$$
\begin{aligned}
& \mathrm{K}_{c}[12.5 \mathrm{~mm}(1 / 2 \mathrm{in}) \text { nozzle } \mathrm{WC}]=0.84 \\
& \mathrm{~K}_{c}[10 \mathrm{~mm}(3 / 8 \mathrm{in}) \text { nozzle } \mathrm{WC}]=1.00 \\
& \mathrm{~K}_{c}[12.5 \mathrm{~mm}(1 / 2 \mathrm{in}) \text { nozzle } \mathrm{SN}]=0.76 \\
& \mathrm{~K}_{c}[10 \mathrm{~mm}(3 / 8 \mathrm{in}) \text { nozzle } \mathrm{SN}]=0.95
\end{aligned}
$$

The above result for $n_{c}$ is plotted in figure 22 .

In the present test series the draft board variation to the SN component designs do not appear to alter the efficiency in any significant way. For general comparison, the data from the draft board variation of the SN designs were included in figures 16 and 17 . However, these few data have not been taken account of in the sloped line curve fits. 
It should be noted that in figures 16 and 17 (i.e., the SN data) the number of data points from which the sloped straight line curve fits are constructed are scarce indeed. For example, the figure 17 line is constructed from a single available (unsaturated) data point. More data would clearly enhance confidence in the validity of the Eq. (11) performance characteristics for these latter SN components. Nevertheless, the SN results in hand are reasonable in that they are consistent with the WC results which were constructed from a far firmer data base.

\subsubsection{Water Usage Efficiency as a Function of Extractable Energy Flow Rate}

Eqs. (1), (2), (9), and (10) yield the following equation for water usage efficiency:

$$
\eta_{w}=\frac{.1247\left(10^{4}\right) \dot{E}_{p}^{*} \eta_{c}}{\frac{\rho_{w}(1 i q)}{1 b_{m} / f t^{3}} \frac{\Delta h}{B T U / 1 b_{m}} \dot{G}^{*}}=\frac{11.10 \dot{E}_{p}^{*} \eta_{c}}{\frac{\rho_{w}(1 i q)}{g / m^{3}} \frac{\Delta h}{\mathrm{cal} / g} \dot{G}^{*}}
$$

Using the property values

$$
\begin{aligned}
& \rho_{\mathrm{w}\left(\text { liq }_{)}\right.}=62.41 \mathrm{~b}_{\mathrm{m}} / \mathrm{ft}^{3}=1.000 \mathrm{~g} / \mathrm{cm}^{3} \\
& \Delta \mathrm{h} \quad=1035 \mathrm{BTU} / 1 \mathrm{~b}_{\mathrm{m}}=575 \mathrm{cal} / \mathrm{g}
\end{aligned}
$$

in this last result yields

$$
\eta_{\mathrm{w}}=.0193 \dot{\mathrm{E}}_{\mathrm{p}}^{*} \eta_{\mathrm{c}} / \dot{\mathrm{G}}^{*}=\mathrm{K}_{\mathrm{w}} \dot{\mathrm{E}}_{\mathrm{p}}^{*}
$$

where

$$
\mathrm{K}_{\mathrm{w}}=.0193 \mathrm{n}_{\mathrm{c}} / \dot{\mathrm{G}}^{*}
$$


$=\mathrm{K}_{\mathrm{W}}\left(\dot{G}^{*} ;\right.$ stairwell - sprinkler type $)$

and where $n_{c}$ is provided in Eq. (11).

The above analytic estimate for $\eta_{w}$ which was derived from the Eq. (11) correlation is plotted in figures 18-21 along with the reduced data. For good correlation with the analytic estimate, a data point with 1 ts associated $\dot{G}^{*}$ value should $11 \mathrm{e}$ on an appropriate, constant $\dot{G}^{*}$, sloping line. From all of the data of the four figures only one data point has a water usage efficiency which is significantly below the predicted value, namely, the $\eta_{w}=.026, \dot{E}_{p}^{*}=2.04$ point of figure 18 . For this point, the predicted value of $\eta_{w}=.033$ (at $\dot{E}_{p}^{*}=2.04$ and $\left.\dot{G}^{*}=.62 \leq 1.19\right)$ 1s to be compared to the measured value of $\eta_{w}=.026$.

\subsection{Discussion of Results}

\subsubsection{Cooling Efficiency and Its Application}

The major results of the present experimental study are the cooling efficiency performance characteristics of the specific stairwell-sprinkler component types which were actually tested. These are portrayed graphically in figure 22 and presented analytically in Eq. (11). Assuming that the introduction of one of these tested stairwe11-sprinkler components in a given bullding design would decrease the overall building fire hazard, these results give guidance in implementing one of the various design cholces. For example:

(a) For the same total water delivery rate, the $10 \mathrm{~mm}(3 / 8 \mathrm{in})$ nozzle is preferable to the $12.5 \mathrm{~mm}(1 / 2 \mathrm{in})$ nozzle both in the WC and SN design.

(b) The WC design in the tested configuration may be slightly preferable to the SN design in that approximately five percent less water consumption would be required to provide the same cooling efficiency. 
(c) In the WC design, use of the $10 \mathrm{~mm}$ (3/8 in) nozzle instead of the $12.5 \mathrm{~mm}$ (1/2 in) nozzle results in the same amount of cooling with sixteen percent less water consumption. With the $10 \mathrm{~mm}(3 / 8 \mathrm{in})$ nozzle, water consumption should be restricted to $41 \mathrm{l} / \mathrm{min} / \mathrm{m}^{2}$ ( $1.0 \mathrm{gal} / \mathrm{min} / \mathrm{ft}^{2}$ ) of stairwell opening. Using more water will not result in significantly more cooling. This consumption is equivalent to an average flow rate of $48 \mathrm{l} / \mathrm{min} / \mathrm{m}(3.8 \mathrm{gal} / \mathrm{min} / \mathrm{ft})$ across the length of the opening between the stairway and the burn room.

(d) In the SN design, use of the $10 \mathrm{~mm}$ ( $3 / 8 \mathrm{in}$ ) nozzle instead of the $12.5 \mathrm{~mm}(1 / 2 \mathrm{in})$ nozzle results in the same amount of cooling with twenty percent less water consumption. With the $10 \mathrm{~mm}(3 / 8 \mathrm{in})$ nozzle, water consumption should be restricted to $43 \mathrm{l} / \mathrm{min} / \mathrm{m}^{2}$ (1.1 $\left.\mathrm{gal} / \mathrm{min} / \mathrm{ft}^{2}\right)$ of stairwell opening. Using more water will not result in significantly more cooling. This consumption is equivalent to an average flow rate of $67 \mathrm{l} / \mathrm{min} / \mathrm{m}^{2}\left(1.6 \mathrm{gal} / \mathrm{min} / \mathrm{ft}^{2}\right)$ over the protected opening as measured according to NFPA 101 [4].

(e) Draft boards do not significantly alter the cooling efficiency of the SN design.

The analytic estimate for the cooling efficiency performance characteristic allows a direct estimate for the component outlet stream temperature as a function of the inlet stream temperature. Thus, from $\mathrm{Eq}$. (1) and the definition of Eq. (2) it follows that $\mathrm{T}_{\text {out }}$ can be obtained from

$$
\mathrm{T}_{\text {out }}=\mathrm{T}_{\text {in }}\left(1-n_{c}\right)+n_{c} \mathrm{~T}_{\text {sat }}
$$

where ${ }^{\prime} c$ is given in Eq. (11), and where $\mathrm{T}_{\text {sat }}$, a function of $\mathrm{T}_{\text {in }}$, can be estimated to within $1^{\circ} \mathrm{C}\left(2^{\circ} \mathrm{F}\right)$ in the range $27<\mathrm{T}_{\text {in }}<538, \mathrm{~T}_{\text {in }}$ in ${ }^{\circ} \mathrm{C}$ $\left(80<\mathrm{T}_{\text {in }}<1000, \mathrm{~T}_{\text {in }}\right.$ in $\left.^{\circ} \mathrm{F}\right)$ by

$$
\mathrm{T}_{\text {sat }}=22.7 \mathrm{ln}\left(\mathrm{T}_{\text {in }}+17.8\right)-77.2, \mathrm{~T}_{\text {sat }} \text { and } \mathrm{T}_{\text {in }} \text { in }{ }^{\circ} \mathrm{C}
$$




$$
\mathrm{T}_{\text {sat }}=40.8 \mathrm{ln}\left(\mathrm{T}_{\text {in }}\right)-131, \mathrm{~T}_{\text {sat }} \text { and } \mathrm{T}_{\text {in }} \text { in }{ }^{\circ} \mathrm{F}
$$

Eq. (14) is an empirical curve fit of saturation air temperatures provided in reference [7].

\subsubsection{Water Usage Efficiency and Its Potential Improvement}

It is clear from the plots of figures $18-21$ and from the result of Eq. (12) that for the purpose of evaporation cooling the components under review have very poor water usage efficiencies. In particular, for the extractable energy flow rate levels of the present experiments the values $\eta_{w}$ are of the order of .03 or less. This poor efficiency is not all that surprising when one considers the purpose for which the sprinkler nozzles were designed, namely, to extinguish deep seated fires, or to cool hot surfaces.

Characteristics of a water delivery system that would be successful and efficient in the extinguishment or surface cooling role are incompatible with a system that would efficiently provide gas stream cooling. In extinguishment, for example, one delivers water droplets which are relatively large. Indeed, they should be large enough so that during their trajectory and until they reach their intended target they will achieve or retain enough momentum to negotiate opposing hot gas flows without significant evaporation. Such water droplets will for example, enter the threatening fuel bed with most of their original liquid phase water intact and available to $\operatorname{cool}$ the fuel to the point of extinguishment. In direct contrast to this, when performing an evaporation cooling role, that liquid part of a droplet which passes completely through the hot gas stream intact is totally wasted.

In view of the above 1 would appear that arbitrarily small droplets with corresponding large surface area per unit mass of water may be the appropriate choice for efficient evaporation cooling of a hot gas stream. This choice would, however, lead to a problem in practical systems in that such mist-1ike particles would be rapidly swept away by the gas 
stream near their point of injection thereby never actually penetrating and cooling the stream throughout its depth. What is actually required for effective evaporation cooling is a system that delivers droplets of appropriate size and/or momentum so that, during the same time interval that these droplets successfully penetrate a hot gas stream indepth, they effectively loose all of their liquid phase to evaporation. In any event, one would anticipate that with smaller nozzle sizes than those used in the present component designs (which would lead to smaller droplet sizes for a fixed $\dot{G}^{*}$ ) cooling efficiencies of 1.0 could be achieved at water usage rates which were considerably less than the $\dot{G}^{*}$ $=1.0-1.3$ range required in these tests. Put another way, by using smaller nozzles it should be possible to practically achieve maximum stream cooling $\left(\eta_{c}=1.\right)$ with a tenth or less of the present water delivery rate (i.e., at $\eta_{w} \geq .3$ ).

\subsubsection{Extension of the Results to Other Geometries and Configurations}

The results for the performance characteristics of the actual stairwel1-sprinkler components tested in the present experimental program have been presented above. The outstanding remaining question relative to these results has to do with their potential extention to other stairwell geometries and configurations. For example, if the WC or SN design is used to provide one-sided protection of a high aspect ratio stairwell [as compared to one-sided protection of the present square, $9.3 \mathrm{~m}^{2}\left(100 \mathrm{ft}^{2}\right)$ stairwe11], can the above results be applied with any confidence? Alternatively, can the above results be applied to a square $9.3 \mathrm{~m}^{2}\left(100 \mathrm{ft}^{2}\right)$ stairwell centered in a space of fire origin and protected around its entire periphery (as compared to the one-sided protection required in the present configuration)? Finally, can the results be used in designing protection of stairwells that open upward from a room of fire origin and that have heights significantly higher or smaller than the $3.9 \mathrm{~m}$ (12 ft) height of the present configuration?

The fact of the matter is that each of the above example variations to the tested geometry and configuration represent a new stairwe11sprinkler design in their own right. For confident knowledge of the 
performance characteristics of these variant designs, separate experimental programs would be required. By nature of the geometry (size) and configuration (placement of stairwell within the burn room) of the above example components, such programs would require a much larger area burn room than the one in the existing stairtower facility.

In spite of this last observation, and by nature of its area type of water discharge, it would appear that the performance of the SN type of stairwell-sprinkler component designs based on $G^{*}$ or $E^{*}$ (water usage or extractable energy per unit stairwell area) would be relatively insensitive to the details of total stairwell area [provided the narrow dimension of the planview is not significantly less than $3 \mathrm{~m}(10 \mathrm{ft})$ ], location within room of fire origin and height of room of fire origin. It is not at all clear that the same would be true for the WC type of design which provides cooling in the vicinity of its line of water discharge whose effectiveness may be insensitive to the actual area of the stairwell on which $G^{*}$ and $E^{*}$ are based. However, if extension of the present WC results is valid then it would probably be more appropriate to present and use them on a basis of water usage or extractable energy per unit length of water curtain (as compared to per unit area of stairwe11).

In view of the latter observation, the following new water usage and extractable energy parameters are defined for use with water curtain designs:

$$
\begin{aligned}
& \dot{\mathrm{G}}_{\mathrm{WC}}^{*}=\dot{\mathrm{G}} /\left(\mathrm{gpm} \cdot \mathrm{L}_{\mathrm{WC}} / \mathrm{ft}\right)=.0805 \dot{\mathrm{G}} /\left[(\ell / \mathrm{min})\left(\mathrm{L}_{\mathrm{WC}} / \mathrm{m}\right)\right] \\
& \dot{\mathrm{E}}_{\mathrm{p}(\mathrm{WC})}^{*}=\dot{\mathrm{E}}_{\mathrm{p}} /\left[\left(10^{4} \mathrm{BTU} / \mathrm{hr}\right)\left(\mathrm{L}_{\mathrm{WC}} / \mathrm{ft}\right)\right]=.104 \dot{\mathrm{E}}_{\mathrm{p}} /\left[\mathrm{KW} \cdot\left(\mathrm{L}_{\mathrm{WC}} / \mathrm{m}\right)\right]
\end{aligned}
$$

where $\mathrm{L}_{\mathrm{WC}}$ is the length of the water curtain.

Using a water curtain length of $7.9 \mathrm{~m}(26 \mathrm{ft})$ for the tested WC design, a new abscissa is included at the top of the plot of figure 22 to reflect the $n_{c}$ vs $\dot{G}_{W C}^{*}$ presentation of the WC results. Also, for the 
present tests, the $E_{p}^{*}$ range $.39-2.04$ corresponds to an $E_{p(W C)}^{*}$ range 1.57.9, and the extended useful $E_{p}^{*}$ range .2-5. (i.e., of the order of 1 ) corresponds to an extended useful $\mathrm{E}_{\mathrm{p}(\mathrm{WC})}^{*}$ range .8-20. Finally, the WC results of Eqs. (11) and (12) are rewritten as follows:

For $\dot{\mathrm{E}}_{\mathrm{p}(\mathrm{WC})}^{*}$ in the approximate range .8-20., the cooling efficiency performance of the two water curtain stairwel1-sprinkler components which were tested in the stairtower can generally be given as

$$
n_{c}= \begin{cases}K_{c(W C)} \dot{G}_{W C}^{*} ; \dot{G}_{W C}^{*} \leq 1 / K_{c(W C)} \\ 1 & ; \dot{G}_{W C}^{*}>1 / K_{c(W C)}\end{cases}
$$

where

$$
\mathrm{K}_{\mathrm{c}(\mathrm{WC})}=\mathrm{K}_{\mathrm{c}(\mathrm{WC})} \text { (water curtain type) }
$$

and where, specifically,

$$
\begin{aligned}
& \mathrm{K}_{\mathrm{c}(\mathrm{WC})}[12.5 \mathrm{~mm}(1 / 2 \mathrm{in}) \text { nozzles on } 1.8 \mathrm{~m}(6 \mathrm{ft}) \text { centers }]=0.22 \\
& \mathrm{~K}_{c(W C)}[10 \mathrm{~mm}(3 / 8 \mathrm{in}) \text { nozzles on } 1.8 \mathrm{~m}(6 \mathrm{ft}) \text { centers }]=0.26
\end{aligned}
$$

The water usage efficiency of these water curtain components can be estimated from

$$
\eta_{w}=K_{w(w C)} \dot{E}_{p(w C)}^{*}
$$

where

$$
\begin{aligned}
\mathrm{K}_{\mathrm{W}(\mathrm{WC})} & =.0193{\eta_{\mathrm{C}}} / \dot{\mathrm{G}}_{\mathrm{WC}}^{*} \\
& =\mathrm{K}_{\mathrm{W}(\mathrm{WC})}\left(\dot{\mathrm{G}}_{\mathrm{WC}}^{*}\right. \text {; water curtain type) }
\end{aligned}
$$

and where $\eta_{c}$ is provided in Eq. (16). 
Based on all of the above remarks, the following conclusions result:

a. For $\dot{E}_{p}^{*}$ in the approximate range $0.2-5.0$ and for stairwells with widths not significantly larger than $3 \mathrm{~m}$ (10 ft) but otherwise of arbitrary area and location it is reasonable to estimate performance characteristics of SN stairwell-sprinkler components from Eqs. (11) and (12).

b. For $\dot{E}_{p(W C)}^{*}$ in the approximate range $0.8-20$. and for stairwells of arbitrary area and location and serving floors with heights not significantly larger or smaller than $3.7 \mathrm{~m}$ (12 ft), it is reasonable to estimate performance characteristics of WC stairwellsprinkler components from Eqs. (16) and (17).

To implement a WC design according to the above conclusion obviously requires protection around the entire stairwell perimeter. As in the experimental configuration, this can involve portions of the stairwell perimeter being protected by fixed walls and portions by the actual water curtain. Alternatively, the entire perimeter can be protected by the water curtain.

If the SN or WC is implemented in a given building, it would appear reasonable to do so at the lowest water usage rate which provides $n_{c}=1$. Of the two nozzle sizes investigated the $10 \mathrm{~mm}(3 / 8 \mathrm{in})$ one is preferable and should be implemented at water rates of $\dot{\mathrm{G}}^{*}=1 / .95=$ 1.05 and $\dot{G}_{W C}^{*}=1 / .26=3.8$ for the $S N$ and $W C$ designs respectively. A choice between SN and WC in a given application is a choice between the lowest total water usage rate, $\dot{q}_{a}$, consistant with these latter values. From the definitions of Eqs. (9) and (13) this suggests:

When implemented in the $10 \mathrm{~mm}$ ( $3 / 8 \mathrm{in})$ nozzle, the SN design is more efficient than the WC design if 


$$
\begin{aligned}
& \frac{\text { area of stairwell } / \mathrm{m}^{2}}{\text { length of water curtain/m }}<1.10 \\
& \frac{\text { area of stairwell/ft }{ }^{2}}{\text { length of water curtain/ft }}<3.6
\end{aligned}
$$

and the WC design should be used if Eq. (16) is not satisfied.

As noted in the above conclusion a. and b., this last result would not necessarily be valid if the stairwell width was significantly larger than $3 \mathrm{~m}(10 \mathrm{ft})$, or if the celling height was significantly different than $3.7 \mathrm{~m}$ (12 ft).

Applying the last conclusion to configurations where the WC design would completely surround the perphery of the stairwell yields the result that the SN is preferable to the WC if the stairwell length $\mathrm{L}$ satisfies:

$$
\begin{aligned}
& \mathrm{L} / \mathrm{m}<\frac{2.2(\mathrm{~W}+2 \delta) / \mathrm{m}}{(\mathrm{W} / \mathrm{m}-2.2)} \\
& \mathrm{L} / \mathrm{ft}<\frac{7.2(\mathrm{~W}+2 \delta) / \mathrm{ft}}{(\mathrm{W} / \mathrm{ft}-7.2)}
\end{aligned}
$$

where $W$ is the width of the stairwell and $\delta$ is the distance between the edge of the stairwell opening and the position of the line of water curtain nozzles.

\section{SUMMARY OF CONCLUSIONS}

In this investigation the concept of sprinkler fire protection of open stairways has been studied experimentally. In the event of a threatening fire the implementation of such stairwel1-sprinkler components has previously been assumed to result in less hazardous migrations of products of combustions throughout a building of interest. However, this is not necessarily the case. Whether beneficial or detrimental, the fact of the matter is that the result of implementing such components can be determined only by taking account of the characteristics of the 
overall building system. Besides the stairwell-sprinkler component itself, the significant elements of this system would generally include all components and construction details which impact on the normal or emergency building ventilation system. The nature of most likely fire threat scenarios would also play a key factor in determining the ultimate utility of the stairwell-sprinkler component.

If implementation of a stairwell-sprinkler system component would reduce the fire hazard in a given application, then it would do so by cooling hot fire gases as they pass into or through the component's boundaries. This cooling of the gases reduces their buoyancy and, therefore, the nature of their ultimate spread throughout the building.

In view of the above, the present experimental program was carried out with the objective of evaluating and generalizing the performance characteristics of different stairwell sprinkler designs relative to their cooling capability. Two different types of sprinkler deployment were studied, the water curtain (WC) and the spray nozzle (SN). For each of these, $12.5 \mathrm{~mm}(1 / 2 \mathrm{in})$ and $10 \mathrm{~mm}(3 / 8 \mathrm{in})$ nozzle sizes were evaluated. For the SN design, a minor variation with draft boards surrounding most of the stairwell (above the actual opening) was investigated. A fixed, square, stairwell opening of approximately $9.3 \mathrm{~m}^{2}$ $\left(100 \mathrm{ft}^{2}\right)$ was used in all tests.

The data acquired during the tests were analyzed and correlated within the context of an evaporation cooling model of stairwell-sprinkler component performance. For the fire sizes and specific stairwellsprinkler components which were tested, the following conclusions resulted:

a. The $10 \mathrm{~mm}(3 / 8 \mathrm{in})$ nozzles are more efficient than the $12.5 \mathrm{~mm}(1 / 2$ in) nozzles (for a given water flow rate).

b. The WC design may be more efficient than the SN design, but not significantly so for single side exposure. 
c. Draft boards do not significantly alter the performance of the SN design.

d. With the use of $10 \mathrm{~mm}$ (3/8 in) nozzles, total water usage greater than $41-43 \mathrm{l} / \mathrm{min} / \mathrm{m}^{2}\left(1.0-1.1 \mathrm{gal} / \mathrm{min} / \mathrm{ft}^{2}\right)$ of stairwell plan area [i.e., 380-400 $\mathrm{l} / \mathrm{min}(100-110 \mathrm{gal} / \mathrm{min})]$ will not significantly increase the cooling.

e. Actual cooling efficiency and water usage efficiency can be estimated from Eqs. (11) and (12) and from figure 22. The temperature of the gas stream issuing from a component can be estimated from Eq. (13).

Further study suggested extensions to these above specific results which could be used with some confidence on stairwell-sprinkler components of different geometry and/or configuration. These extensions are found at the end of section 6.7.3. They provide explicit guidance in choosing between the SN or WC designs.

Finally, it was concluded that for the task of evaporation cooling of hot gas streams, fire protection sprinkler or spray nozzles of the types that were used in this study are exceedingly inefficient in their water usage. In particular, it was estimated that with more appropriate nozzle designs, water usage could be reduced to a tenth or less of the tested rates without any degradation in cooling efficiency. It is important to point out, however, that to achieve such high water usage efficiency a significant nozzle technology development program may be required.

\section{ACKNOWLEDGEMENTS}

The authors would like to express thanks to Messrs. Richard Zile and Warren Hayes, Jr. who participated in both the planning and the preparation of the test facility as well as in the experimental work. 


\section{REFERENCES}

[1] O'Neill, J. G., Sprinkler-Vent and Spray Nozzle Systems for Fire Protection of Openings in Fire Resistive Walls and Ceilings - The State of the Art and a Plan for Future Research Work, NBSIR 781571, Nationa1 Bureau of Standards, (1978).

[2] Thompson, N. J., New Method of Protecting Conveyor Openings, NFPA Quarterly Vol. 41, p. 9-18, (July 1947).

[3] Installation of Automatic Sprinkler Systems, NFPA No. 13, National Fire Protection Association, Boston, MA (1978 Edition).

[4] Life Safety Code, NFPA 101, National Fire Protection Association, Boston, MA (1976 Edition).

[5] Heskestad, G., Bidirectional Flow Tube for Fire-Induced Vent Flows. In: Large-Scale Bedroom Fire Test, July 11, 1973, P. A. Croce and H. W. Emmons, eds. FMRC Serial 21011.4, pp. 140-5, Factory Mutual Research Corporation, Norwood, MA (1974).

[6] McCaffrey, G. J. and Heskestad, G., A Robust Bidirectional Low Velocity Probe for Flame and Fire Application, Combustion and Flame, Vo1. 26, pp. 125-7 (1976).

[7] Threlkeld, J. L, Thermal Environmental Engineering, Second Edition, 1970. 
APPENDIX A. PROPERTY VALUES AND DETAILS OF DATA MANIPULATION

The following equations were developed in section 6:

$\dot{\mathrm{E}}_{\mathrm{p}}=\dot{\mathrm{m}}_{\mathrm{in}} \mathrm{C}_{\mathrm{p}}\left(\mathrm{T}_{\text {sat }}-\mathrm{T}_{\text {in }}\right)$

$\dot{\mathrm{E}}_{\mathrm{a}}=\dot{\mathrm{m}}_{\text {in }} \mathrm{C}_{\mathrm{p}}\left(\mathrm{T}_{\text {out }}-\mathrm{T}_{\text {in }}\right)$

$\dot{G}=$ volume flow rate of water

$\dot{G}_{\text {evap }}=\dot{\mathrm{E}}_{\mathrm{a}} /\left[\rho_{\mathrm{w}(1 \mathrm{iq})} \Delta \mathrm{h}\right]$

$\eta_{c}=\dot{E}_{a} / \dot{E}_{p}=$ cooling efficiency

$\eta_{\mathrm{w}}=\dot{\mathrm{G}}_{\text {evap }} / \dot{\mathrm{G}}=$ water usage efficiency

$\overline{\mathrm{hA}}=466 \mathrm{BTU} /\left(\min { }^{\circ} \mathrm{F}\right)=14.7 \mathrm{~kW} /{ }^{\circ} \mathrm{C}$

$\mathrm{T}_{\text {in }}=\mathrm{T}_{\mathrm{amb}}+\dot{\mathrm{Q}}\left(\dot{\mathrm{m}}_{\mathrm{in}} \mathrm{C}_{\mathrm{p}}+\overline{\mathrm{hA}}\right)$

It is the purpose of this appendix to explain the details of how actual test data were used in these equations to obtain the plots of Figures 14-21.

To begin with, the following property values were used in the calculations

$$
\begin{aligned}
& \mathrm{C}_{\mathrm{p}}=0.24 \mathrm{BTU} /\left(1 \mathrm{~b}_{\mathrm{m}}{ }^{\circ} \mathrm{F}\right)=0.24 \mathrm{cal} /\left(\mathrm{g}^{\circ} \mathrm{C}\right) \\
& \rho_{\text {am }} \mathrm{a} 540^{\circ} \mathrm{R}=300^{\circ} \mathrm{K}=.07351 \mathrm{~b}_{\mathrm{m}} / \mathrm{ft}^{3}=1.177\left(10^{-3}\right) \mathrm{g} / \mathrm{cm}^{2} \\
& \rho_{\mathrm{w}(1 \mathrm{iq})}=62.41 \mathrm{~b}_{\mathrm{m}} / \mathrm{ft}^{3}=1.000 \mathrm{~g} / \mathrm{cm}^{3}
\end{aligned}
$$




$$
\begin{aligned}
& \mathrm{T}_{\text {sat }} /{ }^{\circ} \mathrm{C}=22.7 \ln \left(\mathrm{T}_{\mathrm{dry}} /{ }^{\circ} \mathrm{C}+17.8\right)-77.2 \\
& \mathrm{~T}_{\text {sat }} /{ }^{\circ} \mathrm{F}=40.8 \ln \left(\mathrm{T}_{\mathrm{dry}} /{ }^{\circ} \mathrm{F}\right)-131 .
\end{aligned}
$$

for $\mathrm{T}_{\text {sat }}$ and $\mathrm{T}_{\mathrm{dry}}$ in the range

$$
\begin{aligned}
& 16 \leq \mathrm{T}_{\text {sat }} /{ }^{\circ} \mathrm{C} \leq 54 ; 43 \leq \mathrm{T} \text { dry } /{ }^{\circ} \mathrm{C} \leq 318 \\
& 60 \leq \mathrm{T}_{\text {sat }} /{ }^{\circ} \mathrm{F} \leq 130 ; 109 \leq \mathrm{T}_{\mathrm{dry}} /{ }^{\circ} \mathrm{F} \leq 604 \\
& \Delta \mathrm{h} /(\mathrm{cal} / \mathrm{g})=597.5-.5821 \mathrm{~T} \mathrm{sat} /{ }^{\circ} \mathrm{C} \\
& \Delta \mathrm{h} /\left(\mathrm{BTU} / 1 \mathrm{~b}_{\mathrm{m}}\right)=1094.1-0.5821 \mathrm{~T}_{\text {sat }} /{ }^{\circ} \mathrm{F}
\end{aligned}
$$

for $T_{\text {sat }}$ in the range

$$
10 \leq \mathrm{T}_{\text {sat }} /{ }^{\circ} \mathrm{C} \leq 93 ; 50 \leq \mathrm{T}_{\text {sat }} /{ }^{\circ} \mathrm{F} \leq 200
$$

The above equation for $\mathrm{T}_{\text {sat }}$ as a function of $\mathrm{T}_{\mathrm{dry}}$ was generated as a linear (in semilog coordinates) curve fit to $T_{\text {sat, }} T_{\text {dry }}$ temperature pairs which were computed using Eq. 8.31 and tables A.1 and A.5 of Threlkeld [7]. The approximation of Eq. (A-2) and these computed values are plotted in figure 23.

Compatible with the ideas of section 6.3, $\mathrm{T}_{\text {sat }}$ of the first of Eqs. (1) is the saturation temperature of the inlet air stream (to the stairwell-sprinkler component - see figure 12) assuming that this inlet air, at temperature $T_{1 n}$, is in a dry state. Thus, $T_{\text {sat }}$ of the first of Eqs. (1) was computed from Eq. (A-2) where $T_{d r y}$ was taken as $T_{1 n}$, and where $\mathrm{T}_{\text {in }}$ was computed from Eq. (8).

Eq. (A-3) for $\Delta h$ as a function of $T$ sat, which was used in the last of Eqs. (1), is a linear curve fit to tabulated $\Delta$ h values provided in table A.5 of [7]. The approximation of this equation and the tabulated 
values for $\Delta h$ are plotted in figure 24.

The value for $\dot{\mathrm{m}}_{1 \mathrm{n}}$, used in the first two of Eqs. (1) was computed f rom:

$$
\dot{\mathrm{m}}_{\text {in }}=\mathrm{A}_{i} \mathrm{~V}_{i} \rho_{\mathrm{amb}}
$$

where $A_{i}$ is the cross-section area of the circular inlet duct to the stairtower, $\rho_{a m b}$ is the density of the incoming ambient air, and $v_{i}$ is the average incoming air velocity. $A_{i}$ and $\rho_{\text {amb }}$ were taken as

$$
\begin{aligned}
\mathrm{A}_{\mathrm{i}}= & .393 \mathrm{~m}^{2}=4.24 \mathrm{ft}^{2} \\
\rho_{\mathrm{amb}} & =\left[1.177\left(10^{-3}\right)(300 .) /\left(\mathrm{T}_{\mathrm{amb}} /{ }^{\circ} \mathrm{K}\right)\right] \mathrm{g} / \mathrm{cm}^{3} \\
& =\left[.0735(540 .) /\left(\mathrm{T}_{\mathrm{amb}} /{ }^{\circ} \mathrm{R}\right)\right] 1 \mathrm{~b}_{\mathrm{m}} / \mathrm{ft}^{3}
\end{aligned}
$$

where $T_{a m b}$ is the measured temperature of the ambient air. $V_{i}$ was taken as the air velocity measured on the duct axis. The actual value for $V_{i}$ used in Eq. (A-4) was an average of those ten consecutive data points (taken at 10 second intervals) which appeared to best represent a quasisteady condition for the portion of a given test run being analyzed.

The value of $\dot{Q}$ in Eq. (8) was computed from the measured flow rate of burner fuel.

The value for $\dot{G}$ used in the third of Eqs. (1) was the actual total measured volume flow rate of water averaged over the above mentioned 100 second quasi-steady test interval.

The value of $\mathrm{T}_{\text {out }}$ used in the second of Eqs. (1) was taken to be the average of the time averaged measurements of the two thermocouples 14 and 15 (see figures 2 and 3 ). 
Table 1. Water curtain and spray nozzle systems

Type I: Water Curtain (WC). Sprinklers on six foot centers surround the portion of the periphery of the stairwell which is open to the room of fire origin.

Variation IA: $10 \mathrm{~mm}$ (3/8 inch) sprinkler head opening.

Variation IB: $\quad 12.5 \mathrm{~mm}$ (1/2 inch) sprinkler heat opening.

Type II: Spray Nozzle (SN). Spray nozzles located within the stairwell opening. The spray pattern covers the entire area of the opening.

Variation IIA: $10 \mathrm{~mm}(3 / 8 \mathrm{inch})$ spray nozzle heat opening.

Varlation IIA-DB: Same as IIA but with draft boards surrounding the opening above the stairwell.

Variation IIB: $12.5 \mathrm{~mm}$ (1/2 inch) spray nozzle head opening.

Variation IIB-DB: Same as IIB but with draft boards. 
Table 2. Instrument description

I.D.

TC 1

TC 22

TC 23

TC 24

TC 5

TC 6

TC 7

TC 8

TC 9

TC 21

TC 25

TC 26

TC 10

TC 11

TC 12

TC 13

TC 14

TC 15

TC 16

TC 17

TC 18

TC 19

TC 20

TC 27

PRS 1

PRS 2

PRS 3

PRS 4

VEL 1

VOL 1

VEL 2

VOL 2

VEL 3

VOL 3

CO 1

\section{Description}

Room Tree A, 11'10" from Floor (2" down)

Room Tree D, 2" from Ceiling

Room Tree D, 8" from Celling

Room Tree D, 14" from Celling

Room Tree B, $11^{\prime} 10^{\prime \prime}$ from F1oor (2" down)

Room Tree B, 10' from Floor

Room Tree B, 5' from Floor

Room Tree B, 1' from Floor

Room Tree C, 17'10" from Floor

Velocity Probe, Burn Room Air Intake

Room Tree D, 20" from Ceiling

Room Tree D, 32" from Celling

Basement, 9' from East Wall, $5^{\prime}$ from Floor

Basement, 3' from West Wa11, 5' from Floor

Basement Stair, First Landing, North Rail

Basement Stair, Second Landing

First Floor Stair Opening

First Floor

Second Floor, Stair Opening

Second Floor

Second Floor Ceiling Gas

Velocity Probe, Roof Vent No. 1

Velocity Probe, Roof Vent No. 2

Room Tree D, 44" from Ceiling

Air Pressure, Burn Room 10.5' Level

Air Pressure, Stairwell, Basement Referenced to First Floor

Air Pressure, First Floor, 3' Level

Air Pressure, Second Floor, 3' Level

Air Velocity, Burn Room Air Intake

Air Volume, Burn Room Air Intake

Air Velocity, Roof Vent, No. 2

Air Volume, Roof Vent, No. 2

Air Velocity, Roof Vent, No. 1

Air Volume, Roof Vent, No. 1

Carbon Monoxide Concentration, Floor Level, First Floor 
Table 2 (continued)

$\underline{\text { I.D. }}$

Description

OXY 1

OXY 2

OXY 3

FLX 1

FLX 2

FLO 1

Oxygen Concentration, Burn Room 10' Level

Oxygen Concentration, Floor Leve1, First Floor Oxygen Concentration, Roof Vent

Total Heat Flux, Burn Room East Wall, $8^{\prime}$ Leve1, Horizontal View

Total Heat Flux, Stairwe1l, No. Wa1l, 8' Level, Horizontal View

Sprinkler Water Flow 
Table 3. List of Fire Tests

\section{Water Curtain System Tests}

\begin{tabular}{|c|c|c|c|c|c|}
\hline$Q(M W)$ & $\dot{G} / L_{W C}(g a l / m i n / f t)$ & $\mathrm{Nd}$ (in) & $\underline{\mathrm{K}}$ & $A_{1}\left(f t^{2}\right)$ & $A_{e}\left(f t^{2}\right)$ \\
\hline 1.5 & $3,4,5,6$ & $1 / 2$ & 5.6 & 4.2 & 18.8 \\
\hline 1.5 & $3,4.5 .6$ & $3 / 8$ & 2.7 & 4.2 & 18.8 \\
\hline 4.0 & $4,5,6$ & $1 / 2$ & 5.6 & 4.2 & 18.8 \\
\hline 4.0 & 7,8 & $1 / 2$ & 5.6 & 4.2 & 18.8 \\
\hline 4.0 & 3 & $1 / 2$ & 5.6 & 4.2 & 18.8 \\
\hline 4.0 & 3,4 & $3 / 8$ & 2.7 & 4.2 & 18.8 \\
\hline 4.0 & 5,6 & $3 / 8$ & 2.7 & 4.2 & 18.8 \\
\hline 4.0 & $4,5,6$ & $3 / 8$ & 2.7 & 4.2 & 18.8 \\
\hline 4.0 & 6,7 & $3 / 8$ & 2.7 & 4.2 & 18.8 \\
\hline
\end{tabular}

Spray Nozzle System Tests

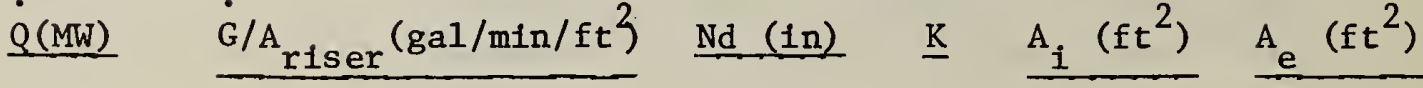

$\begin{array}{llllll}4.0 & 2.0 & 3 / 8 & 2.96 & 4.2 & 18.8 \\ 4.0 * & 1.66 & 3 / 8 & 2.96 & 4.2 & 18.8 \\ 4.0 & 1.66 & 3 / 8 & 2.96 & 4.2 & 18.8 \\ 4.0 & 1.66 & 3 / 8 & 2.96 & 4.2 & 18.8 \\ 4.0 & 2.0 & 1 / 2 & 4.96 & 4.2 & 18.8 \\ 4.0 & 2.16 & 1 / 2 & 4.96 & 4.2 & 18.8 \\ 4.0 & 2.33 & 1 / 2 & 4.96 & 4.2 & 18.8 \\ 4.0 * & 2.16 & 1 / 2 & 4.96 & 4.2 & 18.8 \\ 4.0 & 2.16 & 1 / 2 & 4.96 & 4.2 & 18.8 \\ 4.0 * & 2.16 & 1 / 2 & 4.96 & 4.2 & 18.8\end{array}$

$\mathrm{Nd}=$ nozzle size (nominal)

$\mathrm{K}=$ Discharge coefficient $=\frac{\dot{\mathrm{G}}}{\mathrm{P}}$ where $\mathrm{P}=$ nozzle pressure

* = Tests with draft panels. 


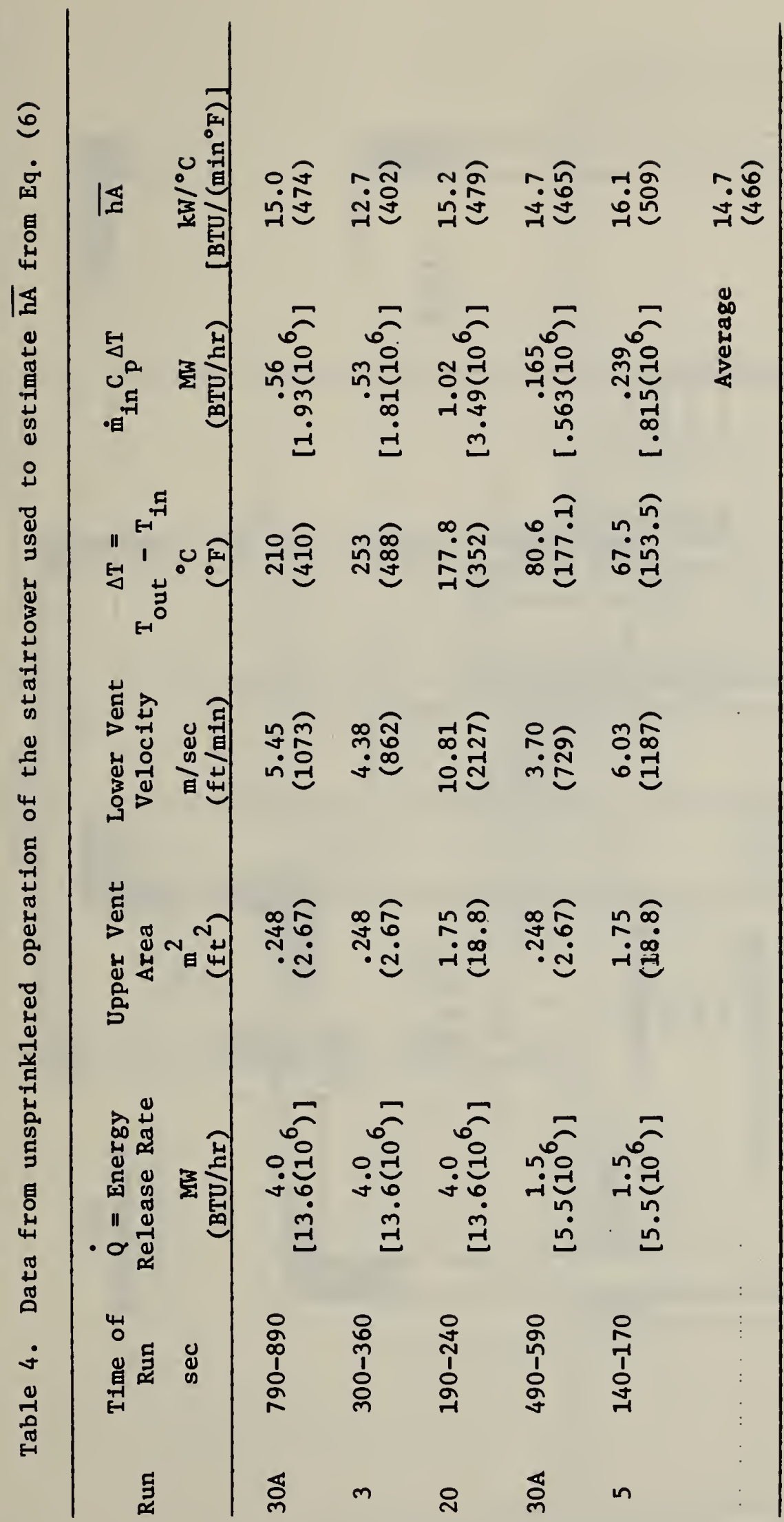




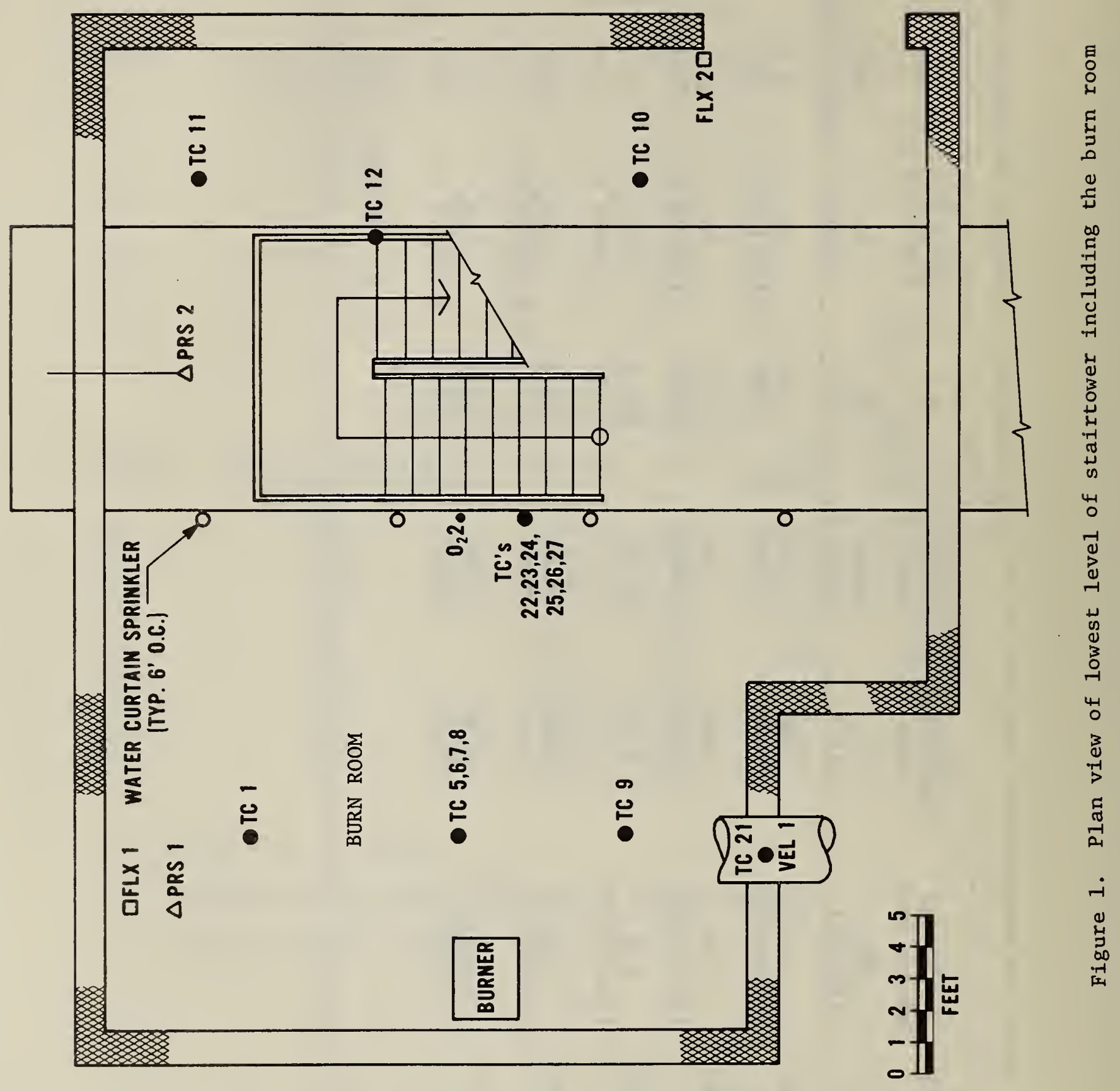




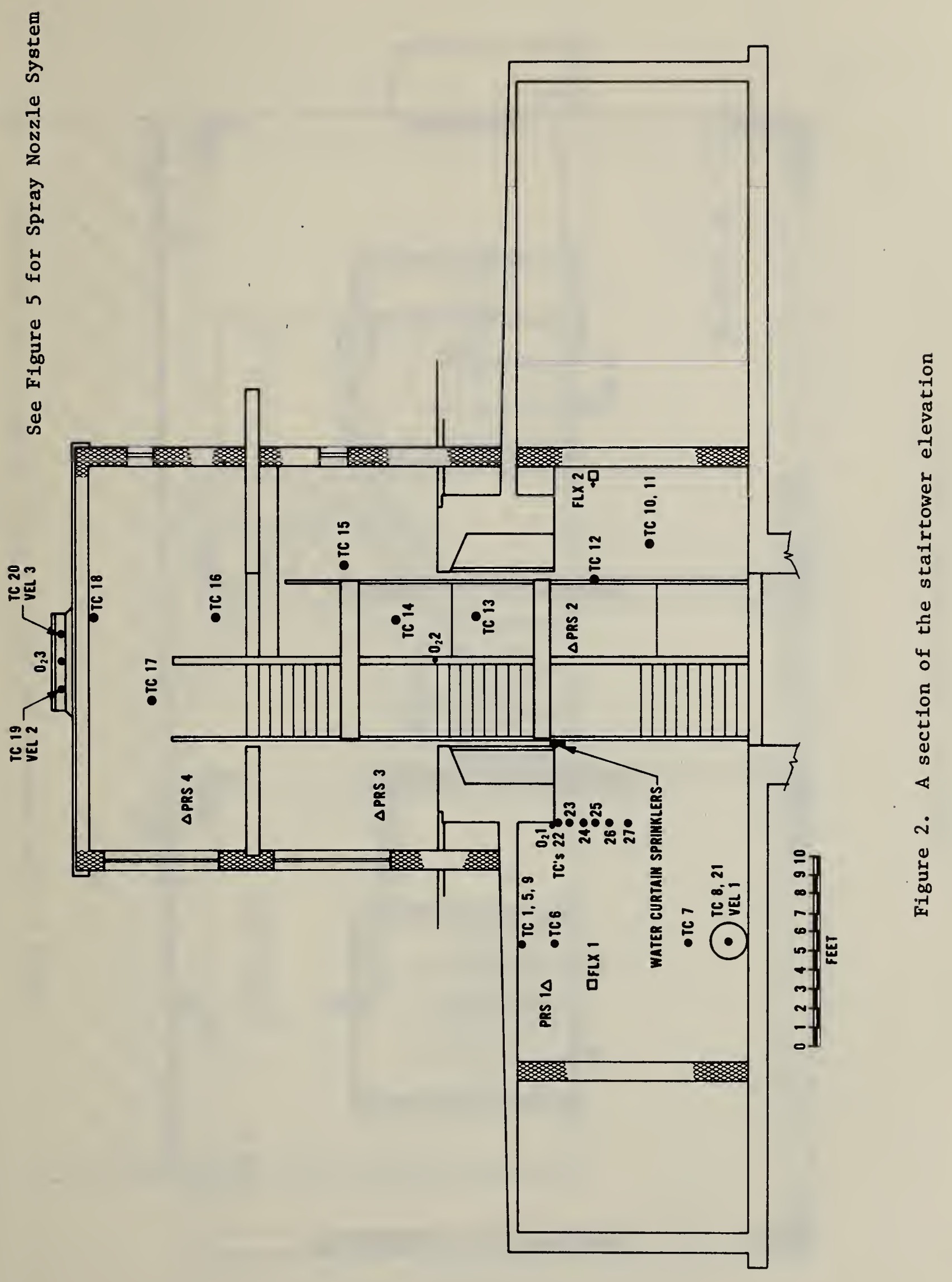




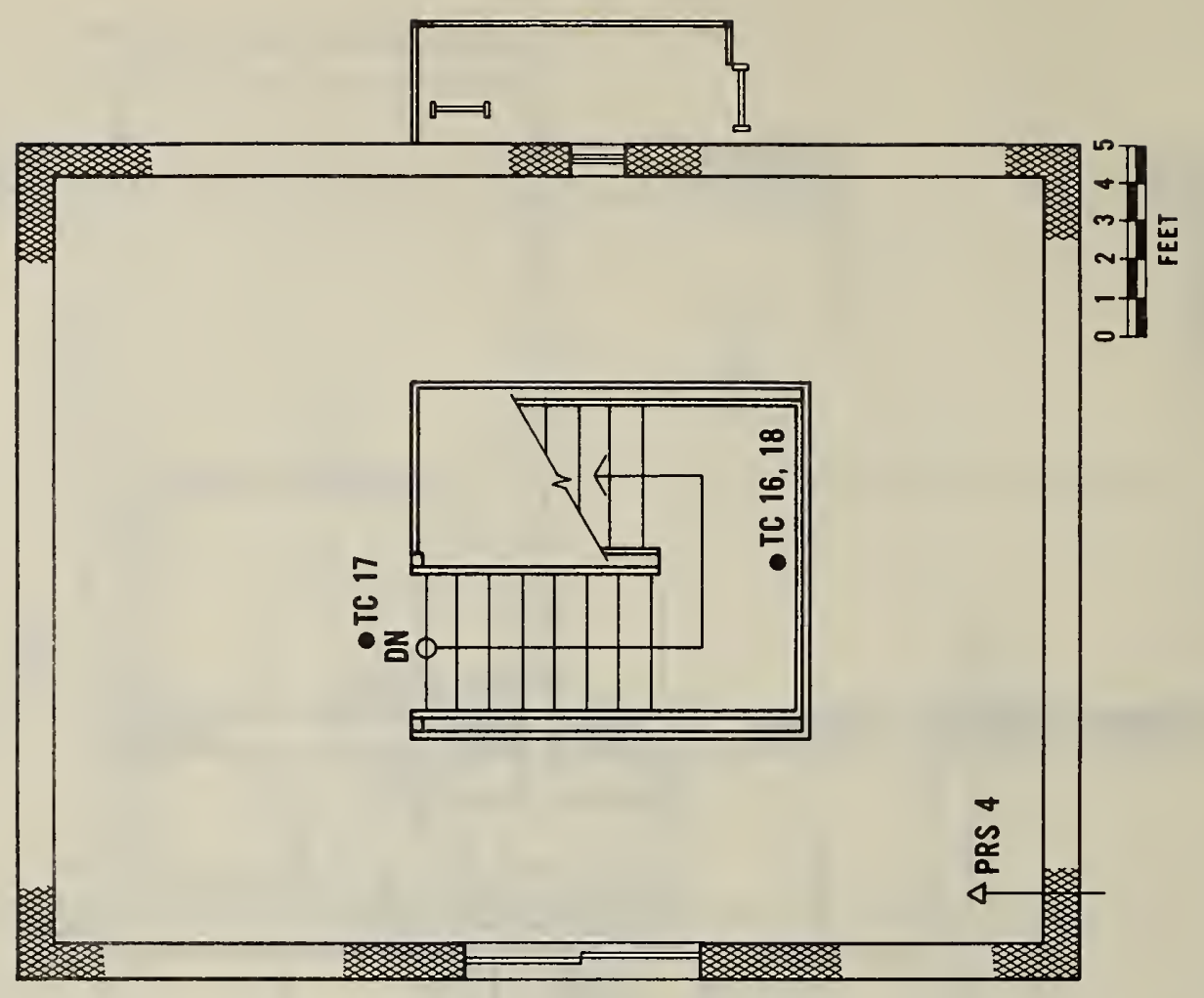

H

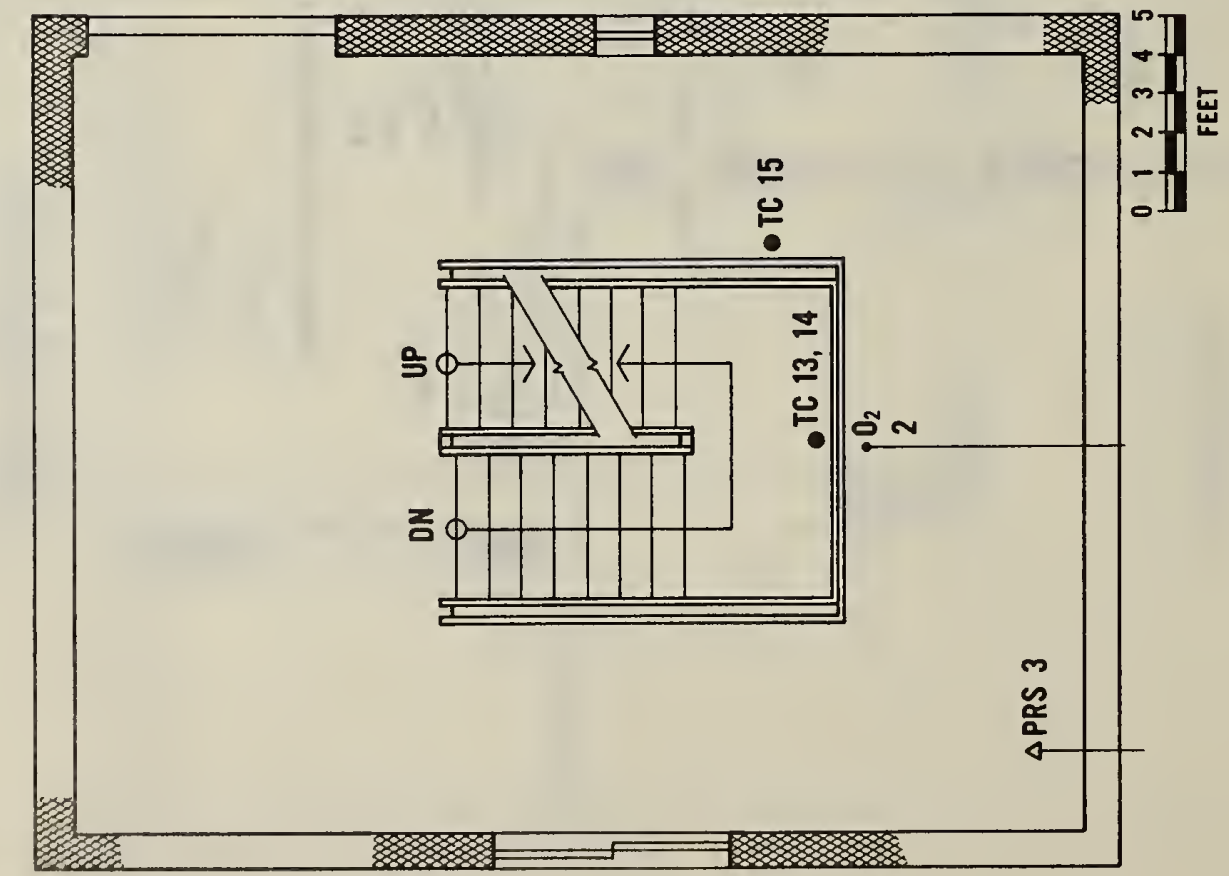




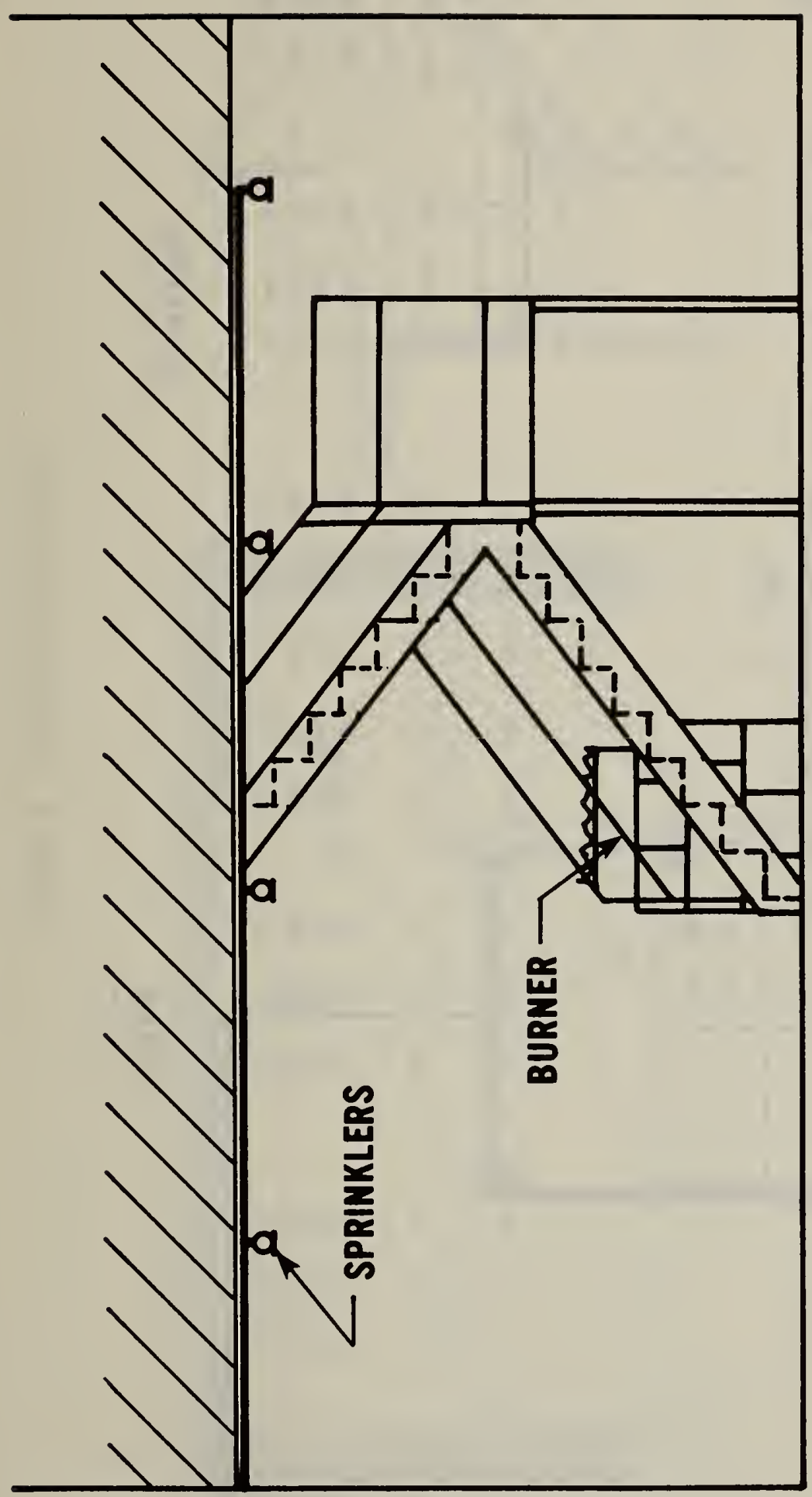

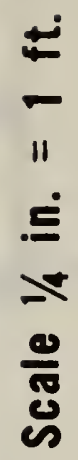

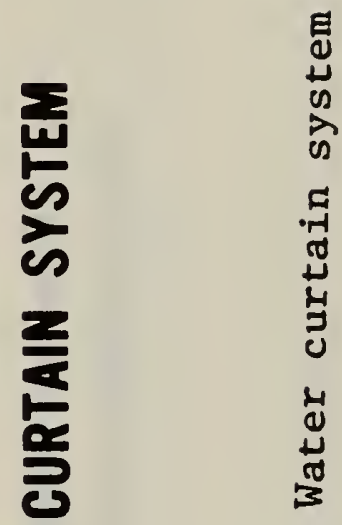

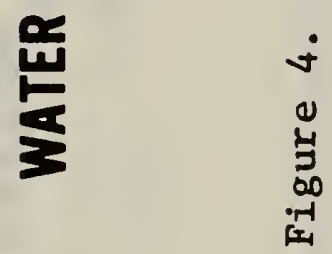




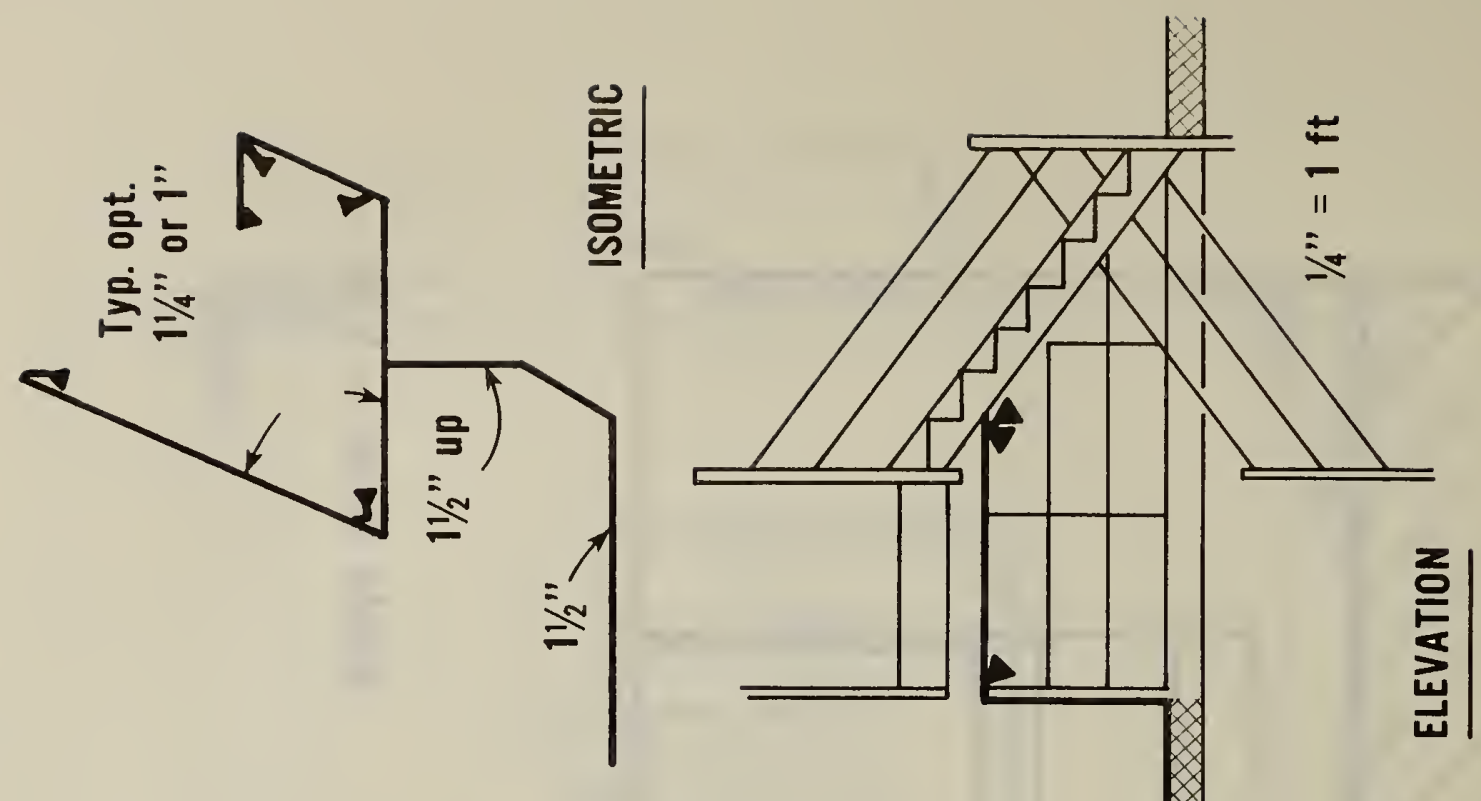

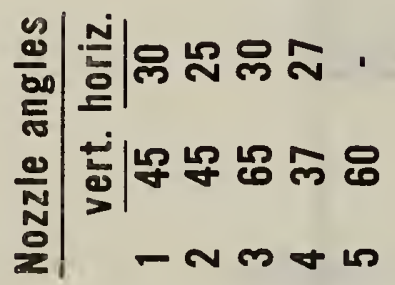

ह
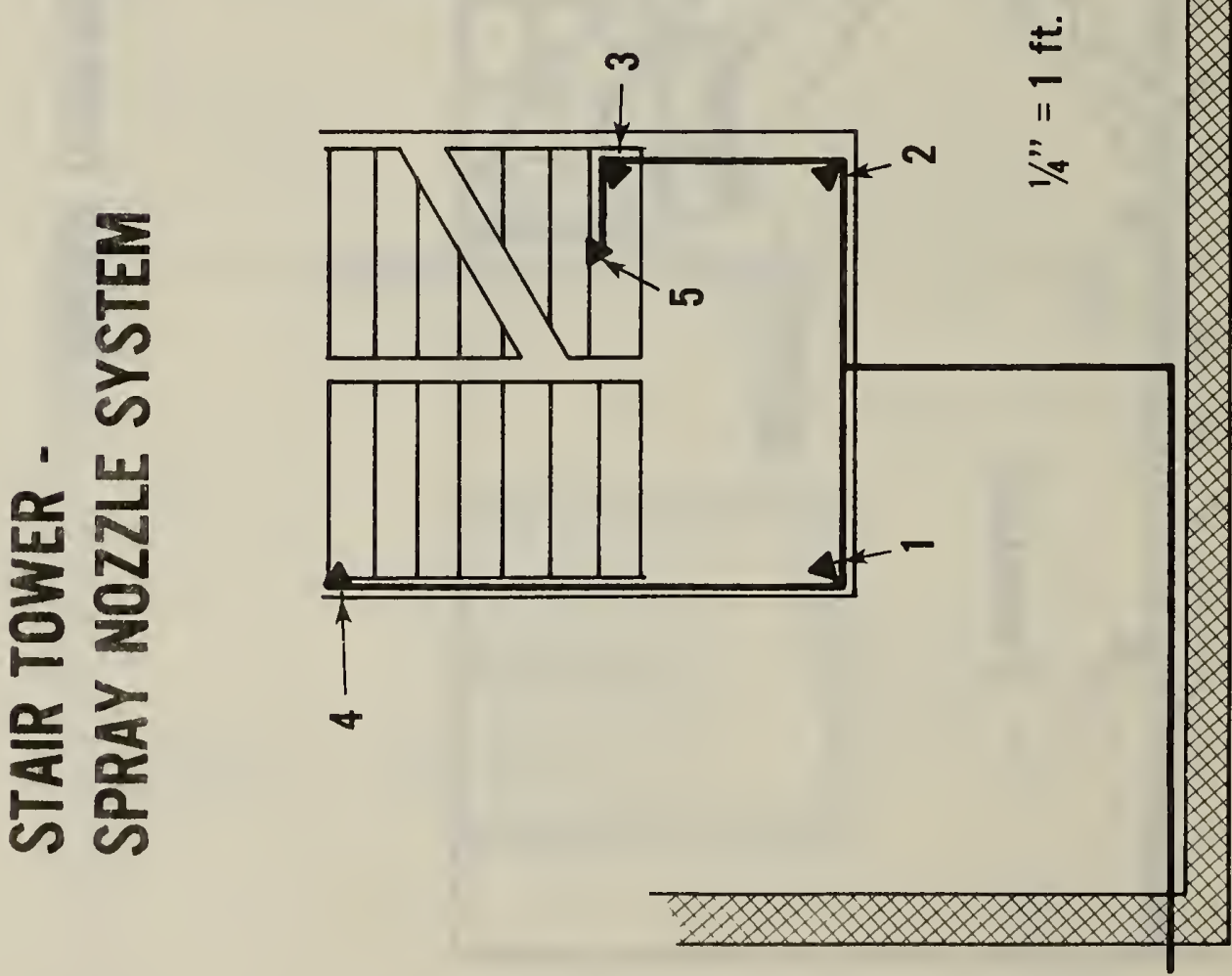

$\frac{3}{2}$ 


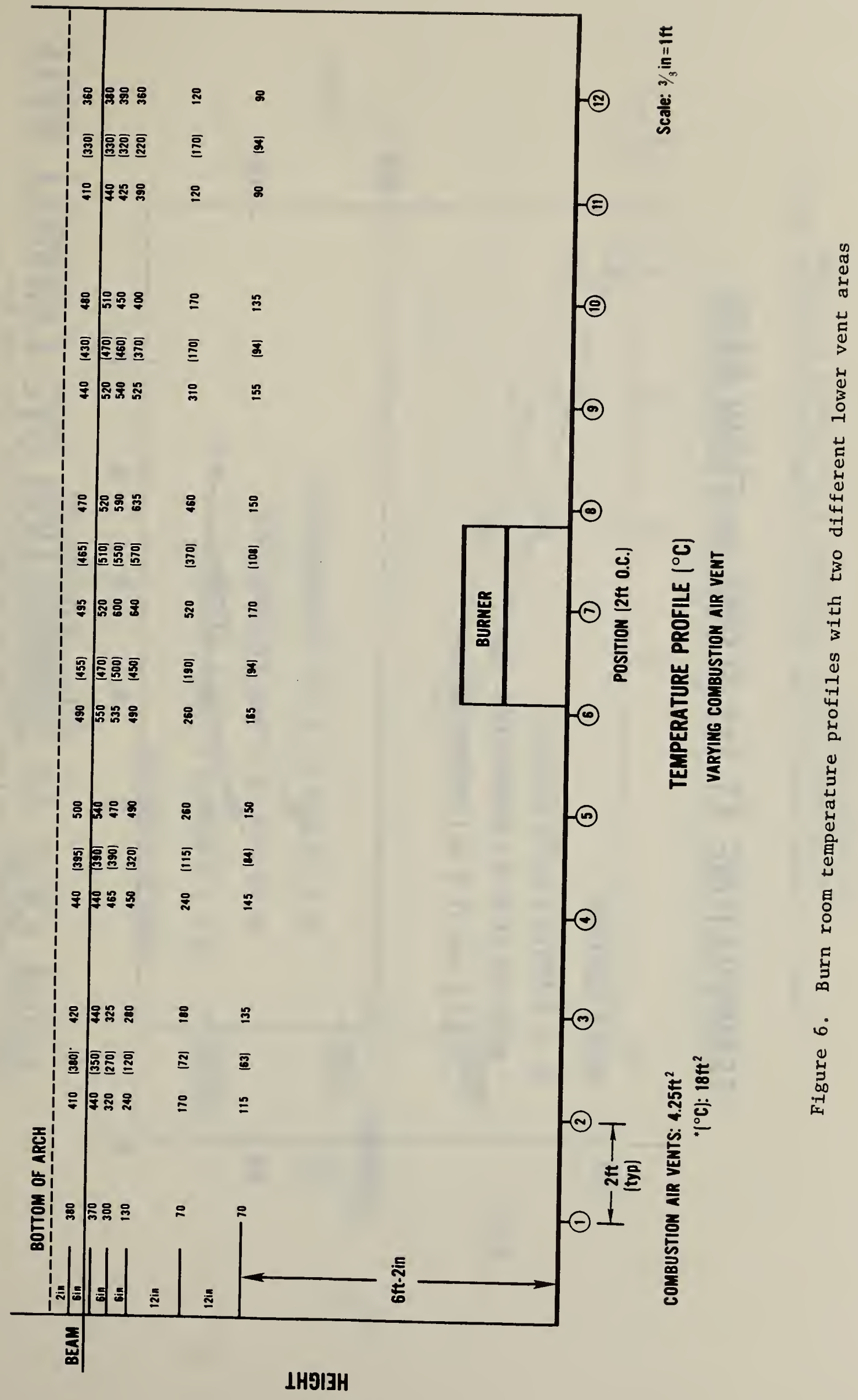




\section{$\stackrel{\frac{\pi}{5}}{\circ}$}

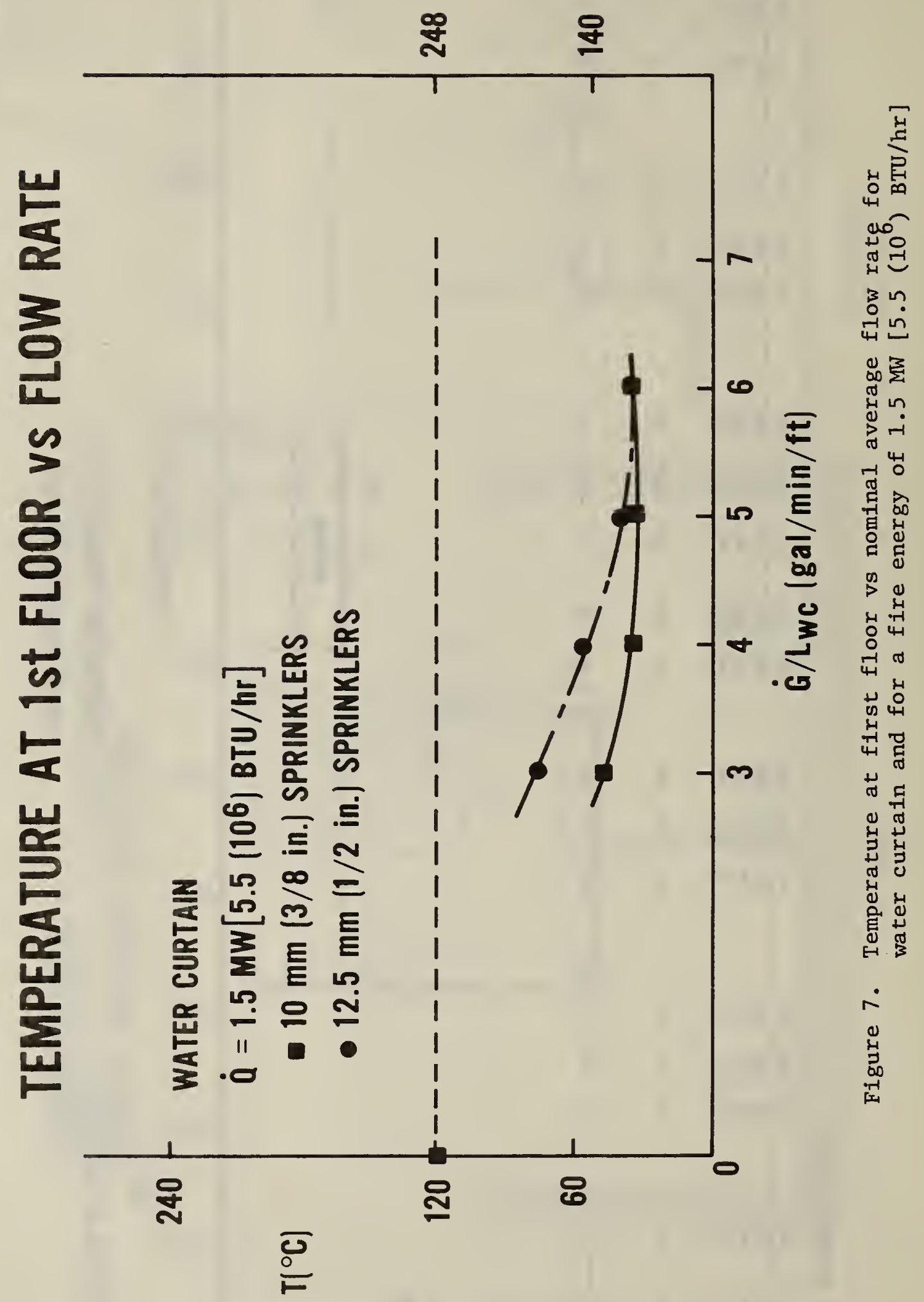




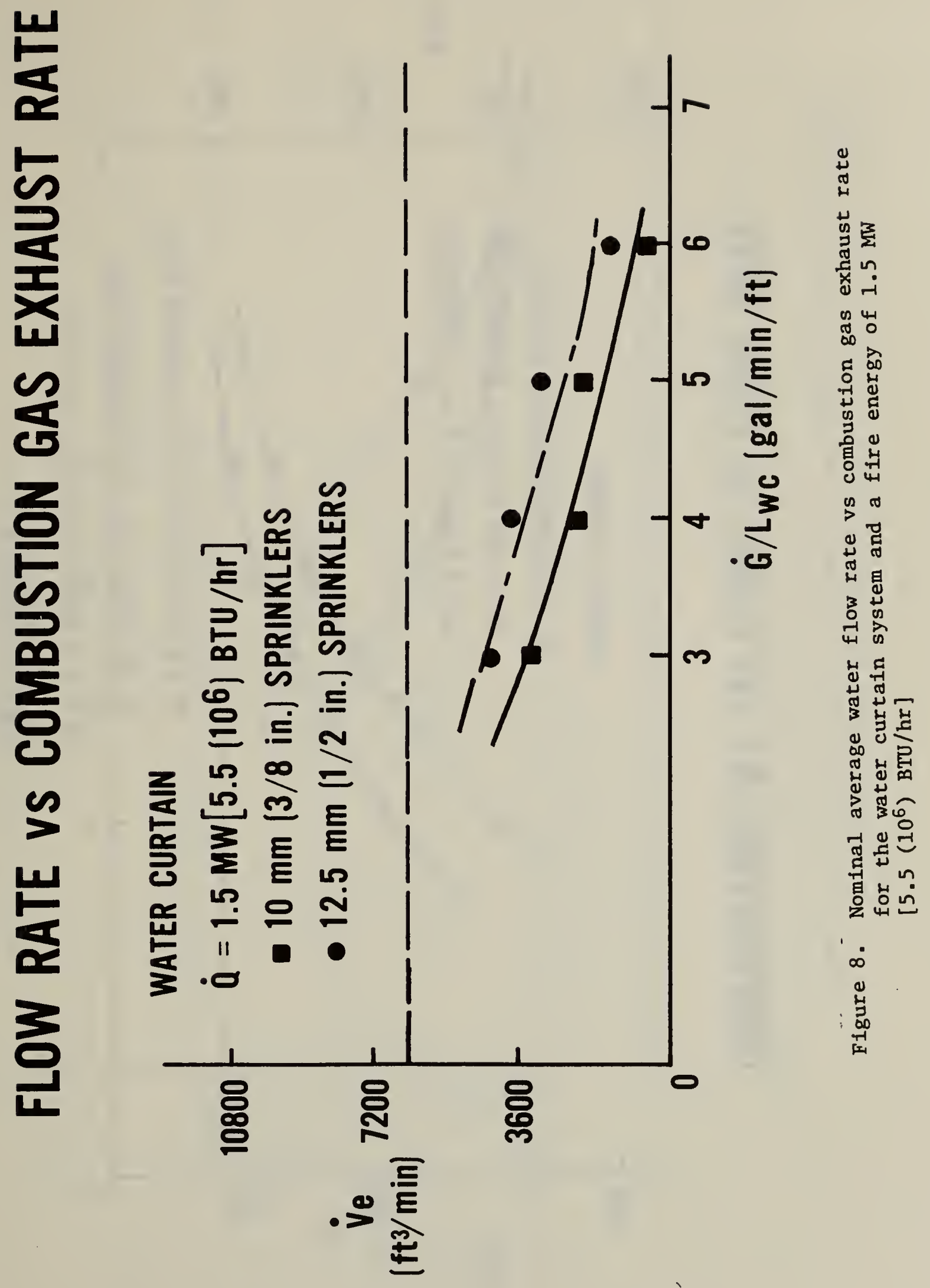




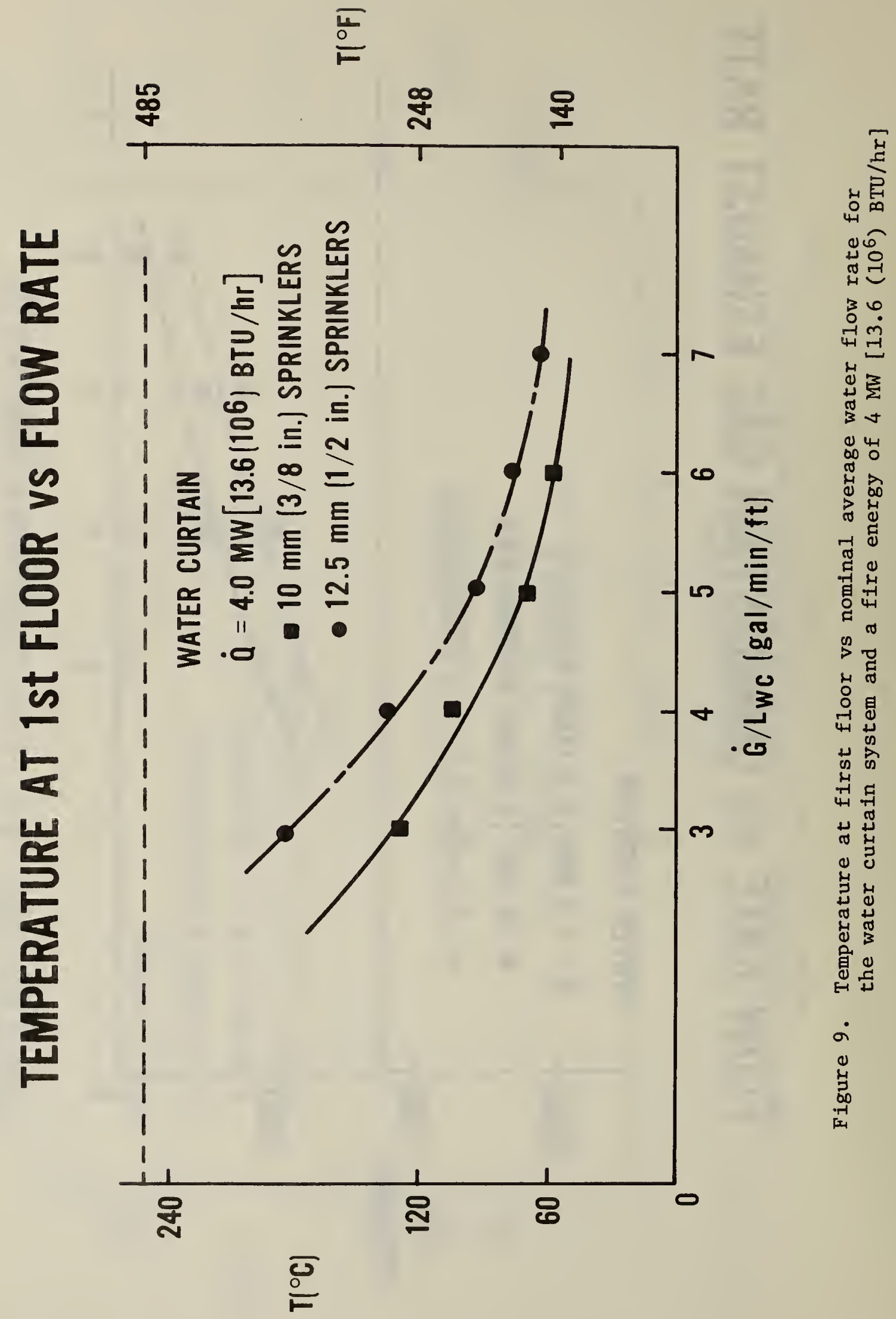




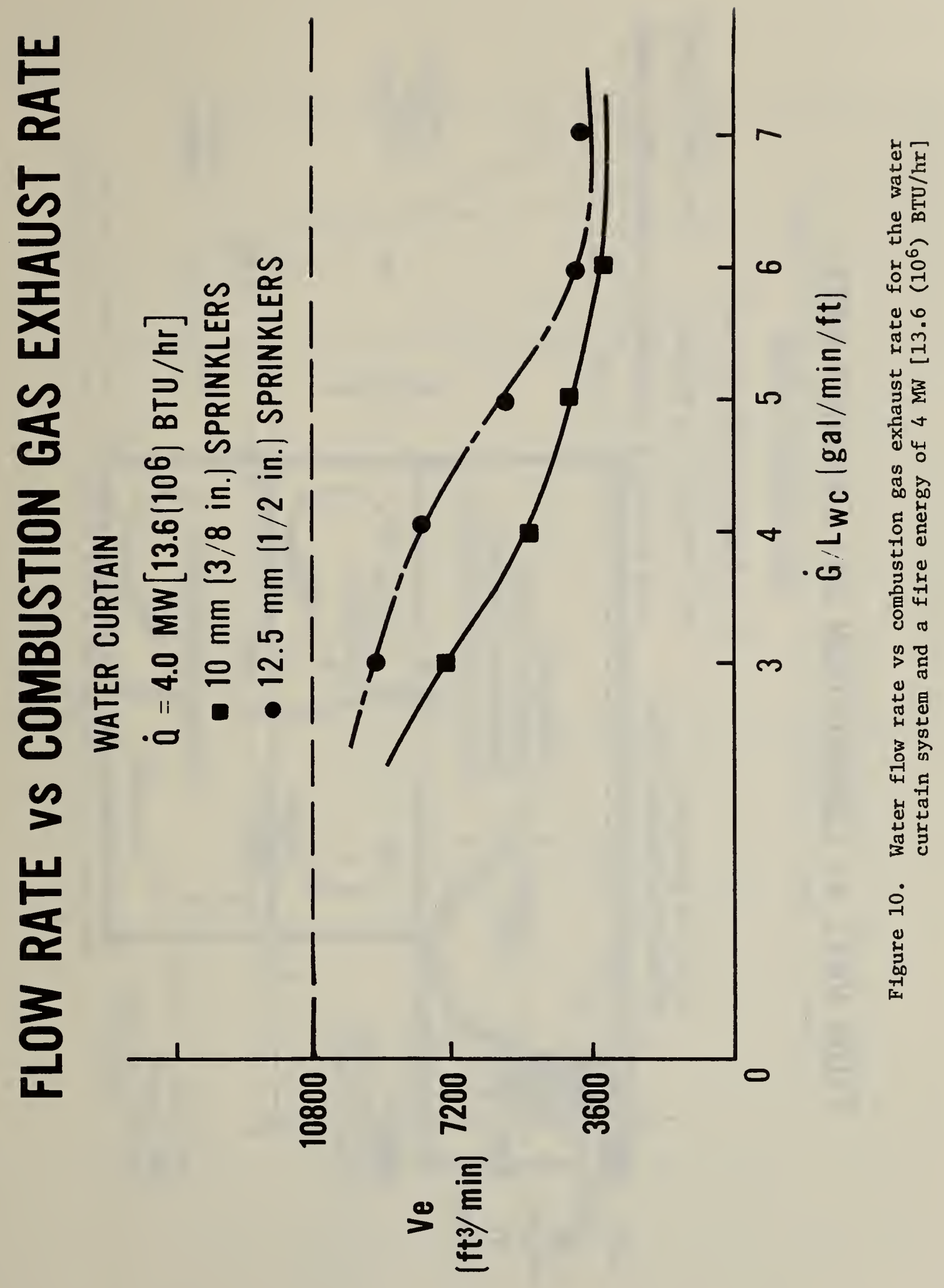




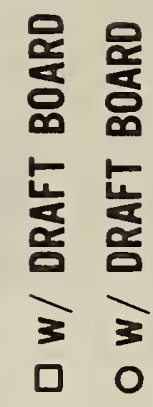

崖

突总岕

㟧

के

实 응 主至

욜 $\stackrel{\infty}{m}=1$

文昱晨

密

."

-

$\infty$

苾实

里

舟员

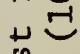

$\exists$

\%

齐

恋空

$\infty$

ธ두

ग्र

劉

כo

ठ .

ป

Е $\quad 0 \underset{4}{4}$

हE $\quad$ 峁
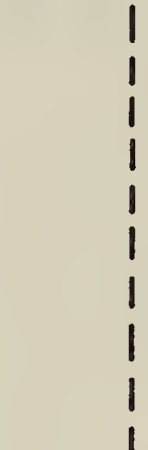

ㅁ

芯 总范

느

은 包苛

$\leqslant$ 每

5

()

$\infty$ N

त

匆

तो त

तु นู

क क

苔选
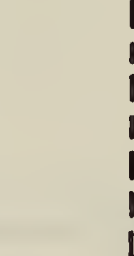

๑ั

กิ

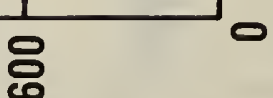

H

$\rightarrow \frac{E}{\pi}$ 


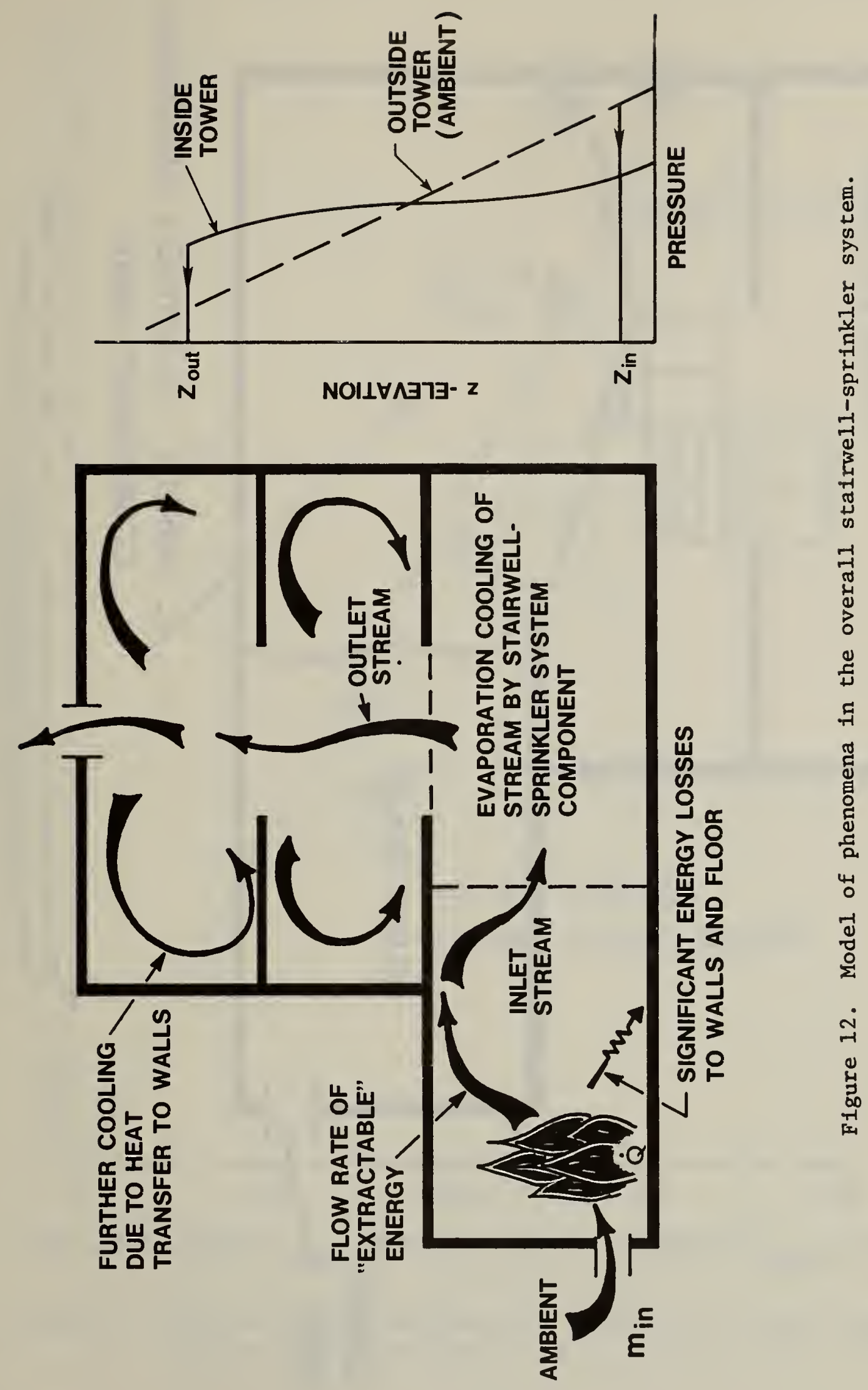




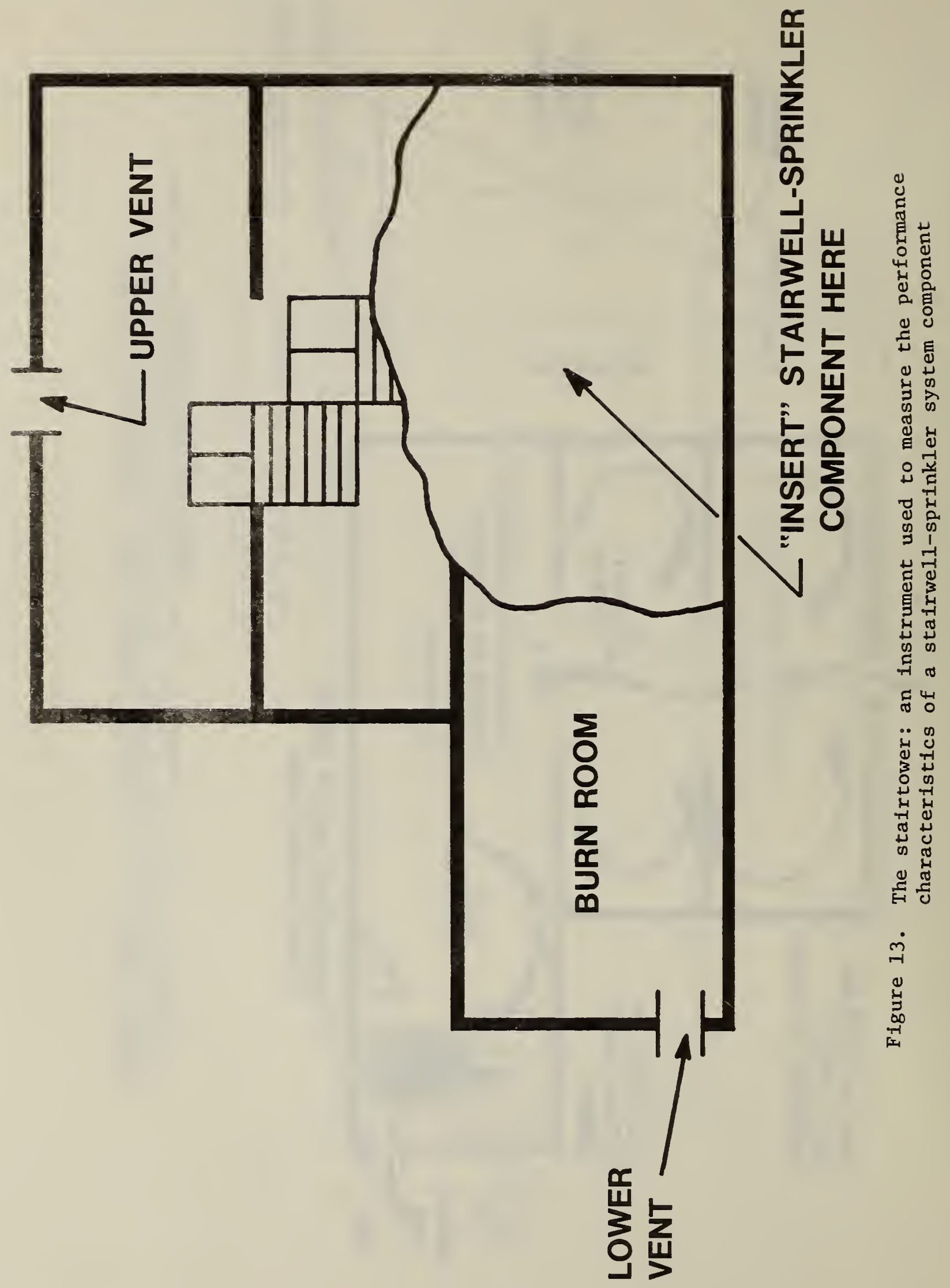




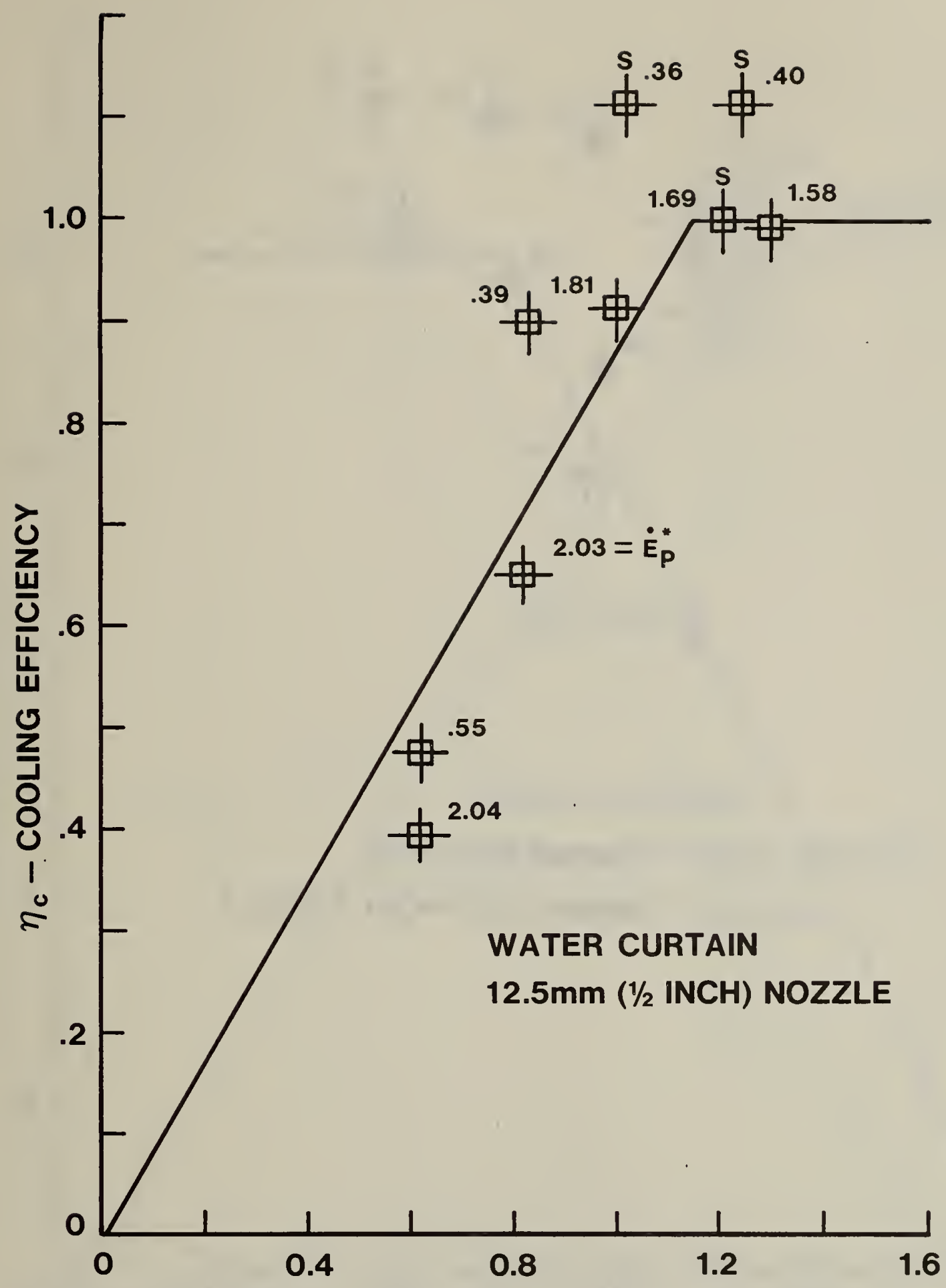

$\left.\left.\dot{\mathrm{G}}^{*}=\dot{\mathrm{G}} /\left[\mathrm{GPM} \cdot \mathrm{A}_{\mathrm{WELL}} / \mathrm{FT}^{2}\right]=.0245 \dot{\mathrm{G}} / \quad \mathrm{l} / \mathrm{MIN}\right) \cdot\left(\mathrm{A}_{\mathrm{WELL}} / \mathrm{m}^{2}\right)\right]$

Figure 14. Plot of cooling efficiency as a function of water usage - WC, $12.5 \mathrm{~mm}$ (1/2 in) nozzle 


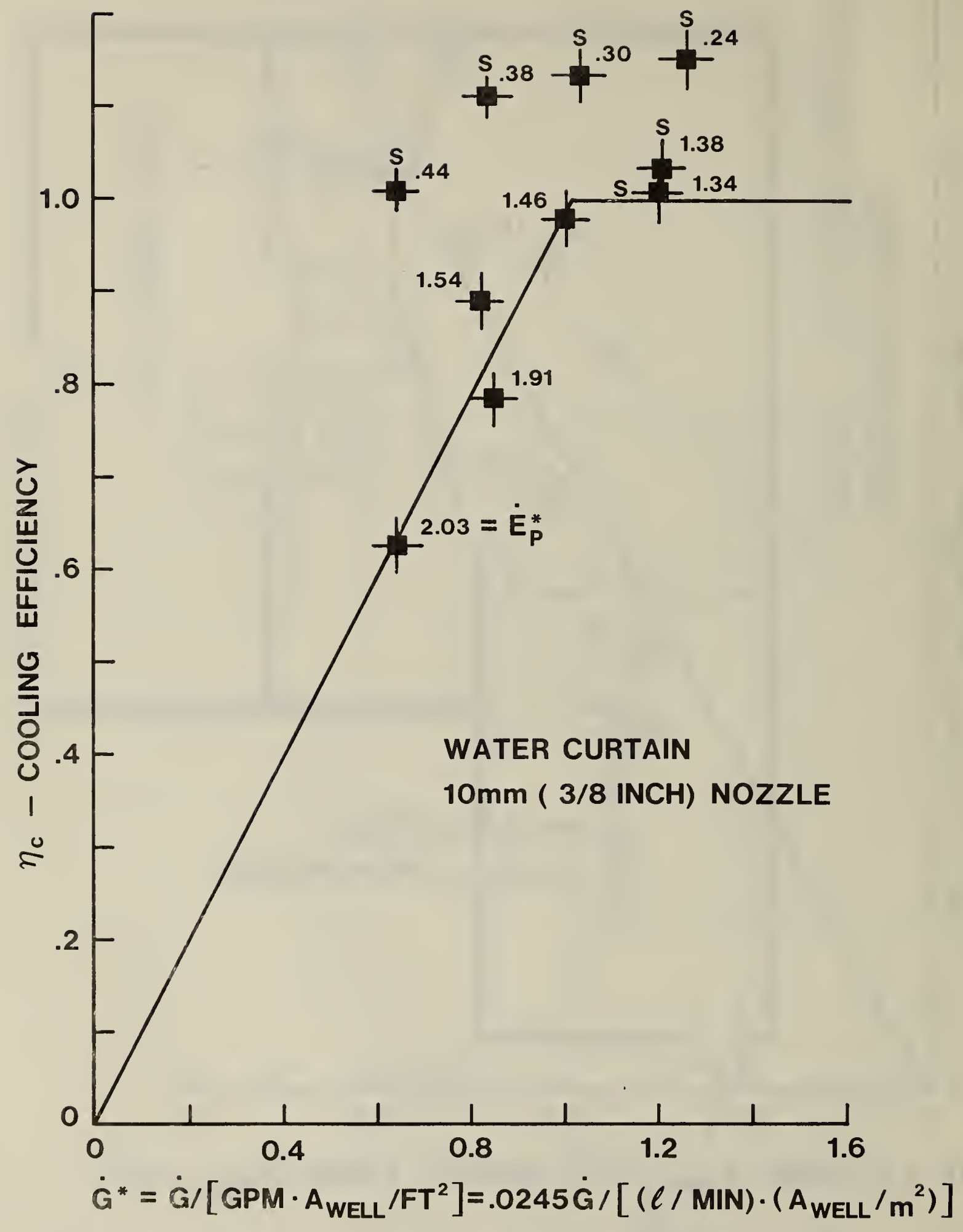

Figure 15. Plot of cooling efficiency as a function of water usage WC, $10 \mathrm{~mm}(3 / 8 \mathrm{in})$ nozzle 


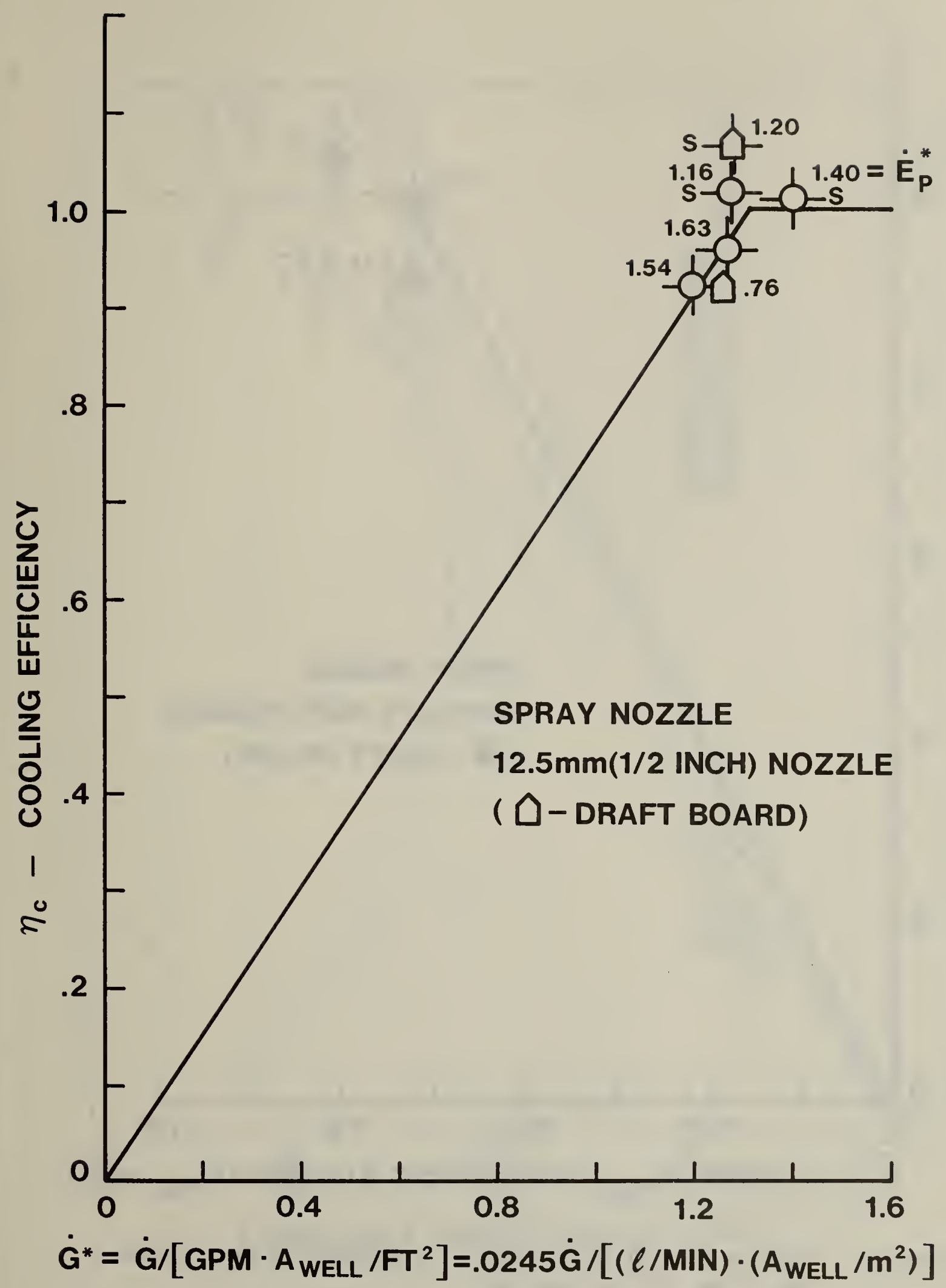

Figure 16. Plot of cooling efficiency as a function of water usage $\mathrm{SN}, 12.5 \mathrm{~mm}(1 / 2 \mathrm{in})$ nozzle 


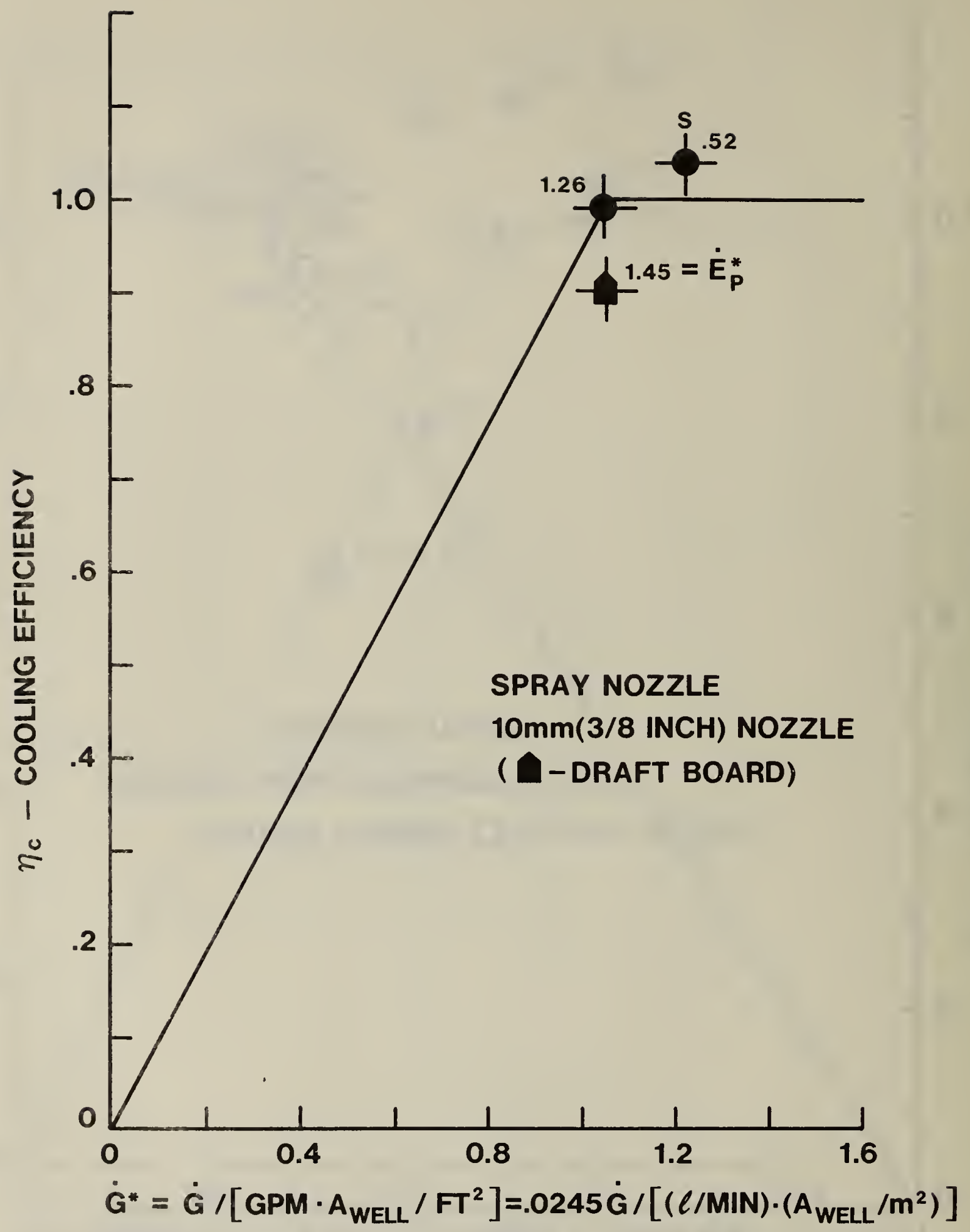

Figure 17. Plot of cooling efficiency as a function of water usage $\mathrm{SN}, 10 \mathrm{~mm}$ (3/8 in) nozzle 


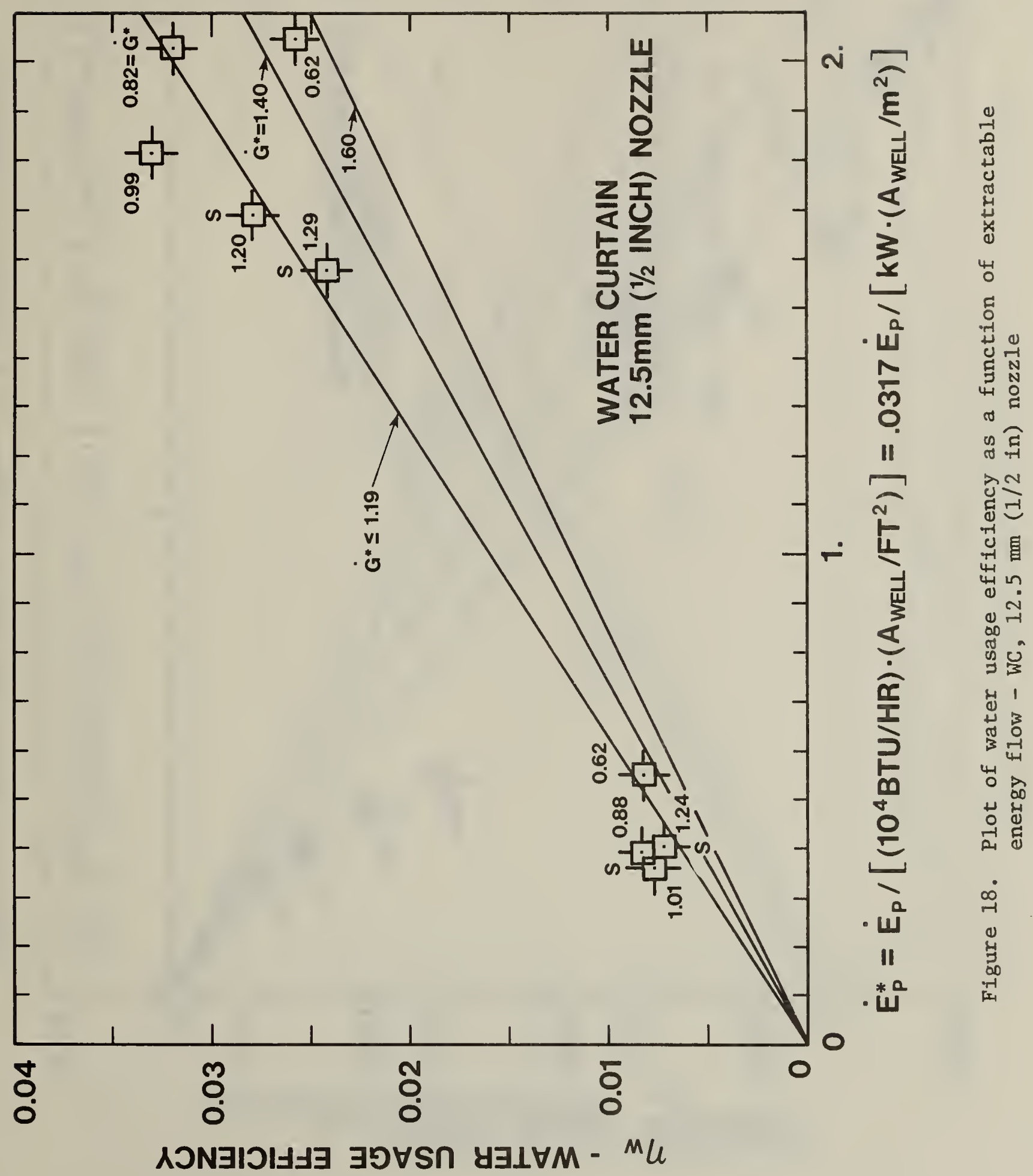




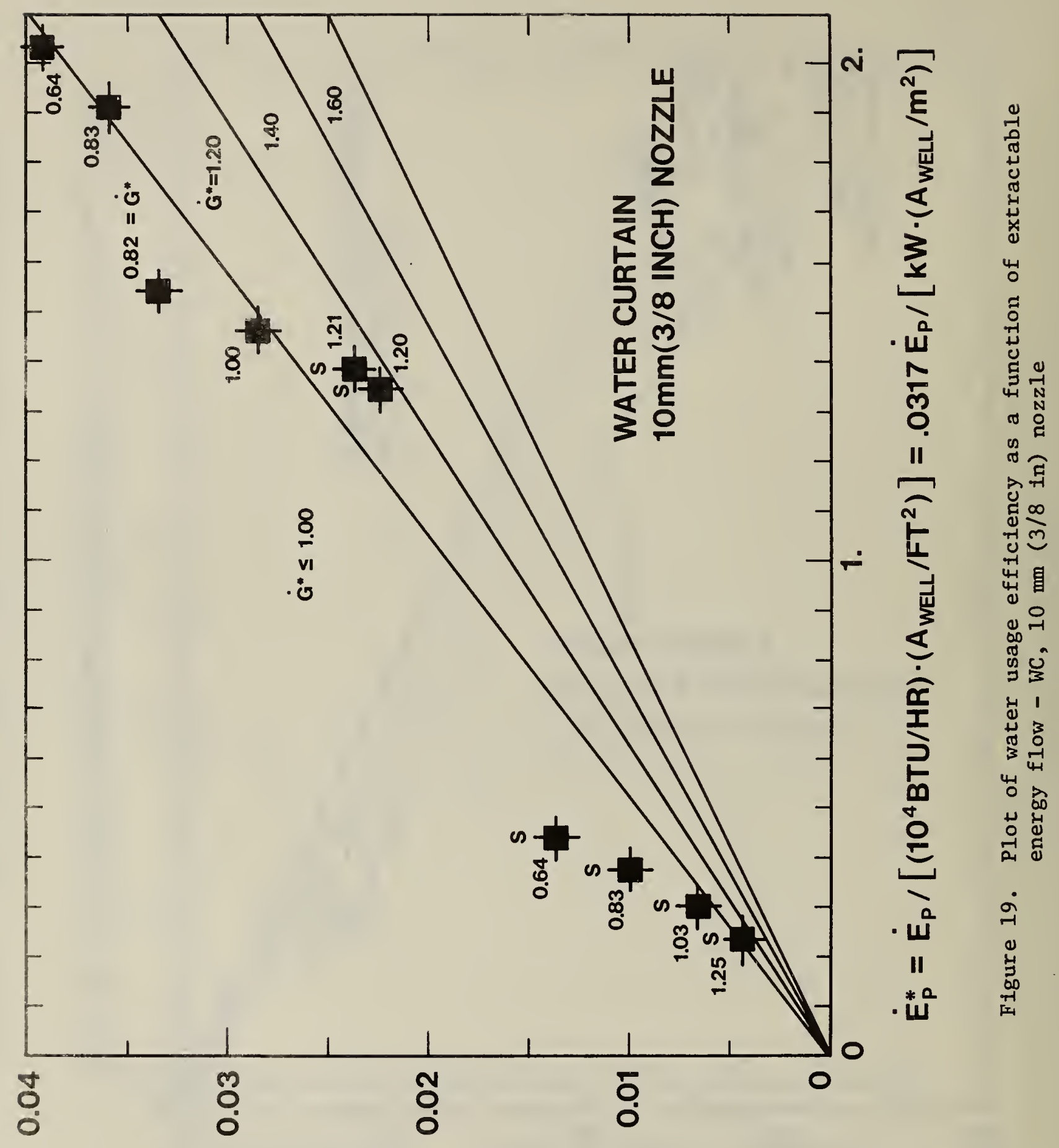

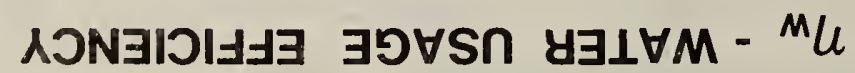




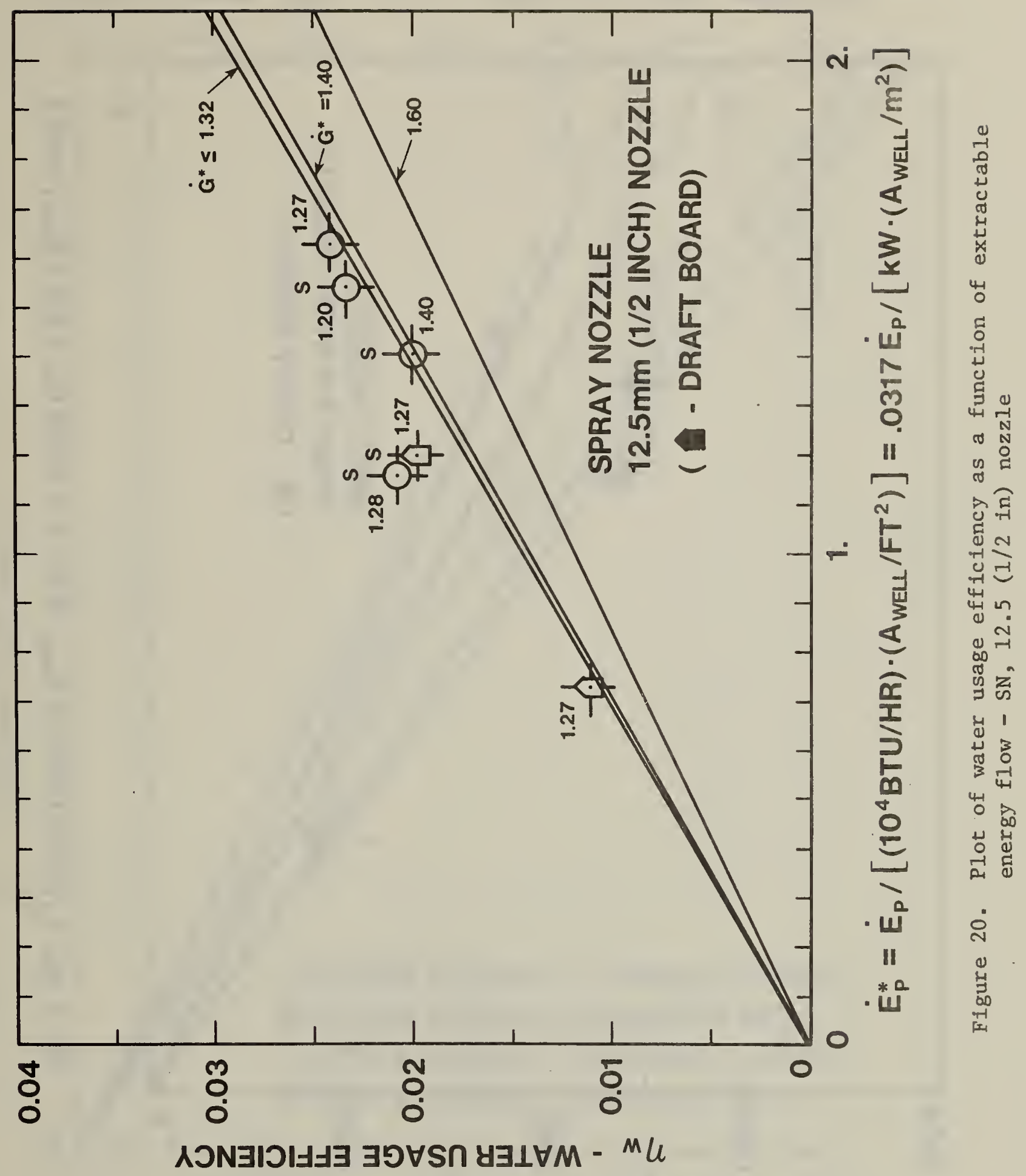




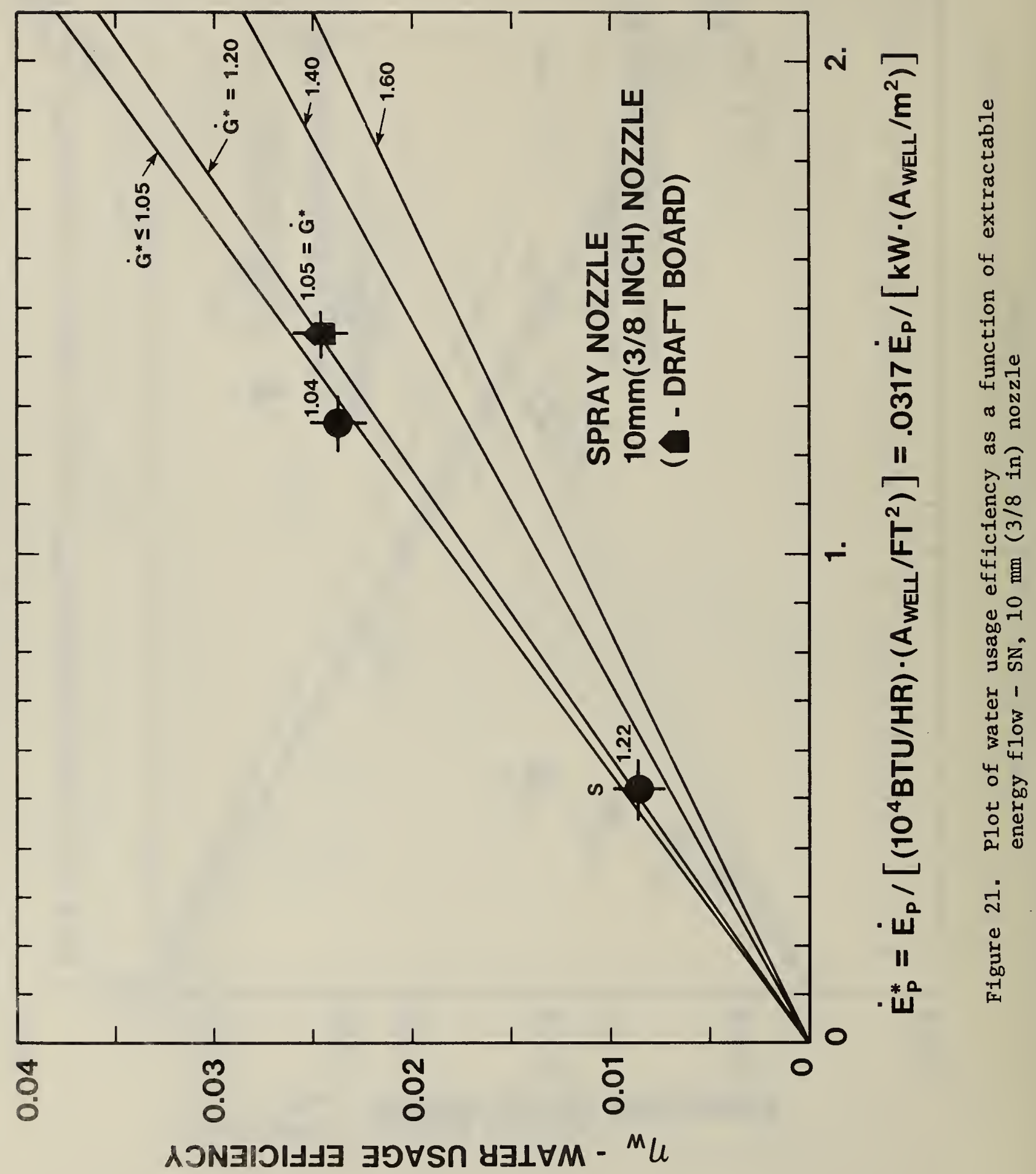




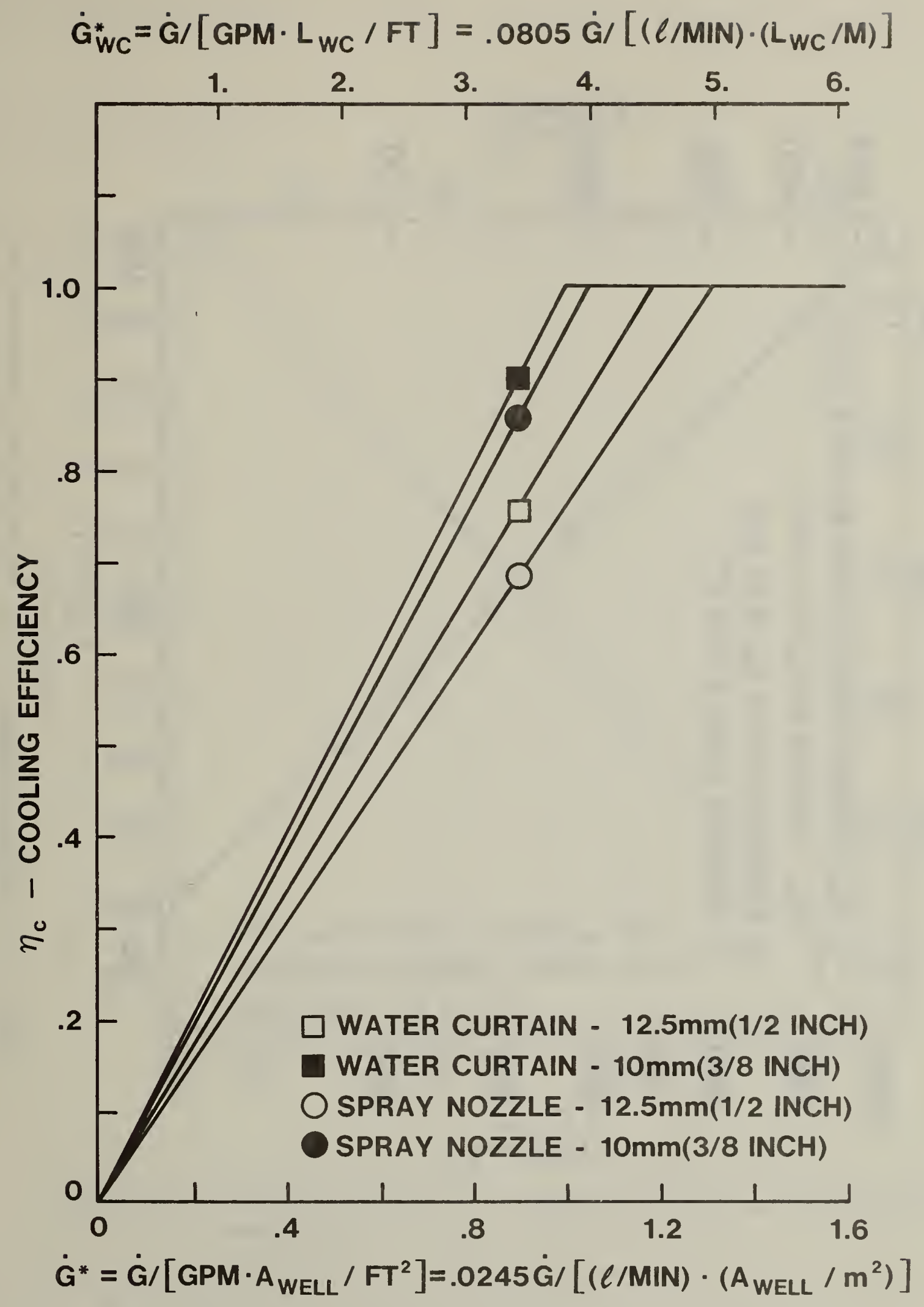

Figure 22. Estimate of cooling efficiency as a function of water usage for the four tested designs - a plot of Eq. (11) 


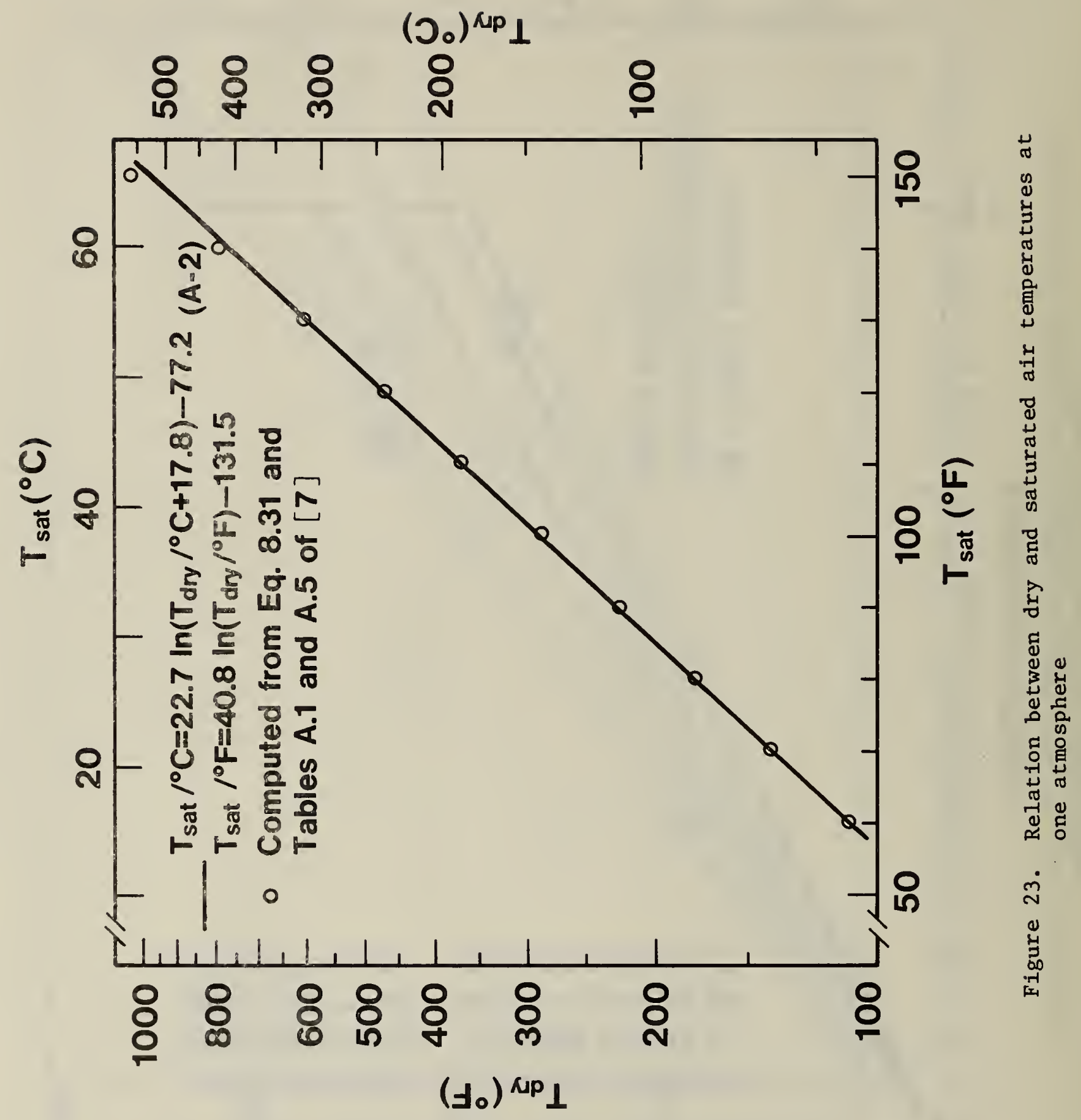




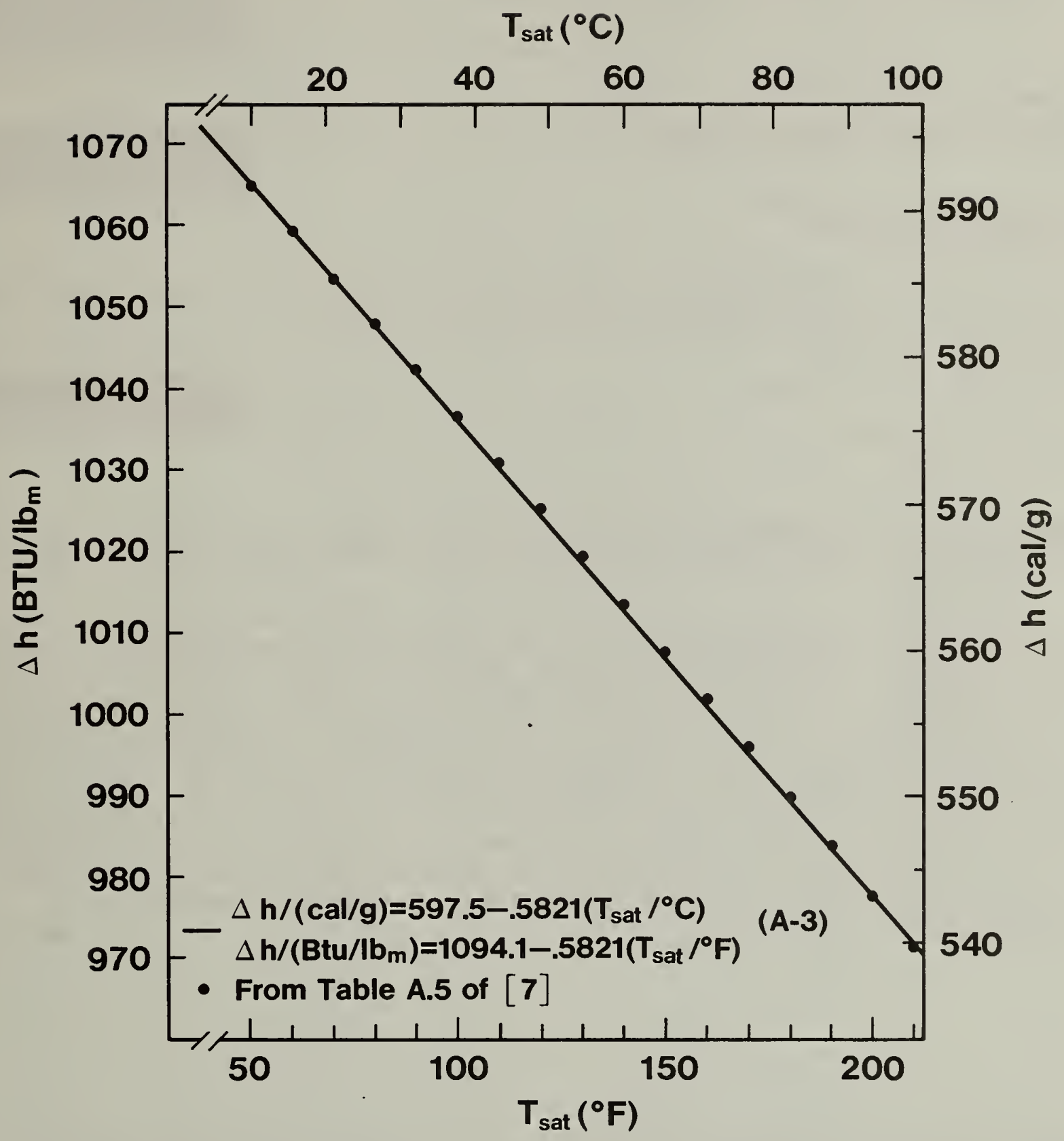

Figure 24. Heat of vaporization of water as a function of saturation temperature 
NBS-1I 4 A IFEV.

\begin{tabular}{|c|c|c|c|}
\hline $\begin{array}{l}\text { U.S. DEPT. OF COMM. } \\
\text { BIBLIOGRAPHIC DATA } \\
\text { SHEET }\end{array}$ & $\begin{array}{l}\text { 1. PUBLICATION OR REPORT NO. } \\
\text { NBSIR } 81-2202\end{array}$ & 2. Gov't Accession No. & \% \\
\hline \multirow{2}{*}{\multicolumn{3}{|c|}{$\begin{array}{l}\text { 4. TITLE AND SUBTITLE } \\
\text { FIRE TESTS OF STAIRWELI_SPRINKIER SYSTEMS }\end{array}$}} & $\begin{array}{l}\text { 5. Publication Date } \\
\text { April } 1981\end{array}$ \\
\hline & & & 6. Performing Organization Code \\
\hline \multicolumn{3}{|c|}{$\begin{array}{l}\text { 7. AUTHOR(S) } \\
\text { Leonard Y. Cooper and John G. O'Neill }\end{array}$} & 8. Performing Organ. Report No. \\
\hline \multirow{2}{*}{\multicolumn{3}{|c|}{$\begin{array}{l}\text { NATIONAL BUREAU OF STANDARDS } \\
\text { DEPARTMENT OF COMMERCE } \\
\text { HA SHINGTON, DC } 20234\end{array}$}} & 10. Project/Task/Work Unit No. \\
\hline & & & 11. Contract/Grant No. \\
\hline \multirow{2}{*}{\multicolumn{3}{|c|}{$\begin{array}{l}\text { 12. 3. DSORIV ORGANIZATION NAME AND COMPLETE ADDRESS (Stroot, crty, Stato, zIP) } \\
\text { The Occupational Safety and Health Administration (OSHA) } \\
\text { Department of Labor } \\
\text { Washington, D.C. } 2021.0\end{array}$}} & $\begin{array}{l}\text { 13. Type of Report \& Period Covered } \\
\text { Final }\end{array}$ \\
\hline & & & 74. Sponsoing Agency Code \\
\hline
\end{tabular}

15. SUPPLEMENTARY NOTES

Document describes a computer program; SF-185, FIPS Software Summary, is attached.

16. ABSTRACT (A 200-word or less factual summary of most sigrificant information. If document includes a significant bibliography or literature survey, mention it hare.)

The effect of water curtain or spray nozzle fire protection of an open stairwell was studied experimentally. The experimental setup includes a three stcry stairtower with a contiguous first story burn room. The instrumentation used to measure the flow phenomenology resulting from fire sizes up to 4MW [13.6(106) BTU/hr] with and without sprinkler operation is described. A model of evaporation cooling of the hot fire gases as they pass up through the first to second floor stairwell-sprinkler system component is introduced. Based on. this model the data are analyzed and correlated for the purpose of identifying both a cooling and a water usage efficiency for each of the system components that were tested. Application of these measured perfonmance characteristics and their extension to stairwell-sprinkler components of different geometries and configurations are discussed.

17. KEY WORDS (six to twelve entries; slphabetical order; capitalize only the first letter of the first key word unleso a proper namo; separatod by oemicolons)

Automatic sprinklers; cooling efficiency; evaporation cooling; smoke movement; spray nozzle; stairway protection; ventilated stair.

18. AVAILABILITY

For Osficial Distribution. Do llot Release to NTIS

Order From Sup. of Doc., U.S. Government Printing Office, Washington, DC 20402, SD Stock No. SNO03-003-

$$
\text { [x] Unlimited }
$$

z] Order From Natıonal Technical Information Service (NTIS), Springfield, VA. 2216

\begin{tabular}{|l|c|}
$\begin{array}{l}\text { 19. SECURITY CLASS } \\
\text { (THIS REPORT) }\end{array}$ & $\begin{array}{c}\text { 21. NO. OF } \\
\text { PRINTED PAGES } \\
\text { UNCLASSIFIED }\end{array}$ \\
\hline $\begin{array}{l}\text { 20. SECURITY CLASS } \\
\text { (THIS PAGE) }\end{array}$ & $\begin{array}{c}\text { 22. Price } \\
\$ 9.50\end{array}$ \\
UNCLASSIFIED & USCOMM-DC
\end{tabular}



